\title{
PARVALBUMIN-CONTAINING INTERNEURON CONNECTIVITY AND CRITICAL PERIOD MODULATION
}

\author{
Marc Nahmani \\ Rockville, $M D$
}

B.S., University of Maryland, 1999

A Dissertation presented to the Graduate Faculty of the University of Virginia in Candidacy for the Degree of

Doctor of Philosophy

Department of Psychology

University of Virginia

August, 2008

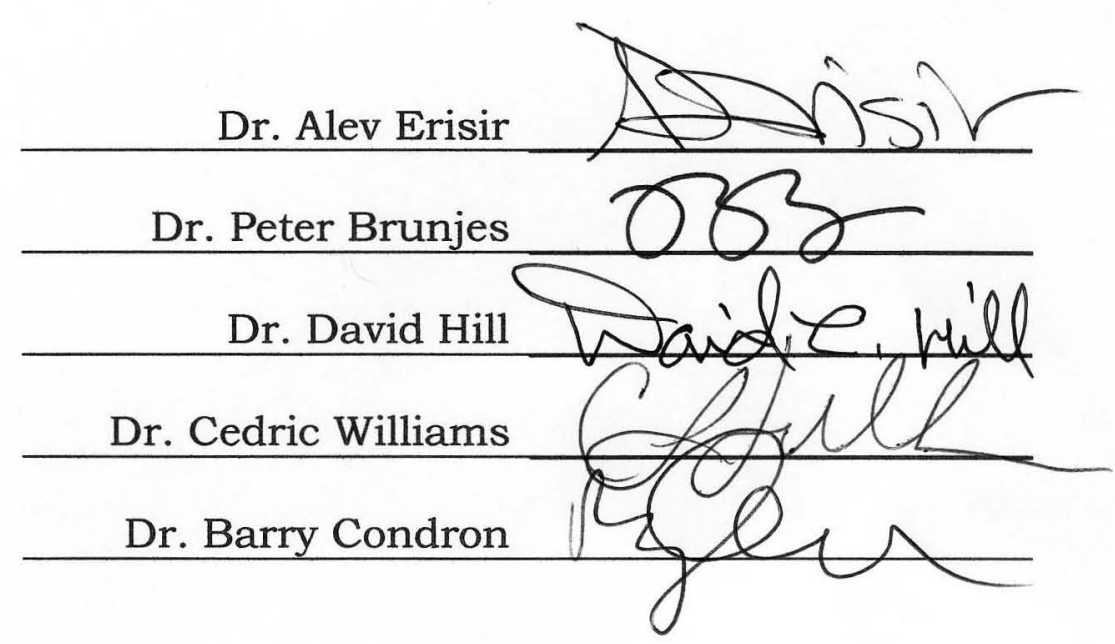




\begin{abstract}
Local inhibitory interneurons in cortex comprise a diverse group of cells whose properties may lend themselves to distinct roles within cortical microcircuits. Yet the position of these cells with respect to incoming sensory input, and the development of their specific laminar connections have not been established. Fast-spiking parvalbumin-containing (PV) cells comprise the largest subset of GABAergic interneurons in visual cortex, and have been implicated in developmental plasticity. To explore the position of these cells with respect to sensory input, I determined the synaptic contribution of thalamic input onto PV interneurons in layer 4 of ferret visual cortex at early postnatal and adult ages. Utilizing dual and triple-labeling immuno-electron microscopy to visualize thalamic arbors, PV interneurons and GABAergic cells, I determined that $\sim 10 \%$ of all thalamocortical targets in adult layer 4 were PV-positive, and that every GABAergic target was immunoreactive for parvalbumin. This selective thalamocortical drive onto parvalbumin fast-spiking cells may account for the total thalamic innervation to GABAergic interneurons in adult layer 4. To investigate how PV interneuron inhibition impinges upon the subsequent cortical circuit, I conducted a laminar developmental analysis of PV terminal synapses with GABAergic and non-GABAergic targets using pre- and post-embedding electron microscopy. Moreover, I determined the contribution of inhibitory and excitatory synaptic input to PV interneurons within the same sections. This developmental analysis was performed in a line of transgenic mice in which the parvalbumin promoter drives enhanced green fluorescent protein expression. I found that PV
\end{abstract}


interneuron input to other GABAergic cells is nearly lost in layers $2 / 3$ and 4 , at an age commensurate with the peak for anatomical plasticity in visual cortex. Yet by the end of this critical period, parvalbumin containing interneurons have established a strong reciprocal inhibitory circuit with other GABAergic cells. These results are discussed in relation to the role that PV interneurons play in the generation of cortical response properties, and their possible modulation of a period for reduced anatomical and physiological malleability in visual cortex. 
TABLE OF CONTENTS

\begin{tabular}{ll} 
ABSTRACT & 2 \\
\hline
\end{tabular}

TABLE OF CONTENTS

4

CHAPTER I

5

GENERAL INTRODUCTION

CHAPTER II

22

SPECIFICITY OF THALAMOCORTICAL INPUT FOR PARVALBUMINCONTAINING INTERNEURONS IN PRIMARY VISUAL CORTEX

CHAPTER III

70

LAMINAR AND TARGET-SPECIFIC ALTERATIONS OF

PARVALBUMIN-CONTAINING INTERNEURON CONNECTIVITY

OVER CRITICAL PERIOD AGES

CHAPTER IV

116

GENERAL DISCUSSION 
CHAPTER I:

\section{GENERAL INTRODUCTION}


Neuronal circuitry in the developing sensory cortex displays a remarkable ability to reconfigure its anatomical connections and physiological response properties when compared to adulthood. This capacity for cortical "plasticity" has been intimated at for well over a century, in large part because an understanding of the constraints that ultimately prevent neurons in cortex from successfully rewiring is crucial in the quest to engineer targeted therapeutic strategies for the mature brain (Azmitia, 2007).

For nearly fifty years, primary visual cortex has been used a model for cortical plasticity, because of our ability to easily manipulate its incoming sensory information through either eye, and due to the fact that its relatively well understood circuitry is highly conserved across mammalian species (Hofer et al., 2006). Pioneering research in this field was conducted by David Hubel \& Torsten Wiesel, who discovered the cortical response property of ocular dominance, whereby cells preferentially respond to stimulation of either the left or right eye (Hubel and Wiesel, 1962). Normally cells within a particular hemisphere of primary visual cortex respond preferentially to stimulation of the contralateral eye, a phenomenon termed "contralateral bias". However, closing one eye for a period of days or weeks (called monocular deprivation) during a defined temporal window shifts the responses of a majority of cells toward the open non-deprived eye (Hubel and Wiesel, 1970). This shift occurs in parallel with a conspicuous alteration of thalamocortical axon and cortical morphology, yet monocular deprivation is only able to produce dramatic changes in either cortical physiology or anatomy during this "critical period" in development (Antonini et al., 1999; 
Antonini and Stryker, 1996; Katz and Crowley, 2002; LeVay et al., 1978;

Valverde, 1971).

In primary visual cortex, these thalamocortical axons arise from the lateral geniculate nucleus and provide primary visual input to layer 4 excitatory and inhibitory cells (Benshalom and White, 1986; Guillery and Sherman, 2002; Jones and Powell, 1970). Moreover, they establish the foundation for cortical response properties, such as receptive field generation, orientation selectivity and ocular dominance (Alonso and Swadlow, 2005; Ferster et al., 1996; Hubel and Wiesel, 1962; White et al., 1999). As essential modulators of this thalamic drive, $\gamma^{-}$ aminobutyric acid (GABA)ergic cortical cells are thought to supply the necessary opponent inhibition to allow for dynamic changes in luminance contrast, orientation, and shifts in ocular dominance (Mower and Christen, 1989; Mower et al., 1984; Schummers et al., 2005; Shapley et al., 2003; Troyer et al., 1998). However while the prominent contribution of thalamocortical drive onto excitatory circuitry has been intensively studied, a detailed account of the distribution of thalamic input to diverse groups of interneurons, possessing defined firing properties and specific innervation patterns remains to be explored (see Fig. 1).

Accumulating evidence suggests that parvalbumin-containing (PV) interneurons are a select group of inhibitory cells, uniquely situated to receive and transmit incoming sensory information from thalamocortical axons. PV neurons constitute the largest subset of GABAergic cells in layer 4 of rat visual cortex (Gonchar and Burkhalter, 1997), and receive potent monosynaptic input from thalamocortical afferents in layer 4 of barrel cortex (Agmon and Connors, 
1992; Beierlein et al., 2003). Furthermore in ferret visual cortex, parvalbumin immunoreactivity is present in cortical cells at birth and displays a second peak between postnatal day 60 into adulthood, suggesting that $\mathrm{PV}$ circuitry may remain immature until the end of the critical period and hence play a role in its closure (Gao et al., 2000). Thus, I first sought to characterize the development of thalamocortical synaptic input onto this subset of inhibitory interneurons in layer 4 of primary visual cortex (Chapter II). We chose to do this study in ferret in light of its similarity to the cat, monkey and rodent circuitry (Jackson and Hickey, 1985), and because we had previously established the exclusivity of vesicular glutamate transporter 2 (VGluT2) as a marker for thalamic terminals in layer 4 of ferret (Nahmani and Erisir, 2005).

In Chapter II, I hypothesized that if PV interneurons were essential in shaping receptive field generation and orientation selectivity in adult cortex, they would receive a large component of primary visual input at this age. In addition, I postulated that if $\mathrm{PV}$ interneurons were involved in modulating the end of the critical period for ocular dominance, they should receive a larger amount of thalamocortical drive at ages commensurate with declining cortical plasticity. The findings described in Chapter II hold intrinsic importance for understanding the formation of visual cortical response properties following thalamic stimulation. Moreover, these results intimated that $\mathrm{PV}$ interneurons were in prime position to supply powerful feedforward inhibition at ages of reduced physiological and anatomical cortical plasticity. 


\section{Inhibition and critical period modulation}

A natural progression of research into ocular dominance plasticity is its maturation into a tractable model to uncover the underlying anatomical and physiological constraints that ultimately prevent neurons in cortex from successfully rewiring. To this end, we have been severely limited in our understanding of how synaptic connections between subgroups of neurons develop, and the determination of which specific connections might contribute to the initiation and closure of this window for cortical plasticity.

To begin to unravel these questions, investigators have employed the paradigm of monocular deprivation (MD); used to reveal the extent that circuitry in visual cortex is plastic. During a defined critical period, activity can alter neuronal circuit physiology and morphology, and these modifications are able to recover. Suturing one eye shut for a period of approximately four days results in a maximal loss of neuronal responses to the deprived eye, and shifts the contralateral bias response in favor of the open ipsilateral eye in mouse visual cortex (Gordon and Stryker, 1996). Surprisingly, in collaboration with Mark Bear's lab we have shown that three to four days of MD is also sufficient to induce the anatomical loss of synaptic thalamocortical terminals in the contralateral mouse visual cortex (Coleman et al., 2007).

Yet, in mice lacking functional GABAergic release, MD is ineffective in shifting the contralateral bias response toward the open eye (Hensch et al., 1998). This plasticity can be recovered, however, if GABA agonist (e.g. 
diazepam) is infused into visual cortex (Fagiolini and Hensch, 2000). It follows that cortical inhibition from a currently unidentified population of GABAergic neurons might engage the critical period machinery necessary to permit a plastic state. Furthermore, since increased GABA release in wild-type animals results in a shortened critical period (Fagiolini et al., 2004; Iwai et al., 2003), the developmental maturation and consolidation of this inhibitory circuit may underlie events responsible for critical period closure. However to date, investigations of the critical period have not determined the specific GABAergic cells providing for this powerful modulation of cortical plasticity.

As is detailed above and in Chapter II, parvalbumin-containing (PV) interneurons appeared to be prime candidates to supply the necessary inhibitory release at the end of this critical period in visual cortex. PV interneurons are characterized by evoked firing patterns with short after-hyperpolarizations and rapid spike trains attributed to Kv3.1, a specific potassium channel restricted to the somata and proximal dendrites of PV-containing interneurons (Erisir et al., 1999; Weiser et al., 1995). In visual cortex, PV-immunoreactive neurons develop over a protracted period, only reaching an adult-like density by the end of the critical period for ocular dominance (del Rio et al., 1994; Gao et al., 2000). During this time, PV interneurons bear axons able to impinge on the activity of opposite eye columns (Buzas et al., 2001). Furthermore, PV interneuron boutons develop dense basket-like formations around pyramidal cell somata, providing fast and powerful inhibitory control of cortical excitatory output (Martin et al., 1983; Tamas et al., 1998). Interestingly, the targeted acceleration of PV 
interneuron perisomatic innervation of pyramidal neurons in transgenic mice effectively induces an early end of the critical period for ocular dominance plasticity (Chattopadhyaya et al., 2004). Hence, the development of PV circuitry might provide a substrate for ending this window of cortical plasticity.

Indeed, multiple theories exploring the underpinnings of crtical period have invoked PV inhibition in attempting to explain the neuronal circuitry behind the onset, modulation and/or closure of this window for cortical plasticity. Theories on the involvement of PV inhibition in the critical period can be parsed accordingly to the emphasis they place on different aspects of PV inteneuron morphology (see Fig. 2). For instance, long-term potentiation/depression (LTP/LTD) models of visual cortex plasticity stipulate that PV cells progressively inhibit the spread of exitation from layer 4 to layers $2 / 3$. Increased PV synapses with pyramidal dendrites are thought to be the neural substrate for this inhibition, leading to a switch form LTP to LTD in layer $2 / 3$ by the end of the critical period (Rozas et al., 2001). Conversely, models of exitatory/inhibitiory balance in visual cortex postulate that PV axosomatic contacts with pyrmadial somata release a permissive level of inhibition via downstream molecular cascades, enabling some requisite level of anatomical plasticity. As these PV basket-like synapses increase in number, they eventually limit cortical plasticity through downstream signaling that acts to solidiy the extracellular matrix (Hensch, 2005). A third model, spike-timing dependent plasticity, posits that a "teacher" neuron firing at a high frequency is able to entrain "student" neurons firing at lower frequencies (Dan and Poo, 2004). PV interneuron inhibition is thought to dynamicly regulate 
the amplitude or gain of excitatory cells over critical period ages, specifically within within layer 4 . This model holds that as the speed of GABAergic interneuron inhibition to excitatory cells increases, it effectively dyregulates and decreases the gain of excitatory cell output (Young et al., 2007). Consequently, the temporal and spatial spread of this competition based plasticity is diminished.

Yet, a model invoking the importance of PV or GABAergic inhibition in modulating cortical plasticity must account for that fact that PV interneuron input to neuronal populations in adult visual cortex has defined laminar characteristics and target specificity. Large PV containing basket cells primarily target the somata, proximal dendrites, and spines of layer $5 / 6$ pyramidal cells (Somogyi et al., 1983), while smaller PV-immunoreactive clutch cells prefer spiny stellate and pyramidal dendrites (Kisvarday et al., 1986). Furthermore, PV containing chandelier cells predominantly synapse with the initial axon segments of layer 2/3 pyramidal cells (DeFelipe et al., 1989; Peters et al., 1982). Therefore, a laminar analysis of the development of PV interneuron connectivity would not only contribute to our understanding of the role of inhibition in visual cortex, it would highlight how PV inhibition impinges on specific circuits in relation to increasing activity exposure.

I chose to investigate the synaptic development of PV interneuron and cortical GABAergic circuitry in a line of bacterial artificial chromosome (BAC) transgenic mice in which the parvalbumin promoter drives enhanced green fluorescent protein (EGFP) expression within this subset of interneurons. This model holds several advantages: (1) EGFP expression in these cells is robust, 
labeling a large portion of the dendritic and axonal arbors, whereas using PVimmunohistochemistry, only proximal arbors are visible. Moreover, similar to immuno-stained cells in ferret, these GFP cells all colocalize with $\mathrm{Kv} 3.1 \mathrm{~b}$, a $\mathrm{K}^{+}-$ channel specific to fast-spiking interneurons (see Chapters II and III); (2) The intrinsic firing properties and distinct neurite morphology of these EGFP cells has been well characterized, and these features suggest that this group of PV cells form a distinct subset of interneurons in mouse visual cortex (Dumitriu et al., 2007); (3) The mouse visual system is becoming the species of choice to investigate cortical plasticity under the ocular dominance paradigm due to its advantages with regard to genetic manipulation, recent advances teasing out molecular pathways, and the similarity of its circuit properties to that of rodents, cats and monkeys (Hofer et al., 2006).

In Chapter III I hypothesized that if PV interneuron connections are integrally involved in modulating cortical plasticity in visual cortex, their synaptic connectivity should be regulated over critical period ages. It follows that if PV interneuron contacts regulate critical period closure, their synaptic connectivity should differ at ages commensurate with enhanced plasticity versus those of reduced anatomical malleability. These results significantly impact our understanding of intralaminar GABAergic connectivity across key developmental time points. Moreover, these findings suggest that at the end of a critical period PV interneurons may limit the gain of cortical excitation and the spread of competitive neuronal interactions in a spike-timing dependent fashion. 


\section{References}

Agmon A, Connors BW. 1992. Correlation between intrinsic firing patterns and thalamocortical synaptic responses of neurons in mouse barrel cortex. $J$ Neurosci 12(1):319-329.

Ahmed B, Anderson JC, Martin KA, Nelson JC. 1997. Map of the synapses onto layer 4 basket cells of the primary visual cortex of the cat. J Comp Neurol 380(2):230-242.

Alonso JM, Swadlow HA. 2005. Thalamocortical specificity and the synthesis of sensory cortical receptive fields. J Neurophysiol 94(1):26-32.

Antonini A, Fagiolini M, Stryker MP. 1999. Anatomical correlates of functional plasticity in mouse visual cortex. J Neurosci 19(11):4388-4406.

Antonini A, Stryker MP. 1996. Plasticity of geniculocortical afferents following brief or prolonged monocular occlusion in the cat. J Comp Neurol 369(1):64-82.

Azmitia EC. 2007. Cajal and brain plasticity: insights relevant to emerging concepts of mind. Brain Res Rev 55(2):395-405.

Beierlein M, Gibson JR, Connors BW. 2003. Two dynamically distinct inhibitory networks in layer 4 of the neocortex. J Neurophysiol 90(5):2987-3000.

Benshalom G, White EL. 1986. Quantification of thalamocortical synapses with spiny stellate neurons in layer IV of mouse somatosensory cortex. J Comp Neurol 253(3):303-314.

Buzas P, Eysel UT, Adorjan P, Kisvarday ZF. 2001. Axonal topography of cortical basket cells in relation to orientation, direction, and ocular dominance maps. J Comp Neurol 437(3):259-285.

Chattopadhyaya B, Di Cristo G, Higashiyama H, Knott GW, Kuhlman SJ, Welker E, Huang ZJ. 2004. Experience and activity-dependent maturation of perisomatic GABAergic innervation in primary visual cortex during a postnatal critical period. J Neurosci 24(43):9598-9611.

Coleman JE, Nahmani M, Erisir A, Bear MF. 2007. Rapid, experience-dependent structural remodeling of thalamocortical synapses in mouse primary visual cortex. Society for Neuroscience. San Diego, CA.

Dan Y, Poo MM. 2004. Spike timing-dependent plasticity of neural circuits. Neuron 44(1):23-30.

DeFelipe J, Hendry SH, Jones EG. 1989. Visualization of chandelier cell axons by parvalbumin immunoreactivity in monkey cerebral cortex. Proc Natl Acad Sci U S A 86(6):2093-2097.

del Rio JA, de Lecea L, Ferrer I, Soriano E. 1994. The development of parvalbumin-immunoreactivity in the neocortex of the mouse. Brain Res Dev Brain Res 81(2):247-259.

Dumitriu D, Cossart R, Huang J, Yuste R. 2007. Correlation between axonal morphologies and synaptic input kinetics of interneurons from mouse visual cortex. Cereb Cortex 17(1):81-91.

Erisir A, Dreusicke M. 2005. Quantitative morphology and postsynaptic targets of thalamocortical axons in critical period and adult ferret visual cortex. J Comp Neurol 485(1):11-31. 
Erisir A, Lau D, Rudy B, Leonard CS. 1999. Function of specific $\mathrm{K}(+)$ channels in sustained high-frequency firing of fast-spiking neocortical interneurons. J Neurophysiol 82(5):2476-2489.

Fagiolini M, Fritschy JM, Low K, Mohler H, Rudolph U, Hensch TK. 2004. Specific GABAA circuits for visual cortical plasticity. Science 303(5664):1681-1683.

Fagiolini M, Hensch TK. 2000. Inhibitory threshold for critical-period activation in primary visual cortex. Nature 404(6774):183-186.

Ferster D, Chung S, Wheat $\mathrm{H}$. 1996. Orientation selectivity of thalamic input to simple cells of cat visual cortex. Nature 380(6571):249-252.

Gao WJ, Wormington AB, Newman DE, Pallas SL. 2000. Development of inhibitory circuitry in visual and auditory cortex of postnatal ferrets: immunocytochemical localization of calbindin- and parvalbumin-containing neurons. J Comp Neurol 422(1):140-157.

Gonchar Y, Burkhalter A. 1997. Three distinct families of GABAergic neurons in rat visual cortex. Cereb Cortex 7(4):347-358.

Gordon JA, Stryker MP. 1996. Experience-dependent plasticity of binocular responses in the primary visual cortex of the mouse. J Neurosci 16(10):3274-3286.

Guillery RW, Sherman SM. 2002. Thalamic relay functions and their role in corticocortical communication: generalizations from the visual system. Neuron 33(2):163-175.

Hensch TK. 2005. Critical period plasticity in local cortical circuits. Nat Rev Neurosci 6(11):877-888.

Hensch TK, Fagiolini M, Mataga N, Stryker MP, Baekkeskov S, Kash SF. 1998. Local GABA circuit control of experience-dependent plasticity in developing visual cortex. Science 282(5393):1504-1508.

Hofer SB, Mrsic-Flogel TD, Bonhoeffer T, Hubener M. 2006. Lifelong learning: ocular dominance plasticity in mouse visual cortex. Curr Opin Neurobiol 16(4):451-459.

Hubel DH, Wiesel TN. 1962. Receptive fields, binocular interaction and functional architecture in the cat's visual cortex. J Physiol 160:106-154.

Hubel DH, Wiesel TN. 1970. The period of susceptibility to the physiological effects of unilateral eye closure in kittens. J Physiol 206(2):419-436.

Iwai Y, Fagiolini M, Obata K, Hensch TK. 2003. Rapid critical period induction by tonic inhibition in visual cortex. J Neurosci 23(17):6695-6702.

Jackson CA, Hickey TL. 1985. Use of ferrets in studies of the visual system. Lab Anim Sci 35(3):211-215.

Jones EG, Powell TP. 1970. An electron microscopic study of the laminar pattern and mode of termination of afferent fibre pathways in the somatic sensory cortex of the cat. Philos Trans R Soc Lond B Biol Sci 257(812):45-62.

Katz LC, Crowley JC. 2002. Development of cortical circuits: lessons from ocular dominance columns. Nat Rev Neurosci 3(1):34-42.

Kisvarday ZF, Cowey A, Somogyi P. 1986. Synaptic relationships of a type of GABA-immunoreactive neuron (clutch cell), spiny stellate cells and lateral 
geniculate nucleus afferents in layer IVC of the monkey striate cortex. Neuroscience 19(3):741-761.

LeVay S, Stryker MP, Shatz CJ. 1978. Ocular dominance columns and their development in layer IV of the cat's visual cortex: a quantitative study. J Comp Neurol 179(1):223-244.

Martin KA, Somogyi P, Whitteridge D. 1983. Physiological and morphological properties of identified basket cells in the cat's visual cortex. Exp Brain Res 50(2-3):193-200.

Mower GD, Christen WG. 1989. Evidence for an enhanced role of GABA inhibition in visual cortical ocular dominance of cats reared with abnormal monocular experience. Brain Res Dev Brain Res 45(2):211-218.

Mower GD, Christen WG, Burchfiel JL, Duffy FH. 1984. Microiontophoretic bicuculline restores binocular responses to visual cortical neurons in strabismic cats. Brain Res 309(1):168-172.

Nahmani M, Erisir A. 2005. VGluT2 immunochemistry identifies thalamocortical terminals in layer 4 of adult and developing visual cortex. J Comp Neurol 484(4):458-473.

Peters A, Payne BR. 1993. Numerical relationships between geniculocortical afferents and pyramidal cell modules in cat primary visual cortex. Cereb Cortex 3(1):69-78.

Peters A, Proskauer CC, Ribak CE. 1982. Chandelier cells in rat visual cortex. J Comp Neurol 206(4):397-416.

Rozas C, Frank H, Heynen AJ, Morales B, Bear MF, Kirkwood A. 2001. Developmental inhibitory gate controls the relay of activity to the superficial layers of the visual cortex. J Neurosci 21(17):6791-6801.

Schummers J, Sharma J, Sur M. 2005. Bottom-up and top-down dynamics in visual cortex. Prog Brain Res 149:65-81.

Shapley R, Hawken M, Ringach DL. 2003. Dynamics of orientation selectivity in the primary visual cortex and the importance of cortical inhibition. Neuron 38(5):689-699.

Somogyi P, Kisvarday ZF, Martin KA, Whitteridge D. 1983. Synaptic connections of morphologically identified and physiologically characterized large basket cells in the striate cortex of cat. Neuroscience 10(2):261-294.

Tamas G, Somogyi P, Buhl EH. 1998. Differentially interconnected networks of GABAergic interneurons in the visual cortex of the cat. J Neurosci 18(11):4255-4270.

Troyer TW, Krukowski AE, Priebe NJ, Miller KD. 1998. Contrast-invariant orientation tuning in cat visual cortex: thalamocortical input tuning and correlation-based intracortical connectivity. J Neurosci 18(15):5908-5927.

Valverde F. 1971. Rate and extent of recovery from dark rearing in the visual cortex of the mouse. Brain Res 33(1):1-11.

Weiser M, Bueno E, Sekirnjak C, Martone ME, Baker H, Hillman D, Chen S, Thornhill W, Ellisman M, Rudy B. 1995. The potassium channel subunit $\mathrm{KV} 3.1 \mathrm{~b}$ is localized to somatic and axonal membranes of specific populations of CNS neurons. J Neurosci 15(6):4298-4314. 
White LE, Bosking WH, Williams SM, Fitzpatrick D. 1999. Maps of central visual space in ferret V1 and V2 lack matching inputs from the two eyes. J Neurosci 19(16):7089-7099.

Young JM, Waleszczyk WJ, Wang C, Calford MB, Dreher B, Obermayer K. 2007. Cortical reorganization consistent with spike timing-but not correlationdependent plasticity. Nat Neurosci 10(7):887-895. 


\section{FIGURE LEGENDS}

Figure 1. Intralaminar and interlaminar connectivity within primary visual cortex. Left side of figure depicts interlaminar connections, while right side displays intralaminar and intercortical projections. Excitatory pyramidal cells (Ex) within layers $2 / 3$ and $5 / 6$ form the output of visual cortex, while excitatory interneurons (Ex) within layer 4 send feedforward information to layer 2/3. Percentages indicate estimated proportions of thalamic and interneuron input that innervate selected targets (Ahmed et al., 1997; Erisir and Dreusicke, 2005; Nahmani and Erisir, 2005; Peters and Payne, 1993). Note that the proportions of inhibitory to excitatory interlaminar connections are mostly uknown.

Figure 2. Theoretical models of critical period plasticity in visual cortex. Longterm potentiation/depression (LTP/LTD) models suggest that increased parvalbumin interneuron (PV) inhibition of pyramidal cell (Pyr) apical dendrites in layer 4 can account for the switch in layer 2/3 LTP to LTD during the critical period. Models of inhibitory/excitatory (I/E) balance in cortex posit that a progressive increase in PV basket-like synapses engage the molecular machinery with pyramidal somata to tip the balance from "stability" to "plasticity". As this form of inhibition increases over development, the cortex (lamina of origin is not specified) becomes less malleable. Spike-timing dependent plasticity models do not call for PV inhibition per se; rather they implicate general inhibition as the modulator 
of layer 4 excitatory cell (Ex) amplitude over critical period ages. Since decreased gain in cortex canonically decreases the spread of this form of competition, plasticity gradually decreases with age. Yet, this theory remains vague as to how and which circuit that might modulate this inhibition. 
Figure 2.

\section{MODEL $\quad \underline{\text { Critical period initiation } \quad \text { Critical period closure }}$}

\section{LTP/LTD}

Layer 4
I/E Balance Layer?
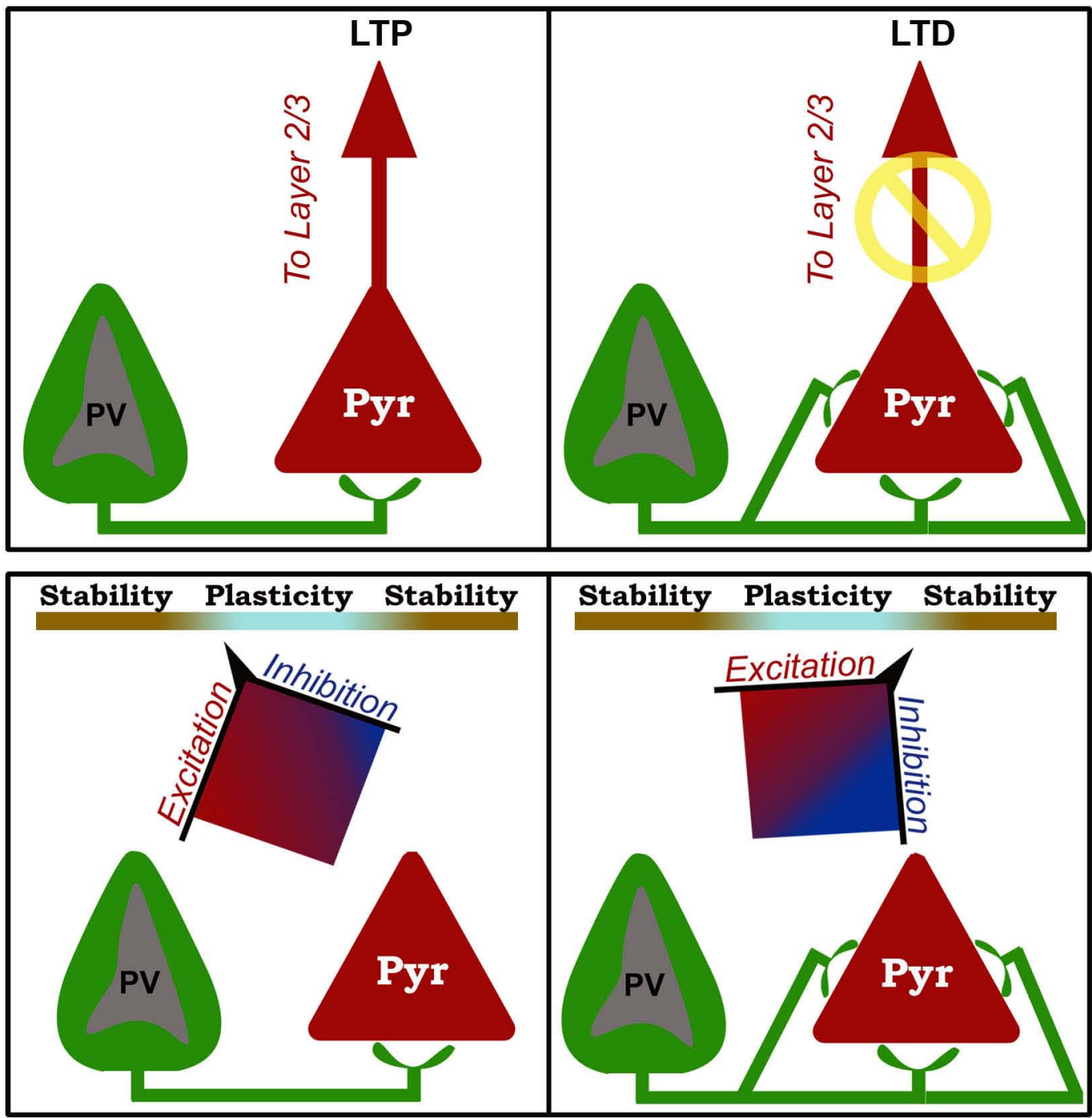

Spike-timing Layer 4

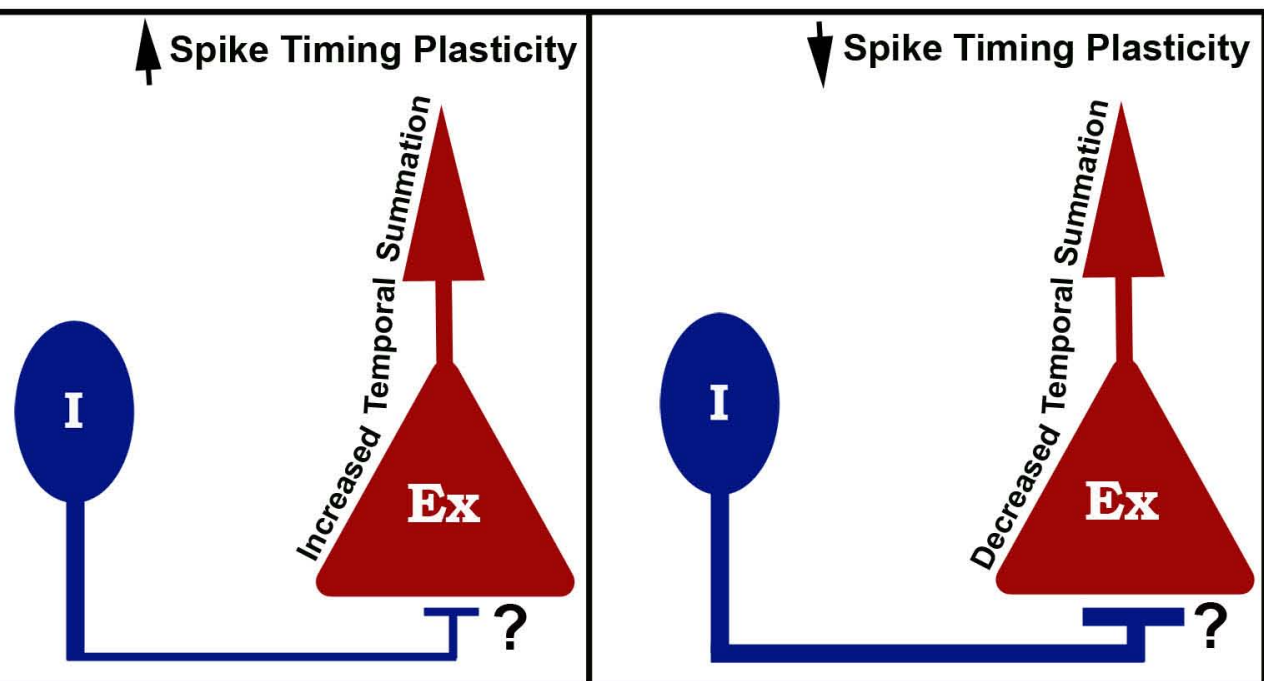




\section{CHAPTER II:}

SPECIFICITY OF THALAMOCORTICAL INPUT FOR PARVALBUMIN-CONTAINING INTERNEURONS IN PRIMARY VISUAL CORTEX 
Relay cells in the mammalian thalamus process incoming sensory information and transmit this signal via their thalamocortical axons to primary cortical areas, where they synapse on excitatory and inhibitory cells (Benshalom and White, 1986; Guillery and Sherman, 2002; Jones and Powell, 1970). In primary visual cortex, the precise projection of thalamocortical axons to layer 4 neurons is thought to establish the foundation for cortical response properties, such as receptive field generation and orientation selectivity (Alonso and Swadlow, 2005; Ferster et al., 1996; Hubel and Wiesel, 1962; White et al., 1999). Subsequent projections of thalamocortical recipient neurons onto granular and extragranular layer neurons seem to act as essential modulators of thalamocortical drive, in supplying opponent inhibition and allowing for dynamic responses to changes in luminance contrast and orientation (Schummers et al., 2005; Shapley et al., 2003; Troyer et al., 1998). Yet while the prominent contribution of thalamocortical drive onto excitatory circuitry has been intensively studied, a detailed account of the distribution of thalamic input to diverse groups of interneurons, possessing defined firing properties and specific innervation patterns remains to be explored.

Earlier anatomical and physiological studies have demonstrated that geniculate axons make synaptic contact with every identified neuronal subclass in cortical layer 4 (Ahmed et al., 1994; Ahmed et al., 1997; Davis and Sterling, 1979; Freund et al., 1989; Hirsch, 1995; Peters and Feldman, 1977). These investigations of thalamocortical connectivity have used classification schemes 
based either on morphology (e.g. stellate, pyramidal shaped) or the presence/absence of $\gamma$-aminobutyric acid (GABA) in a postsynaptic partner. However, GABA-positive cortical cells are not a uniform population, but consist of multiple subpopulations characterized by their distinct morphologies, receptor composition, cellular firing properties, immunoreactive label and axonal targets. (Bacci et al., 2003; Demeulemeester et al., 1988; Gonchar and Burkhalter, 1997; Kawaguchi, 1995). Moreover, phenotypic specification of these interneuron groups appears to be set prior to their migration, emphasizing the role of afferent projections in directing the cortical microcircuit (for review see (Wonders and Anderson, 2006)). For instance, in layer 4 of adult barrel and visual cortex of rodent, approximately 8-9\% of all thalamic contacts contain GABA (Erisir and Dreusicke, 2005; Staiger et al., 1996). However, the specificity of thalamocortical input onto specific subtypes of interneurons, and hence the hierarchical position of interneuron subpopulations in cortical circuitry, has not been examined.

Mounting evidence suggests that parvalbumin cells are a select group of inhibitory interneurons, uniquely situated to receive and transmit incoming sensory information from thalamocortical axons to primary visual cortex. Parvalbumin is a calcium binding protein restricted to the soma and neurites of select neuronal populations in cortex (Celio, 1986). A consistent pattern of parvalbumin-staining has been observed in a subpopulation of GABAergic interneurons in adult rat (Gonchar and Burkhalter, 1997), ferret (Gao et al., 2000), cat (Stichel et al., 1986), monkey and human (Blumcke et al., 1990) primary visual cortex. In addition, parvalbumin-containing neurons constitute the 
largest subset of GABAergic cells in layer 4 of rat visual cortex (Gonchar and Burkhalter, 1997), and receive potent monosynaptic input from thalamocortical afferents in layer 4 of barrel cortex (Agmon and Connors, 1992; Beierlein et al., 2003). In ferret visual cortex, parvalbumin immunoreactivity is present in cortical cells at birth and displays a second peak between postnatal day 60 into adulthood, suggesting that parvalbumin containing neurons remain immature until the end of the critical period (Gao et al., 2000). While thalamocortical connectivity to PV neurons in ferret visual cortex has not yet been established, primary visual input to GABA-containing cells in ferret declines into adulthood (Erisir and Dreusicke, 2005), indicating that certain inhibitory interneurons loose thalamic drive during this period. Thus, we examined the anatomical basis for a selective thalamocortical drive onto parvalbumin-containing neurons in developing and adult ferrets.

To this end, we first confirmed the specificity of the parvalbumin antibody for cells that contain GABA and Kv3.1, a potassium channel that has been shown to afford parvalbumin-positive GABAergic interneurons with fast spiking properties. In addition, we quantified the contribution of thalamocortical synaptic input to parvalbumin-containing neurons in layer 4 of immature and adult ferret primary visual cortex. Portions of these results were presented in abstract format (Nahmani et al., Society for Neuroscience Abstract, 2005). 


\section{MATERIALS AND METHODS}

\section{Source of Tissue}

We used a total of 4 adult (>p90) and 3 immature ferrets for this study. All animal procedures and protocols were in accordance with $\mathrm{NIH}$ guidelines for humane handling of animals and approved by the institutional Animal Care and Use Committee at the University of Virginia.

\section{Tissue Preparation and Immunovisualization}

Perfusions. Animals were given an overdose of pentobarbital sodium (Nembutal $^{\circledR}$, in excess of $50 \mathrm{mg} / \mathrm{kg}$ ) and perfused transcardially with $100 \mathrm{~mL}$ of room temperature Tyrode's solution $(0.8 \% \mathrm{NaCl}, 0.1 \% \alpha$-D-Glucose, $0.0006 \%$ $\mathrm{MgCl}_{2}, 0.015 \% \mathrm{KCl}, 0.006 \% \mathrm{NaH}_{2} \mathrm{PO}_{4}, 0.01 \% \mathrm{CaCl}_{2}, 0.1 \% \mathrm{NaHCO}_{3}$ in $\mathrm{dH}_{2} \mathrm{O}$ ) for 3 minutes, and $500 \mathrm{~mL}$ of $4 \%$ paraformaldehyde and $0.5 \%$ gluteraldehyde in $0.1 \mathrm{M}$ phosphate buffer (PB; pH 7.4) as fixatives, delivered in 15 minutes. Next, brains were removed and stored in $4 \%$ paraformaldehyde overnight at $4^{\circ} \mathrm{C}$. On the following day, each brain was blocked to isolate the binocular region of ferret primary visual cortex (Law et al., 1988), and sectioned on a vibratome at 60um. Free-floating sections were immediately treated with $1 \% \mathrm{NaBH}_{4}$, rinsed in PB until bubbles were no longer present, and stored in 0.01M phosphate buffered saline (PBS; $\mathrm{pH} 7.4$ ) containing $0.1 \% \mathrm{NaN}_{3}$ at $4^{\circ} \mathrm{C}$. This procedure was used for sections processed for both confocal and electron microscopy. 
Confocal microscopy preparation. Sections were rinsed three times for 3 minutes in PBS. Next, sections were preincubated in PBS containing $0.3 \%$ Triton-X and $1 \%$ bovine serum albumin for 30 minutes, and then put into primary antibody: guinea pig anti-vesicular glutamate transporter 2 (VGluT2; 1:2500; Chemicon, Temecula, CA), mouse monoclonal anti-parvalbumin (1:400; Sigma, St. Louis, MO), rabbit anti-glutamic acid decarboxylase $65 / 67\left(\mathrm{GAD}_{65 / 67}, 1: 1000\right.$, Chemicon), rabbit anti-Kv3.1b (1:1000; produced and previously characterized in (Weiser et al., 1995)) in 1\% bovine serum albumin, $0.3 \%$ Triton- $X$ and $0.05 \%$ $\mathrm{NaN}_{3}$ in PBS at room temperature for at least 24 hours. For dual-labeling confocal experiments, sections were incubated in both primary antibodies simultaneously. For sections incubated in anti-GAD $65 / 67,0.05 \%$ Triton-X was used for the preincubation step, and Triton-X was omitted from the primary antibody solution due to a loss of soma staining. These constraints necessarily limited anti-GAD ${ }_{65 / 67}$ penetration into vibratome thick sections. Following primary incubation, sections were rinsed three times for 3 minutes in PBS, and then incubated in the appropriate secondary antibodies: anti-guinea pig Alexa 568, anti-mouse Alexa 488, anti-rabbit Rhodamine Red-X (all at 5 $\mu \mathrm{g} / \mathrm{mL}$; Molecular Probes, Eugene, OR). After rinsing in PBS, sections were mounted onto glass coverslips in a 2:1 glycerol:PBS solution.

Antibody Specificity. The specific monoclonal parvalbumin antibody used in both confocal and electron microscopy experiments has been well characterized (Celio et al., 1988; Celio et al., 1986) in species ranging from mouse to human. 
In addition, a previous study has described the developmental pattern and specificity of this antibody in ferret (Gao et al., 2000). Furthermore, we performed antibody control experiments included with both confocal and electron microscopy experiments by omitting primary or secondary antibody and did not observe chromagen accumulation in cells within these tissue sections.

Electron microscopy preparation. Preembedding immunocytochemistry. After a preincubation in PBS containing $0.05 \%$ Triton- $X$ and $1 \%$ bovine serum albumin for 30 minutes, the sections were incubated in primary antibody: guinea pig antiVGluT2 (1:5000), rabbit anti-parvalbumin (1:1000), containing $1 \%$ bovine serum albumin and $0.05 \% \mathrm{NaN}_{3}$ in PBS for 2 days. Sections were put into anti-rabbit 1nm gold secondary (1:100; Nanoprobes, Yaphank, NY) overnight, followed by biotinylated anti-guinea pig (1:200; Vector Labs, Burlingame, CA) containing 1\% bovine serum albumin/PBS for 2 hours. Sections were then put into avidin-biotin complex in PBS (Vectastain kit, Vector Labs) for 2 hours, and processed in a 1\% DAB solution in the presence of $0.01 \% \mathrm{H}_{2} \mathrm{O}_{2}$ with gentle agitation for 8-10 minutes. Following the $D A B$ incubation, sections were rinsed and put back into anti-rabbit gold secondary for 1 hour, and then into $2 \%$ gluteraldehyde in $\mathrm{dH}_{2} \mathrm{O}$ for 30 minutes. Afterward, sections were rinsed in filtered citrate buffer $(\mathrm{pH} 6.5)$, and placed into a silver enhancement solution (IntenSE kit, Amersham Biosciences, Buckinghamshire, England). The duration of enhancement for each group of sections was determined as the time required for somata to accumulate brownish cytoplasmic staining. 
Embedding. Sections were embedded for electron microscopy following previously published protocols (Erisir et al., 2001; Nahmani and Erisir, 2005). To summarize, sections were postfixed in $1 \% \mathrm{OsO}_{4}$, rinsed in $50 \%$ ethanol, and then incubated in $4 \%$ filtered uranyl acetate. Next, sections were dehydrated in a series of ethanols and acetone, and placed into a 1:1 acetone-Epon mixture for 2 hours or overnight. Sections were then placed in 100\% Epon for 2 hours or overnight. Following this, sections were placed flat between two sheets of aclar (SPI supplies, West Chester, PA) and placed in a $60^{\circ} \mathrm{C}$ oven overnight for polymerization. Desired areas in sections were excised from the flat embeds, placed in BEEM capsules, filled with Epon, and left in a $60^{\circ} \mathrm{C}$ oven overnight or until polymerized. Next, outlines and landmarks were traced using a camera lucida, and an area of $\sim 1 \times 2 \mathrm{~mm}$ was carefully trimmed within the VGluT2 labeled band in layer 4 . Ultrathin sections of trimmed areas were cut at $\sim 70 \mathrm{~nm}$ on an ultramicrotome and collected on copper or nickel mesh grids.

\section{Postembedding and Triple-labeling immunocytochemistry. Sections to be} postembedded for GABA were processed as previously described (Erisir and Dreusicke, 2005; Erisir et al., 1997). Triple-labeling was performed on embedded tissue previously incubated in guinea pig anti-VGluT2 and mouse anti-parvalbumin antibodies (as described above), while double-labeling tissue was previously incubated in mouse anti-parvalbumin primary antibody. Ultrathin sections of double or triple-labeled tissue were collected on glue-covered nickel grids, and rinsed in TRIS-buffered saline (TBS) containing 0.1\% Triton-X (pH 7.4) 
for 15 minutes. Sections were then incubated in primary antibody: rabbit antiGABA (1:500; Sigma) and left overnight at room temperature. Next, sections were rinsed in TBS ( $\mathrm{pH} 7.4$ ), then in TBS ( $\mathrm{pH}$ 8.2), followed by incubation in secondary antibody: goat anti-rabbit $15 \mathrm{~nm}$ gold (1:25 in TBS pH 8.2; Ted Pella, Redding, $\mathrm{CA}$ ) for 2 hours. Sections were rinsed in TBS ( $\mathrm{pH} 7.4)$, fixed in $2 \%$ gluteraldehyde solution for 10 minutes, and rinsed in $\mathrm{dH}_{2} \mathrm{O}$ two times for 5 minutes. They were then counterstained in $5 \%$ uranyl acetate in methanol for 10 minutes, followed by Reynolds solution containing $2 \%$ lead citrate for 2 minutes, and allowed to air dry.

\section{Sampling and Measurements}

Sampling and Measurements with confocal microscope. Sections prepared for confocal microscopy were imaged on an Olympus IX70 laser scanning confocal microscope, with 543nm and 633nm krypton/argon lasers. Labeled areas were examined with $\mathrm{X} 10$ and $\mathrm{X} 20$ objectives, possessing numerical apertures of 0.30 and 0.50 , respectively. Images were captured with Olympus Fluoview FV300 v.5.0 software (Olympus Optical Co., Ltd.), and obtained by z-series (step size: $2 \mu \mathrm{m}(\mathrm{X} 10)$ and $1 \mu \mathrm{m}(\mathrm{X} 20))$ at $1024 \times 1024$ pixel resolution. This resulted in lateral resolution limits of $1-1.2 \mu \mathrm{m}(\mathrm{X} 10)$ and $0.63-0.74 \mu \mathrm{m}(\mathrm{X} 20)$ and final pixel sizes of $1.38 \mu \mathrm{m} / \mathrm{pixel}(\mathrm{X} 10)$ and $0.69 \mu \mathrm{m} / \mathrm{pixel}(\mathrm{X} 20)$. For double labeling experiments, 10 optical sections of $1422 \mu \mathrm{m}^{2} /$ each were chosen at random and examined for instances of colocalization and/or double labeling. 
Sampling and Measurements with electron microscope. Ultrathin sections were examined on a JEOL 1010 electron microscope and digital pictures were captured using a 16 megapixel SIA-12C (sia-cam.com) digital camera coupled with MaxIm DL ${ }^{\circledR}$ CCD software (Diffraction Limited, Ottawa, Canada). Because the antibody penetration can be limited to several microns from the surface of the thick slices, ultrathin sections close to the tissue-epon interface were systematically examined to detect labeled profiles. Every labeled profile encountered was photographed at 12,000X magnification. Each electron micrograph was examined using Image Pro Plus ${ }^{\circledR}$ v.5.0 software, at a final magnification of $60,000-80,000 X$. Profiles that were positive for VGluT2 were located in each digital picture and given sample numbers for identification. Profiles were identified as terminals if they possessed the following criteria: 1) presence of at least 3 vesicles, 2) parallel alignment of presynaptic terminal membrane in apposition with that of the postsynaptic membrane. Profiles were deemed synaptic if they met all the requirements defining a terminal and had a pronounced postsynaptic density. If synaptic, the postsynaptic target was classified as a dendritic spine, shaft, or soma. Dendritic shafts were defined principally by the presence of an organized arrangement of microtubules or at least one mitochondrion. Dendritic spines were identified by their filamentous actin, absence of mitochondria and microtubules, or presence of smooth endoplasmic reticulum (spine apparatus). Given the likelihood of sectioning through dendritic shafts coursing through cortex at irregular angles, it is possible that some dendritic shafts were absent of conspicuous mitochondria and 
recognizable microtubules, and hence were misidentified as spines. Therefore, numbers of spines may have been overestimated, leading to an artificial decrease in the percentage of parvalbumin dendrites contacted by thalamic terminals.

Silver/Gold label criterion. Parvalbumin containing somata, dendrites and spines were identified as parvalbumin-positive if they possessed $\geq 1$ silver-enhanced gold particle. This criterion was determined individually for each animal, by calculating the $95^{\text {th }}$ percentile for silver/gold label density within terminals that formed asymmetric junctions and were VGluT2 negative. This population represents putative parvalbumin negative neuropil because it excludes both thalamocortical and GABAergic terminals (see below). Moreover, we confirmed the reliability of this measure by calculating the silver/gold label density within a sample of putative "parvalbumin-positive" $(n=6)$ and "parvalbumin-negative" $(n=6)$ somas for each brain. Somata that were included in this measure were sampled from micrographs taken at low magnification (4K). Somas deemed "positive" had abundant and unambiguous gold/silver labeling, while sampled somata not meeting this criterion were categorized as "negative". The mean silver/gold label density for either soma sample did not differ from the means of the respective parvalbumin-positive or parvalbumin-negative profiles, as calculated by the $95^{\text {th }}$ percentile criterion ( $p<0.05, t-T e s t$, two-tailed). Postsynaptic profiles were considered GABA-positive if their calculated gold density rose above the $95^{\text {th }}$ percentile for silver/gold labeling as described above; also see (Erisir and Dreusicke, 2005). 
Synapse length. Synapses were traced by following the entire length of the postsynaptic density along the parallel membranes of the synapse, and were given a synapse sample number indicating the target identity. In the event that a postsynaptic density was perforated by a spine protrusion, the synapse was assumed to continue along the length of the protrusion. Unpaired t-Tests (twotailed) were used to determine statistical significance of synapse length and dendrite preference means for labeled versus unlabeled profiles.

Parvalbumin in thalamocortical terminals. As in previous studies of cat and monkey visual cortex connectivity (Alcantara and Ferrer, 1994; Blumcke et al., 1991; Latawiec et al., 2000), parvalbumin was observed in an undetermined proportion of thalamocortical axons. However, the percentage of parvalbuminlabeled thalamic terminals could not be determined due to the affinity of silvergold label artifact for DAB-labeled profiles. 


\section{RESULTS}

\section{Characterization of interneuron markers in ferret visual cortex}

Immunostaining with antibodies directed against calretinin, somatostatin and parvalbumin yielded distinct patterns of laminar staining in neurons of ferret visual cortex (Figures 1-2). Calretinin immunoreactivity was found most prominently in dendritic processes located in layer $2 / 3$, while immunoreactive somata were distributed primarily in layer 2/3, and sparsely in layers 5 and 4 (Fig. 1A). A similar laminar pattern of calretinin labeling has been observed in mouse and rat visual cortices (Gonchar and Burkhalter, 1997; Luth et al., 1993; Park et al., 2002). Somatostatin immunoreactivity was observed almost entirely in somata, with labeled neurons densest in layer $2 / 3$, sparse in layer 4 , and evenly distributed throughout layers 5 and 6 (Fig. 1). Although somatostatin immunolabeling was similarly confined to the cytosolic compartments of neuronal somata, the laminar distribution of labeled cells in ferret cortex differed from that seen in rat (Gonchar and Burkhalter, 1997). In rat, somatostatin-immunoreactive cells were found most numerous in layers 5 and 6 , with a less dense distribution across layer $2 / 3$. This discrepancy may due to differences in species-specific neuronal immunoreactivity, or an alternate distribution of somatostatin-positive cells. In any case, this peptides' lack of immunoreactivity in dendritic segments prevented further analysis of synaptic connectivity at the electron microscope level (see below). 
Parvalbumin immunoreactivity was found in the somata and proximal dendrites of non-pyramidal cells throughout cortical layers 2-6. Parvalbuminimmunoreactive (PV-ir) neurons appeared to cluster in upper layers $2 / 3$ and 5 (Fig 2A, B). To determine if PV-ir cells were interspersed within the primary thalamic projection in layer 4, sections were dual labeled for the presence of parvalbumin and VGluT2 (Nahmani and Erisir, 2005). Indeed, PV-ir cells were also distributed within the VGluT2-labeled band (Fig 2C). Labeled somata throughout the cortical depth displayed at least 4 distinct morphologies, including skinny bipolar, small ovoid clutch-like, large basket-type and horizontally oriented cells present in layers 5 and 6 (Fig. 2B). PV-ir puncta were present throughout the cortex, and were frequently observed in a basket formation around unlabeled neurons in layers $2 / 3$ and 5 . A similar laminar pattern of somatic PV staining and putative axon terminal configurations have been reported previously in ferret, cat and monkey visual cortex (Akil and Lewis, 1992; Gao et al., 2000; Somogyi et al., 1983).

To further characterize the similarities of parvalbumin-immunoreactivity in ferret visual cortex to that in rodents, we examined the co-localization of parvalbumin with other markers using dual-labeling laser confocal microscopy. Two isoforms of glutamic acid decarboxylase $\left(G_{A D} D_{65 / 67}\right)$, which are markers of interneuron axonal boutons and somata respectively (Kaufman et al., 1991), colocalized with parvalbumin in all cortical layers, indicating that parvalbumincontaining cells in adult ferret visual cortex are GABAergic interneurons (Fig $3 A$ ). In addition, Kv3.1b, a potassium channel that is largely restricted to the somatic 
and synaptic membranes of fast-spiking, parvalbumin-containing interneurons in mice (Chow et al., 1999; Erisir et al., 1999; Rudy and McBain, 2001) was present in PV-ir neurons of developing (p43, p47, p60) and adult ferret visual cortex (Fig. 3B-C). For this experiment, ten areas $\left(\sim 1400 \mu \mathrm{m}^{2} /\right.$ each $)$ were examined from six coronal sections of primary visual cortex in each animal. In every optical section examined, PV-ir somata colocalized with Kv3.1b protein, regardless of somatodendritic morphology or laminar position (Fig. 3). These data suggest that similar to mice, rat and cat (Chow et al., 1999; Demeulemeester et al., 1989; Gonchar and Burkhalter, 1997), PV-ir neurons in ferret visual cortex may constitute a fastspiking population of GABAergic interneurons. In addition, as in these previous studies, basket-forming PV-ir puncta frequently colocalized with and/or surrounded Kv3.1b label, however confocal resolution limited our ability to discern whether these corresponded to pre- or postsynaptic elements. Furthermore, no detectable differences were noted in laminar pattern or density of parvalbumin positive cells in the cortex of $\mathrm{p} 43, \mathrm{p} 47$, or p60 animals, confirming that the density of PV-ir neurons was complete before the peak of the critical period for cortical plasticity in the ferret (Gao et al., 2000; Issa et al., 1999).

\section{Thalamocortical boutons contact parvalbumin dendrites}

To resolve if thalamic terminals make synaptic contact with PV-ir interneurons, we processed sections adjacent to those used for confocal experiments for immuno-electron microscopy. Sections of primary visual cortex 
were stained for antibodies against both VGluT2 and PV, and trimmed to contain the neuropil within the labeled VGluT2 band in layer 4 . We observed thalamocortical terminals forming synapses onto both PV-ir and unlabeled profiles (Fig. 4). A large majority of the postsynaptic targets of thalamic terminals were dendritic spines, presumably belonging to excitatory neurons in layer 4 . In contrast, PV-ir targets of thalamocortical synapses were mostly large caliber dendrites, however instances were also found of thalamic terminals forming a synapse onto a PV-ir dendrite that bore a spine. Interestingly, some VGluT2 labeled terminals with synapses on a PV-ir dendrite had an additional synapse with an unlabeled spine (Fig. 4A, C). Furthermore, out of over 530 sampled terminals, only a single case of a labeled thalamocortical terminal with a synapse onto a PV-ir cell body was observed (Fig. 4B).

\section{Thalamic input to somatostatin-containing interneurons}

In order to quantify the extent of thalamic input to somatostatin cells in adult ferret visual cortex, we examined sections dually stained for VGluT2 and somatostatin antibodies. As noted previously in rats (Gonchar and Burkhalter, 1997; Kawaguchi and Kondo, 2002), somatostatin immunolabeling in ferret visual cortex is primarily confined to the cytosolic regions of neuronal somata and is relatively sparse in layer 4 . At electron microscope resolution, somatostatin labeling in dendrites was extremely rare. When present, gold labeling was observed within large dendritic segments adjacent to cell bodies. With the 
proviso that the poor dendritic visualization of somatostatin antibody precludes a thorough analysis of thalamocortical connections with dendritic and spine targets containing somatostatin label, we quantified the percentage of thalamic input to somatostatin-labeled targets in layer 4. In an analysis of over three hundred thalamocortical synapses from three adult brains, approximately $1 \%$ of all thalamic targets contained somatostatin $(1.3 \pm 0.3 \%, n=311$; Mean \pm S.E. $)$. Therefore, somatostatin-positive targets of thalamocortical synapses onto cell bodies and the initial segments of proximal dendrites are likely sparse. However, our visualization approach was not amenable for the detection of thalamocortical synapses on distal dendrites or spines of somatostatin cells if present.

\section{Thalamic input to calretinin positive interneurons}

Similarly, we examined sections from three adult ferrets, dually stained for calretinin and VGluT2. At the electron microscopic level, calretinin was observed within dendrites of a wide range of calibers (Fig. 1). In a sample of over three hundred thalamic synapses (data not shown), we were unable to find a single instance of a VGluT2-labeled terminal forming a synapse on a calretinin-positive profile. This suggests that calretinin containing interneurons are not a target of thalamocortical synapses in layer 4 of adult visual cortex. 


\section{Thalamic input to parvalbumin positive interneurons}

In order to determine the proportion of parvalbumin interneurons contacted by thalamocortical axons in layer 4 , we analyzed double-labeled VGluT2 and PV stained sections of primary visual cortex from three adult ferrets. We analyzed a total of 438 electron micrographs, representing $\sim 10,000 \mu \mathrm{m}^{2}$ area of visual cortex. These micrographs contained 539 synapses from labeled thalamocortical terminals. For each individual micrograph, VGluT2 labeled thalamocortical terminals were identified (criteria in methods), and their synapse cross-section lengths were measured. Moreover, postsynaptic partners were classified as either PV-positive or negative.

Data from individual animals $(\mathrm{n}=3)$ are displayed in Table 1. On average, $10.4 \pm 0.08 \%$ of thalamocortical terminal postsynaptic targets were parvalbuminpositive. While PV-positive targets were significantly more likely to be dendrites $(60 \pm 3.5 \%)$ versus PV-negative targets $(15 \pm 3.8 \%, p<0.002$, two-tailed $t-T e s t)$, their synapse lengths $(455 \pm 40 \mathrm{~nm})$ were not significantly larger than PVnegative targets $(423 \pm 30 \mathrm{~nm}, \mathrm{p}>0.5$, two-tailed $\mathrm{t}$-Test). This $10 \%$ thalamic input preference for parvalbumin targets represented an unexpectedly high ratio, as it is equivalent to the amount of thalamocortical input to all GABAergic interneurons (Erisir and Dreusicke, 2005).

Therefore, this data intimated that PV-positive targets might account for all GABAergic targets of thalamic axons. To investigate this possibility, we performed a triple-labeling immuno-electron study, staining for the presence of VGluT2, PV and GABA within single sections of adult visual cortex. In analyzing 
235 synaptic thalamocortical terminals from two adult brains, every PV-positive profile postsynaptic to a thalamic terminal, was also labeled for the presence of GABA (Fig. 5). Moreover, no instances were found of thalamocortical terminals contacting single-labeled GABA profiles. We therefore conclude that the great majority, if not all, GABAergic targets of thalamic axons in layer 4 of adult visual cortex are PV-ir interneurons.

\section{Development of thalamic input onto parvalbumin containing interneurons}

Given the preference of thalamic axons for PV-ir interneurons in adult, we sought to determine the developmental age at which this selective input was achieved. Accordingly, we labeled sections of primary visual cortex with antibodies against VGluT2 and PV from animals at p43, p47 and p60, corresponding to the approximate beginning, middle and end of the critical period for ocular dominance plasticity in ferret. In examining a total of 256 synaptic thalamocortical terminals from 177 electron micrographs at p43, p47 and p60, we found that approximately $3.5,3.6$ and $5.7 \%$ of thalamic axon targets contained parvalbumin at these ages, respectively.

Moreover, in triple-labeled (VGluT2, parvalbumin and GABA) sections of visual cortex from a p47 ferret, we quantified the ratio of thalamocortical synapses to postsynaptic targets containing either parvalbumin and GABA label, or only GABA label. Out of a total of 93 synaptic targets of thalamocortical boutons, $23.6 \%$ contained GABA, in agreement with earlier findings of thalamic 
connectivity in layer 4 (Erisir and Dreusicke, 2005). Yet out of these total GABA targets, only 3.2\% also contained parvalbumin, while $20.4 \%$ were GABA-positive but did not contain parvalbumin. Therefore, at ages wherein thalamocortical axons have a relatively high proportion of overall drive onto GABAergic circuitry (Erisir and Dreusicke, 2005), parvalbumin interneurons are not the preferred targets. However, as the percentage of thalamocortical synapses with parvalbumin interneurons increases, thalamic input with non-parvalbumin targets within layer 4 disengages. Thus, when physiological and morphological responses to changes in the sensory environment are most plastic in visual cortex, thalamocortical afferents may preferentially target an as yet identified population of GABA-containing cells. 


\section{DISCUSSION}

Using confocal microscopy, double and triple labeling immuno-electron microscopy, we demonstrated that: (1) PV-ir cells in ferret visual cortex are GABAergic interneurons; (2) Regardless of their morphology or laminar position, PV-ir cells all possessed specific Kv3.1b channels characteristic of fast-spiking cortical interneurons; (3) Thalamocortical axons have monosynaptic innervation onto immature and adult parvalbumin interneuron dendrites in visual cortex; (4) PV-ir interneurons can account for nearly every GABAergic target of adult thalamic axons in layer 4, and (5) During a critical period for plasticity, parvalbumin positive targets do not account for all interneuron targets of thalamocortical axons.

\section{Parvalbumin containing subpopulation of interneurons in ferret visual cortex}

Parvalbumin cells comprise a distinct subpopulation of GABAergic neurons in rat, cat and monkey cortex, on the basis of evoked firing pattern, differential $\mathrm{Ca}^{2+}$ binding protein specificity, laminar distribution and morphology (Blumcke et al., 1990; Demeulemeester et al., 1989; Galarreta and Hestrin, 1999; Gibson et al., 1999; Gonchar and Burkhalter, 1997; Hendry et al., 1989; Kawaguchi and Kondo, 2002). Parvalbumin interneuron specificity for Kv3.1b potassium channels has been described previously in mice and rat (Azouz et al., 1997; Erisir et al., 1999; Kawaguchi, 1993; Swadlow, 2003; Weiser et al., 1995). 
We now extend those findings to include parvalbumin cells as GABAergic interneurons possessing fast-spiking $\mathrm{K}^{+}$-channels in ferret.

In visual cortex, parvalbumin interneurons are described as medium to large basket cells (Martin et al., 1983), small basket (clutch) cells (Kisvarday et al., 1986), and axon-targeting chandelier cells (DeFelipe et al., 1989). Furthermore, a study of parvalbumin development in ferret visual cortex found that pyramidal shaped PV-ir cells disappeared by P14, followed by the emergence of adult-like multipolar morphologies by P40, and increased proportions after P60 (Gao et al., 2000). Although we could not discern an individual cell's distal axonal or dendritic branching pattern, the observed bipolar interneurons closely resemble chandelier somata, while ovoid and large baskettype somata are likely small clutch and large basket cells respectively. In addition, the horizontally oriented cells we observed in deep extragranular layers might be medium sized basket cells or may represent a different morphological class. Regardless, the laminar distribution and morphology of parvalbumin cells in adult ferret visual cortex conform to the pattern observed in rat, cat and monkey, adding to the mounting evidence that the anatomy and connectivity of GABAergic interneurons is a highly conserved feature of cortical circuits.

\section{Selectivity of thalamocortical axons for parvalbumin containing interneurons}

Here we provide the first anatomical demonstration of a highly selective thalamocortical input for a subset of interneurons, specifically the parvalbumin 
positive interneurons of cortical layer 4 . Thalamocortical connectivity with defined interneuron subpopulations has previously been studied using electrophysiological recordings of thalamocortical slice preparations. In rodent somatosensory cortex, thalamocortical pathway stimulation induces strong monosynaptic excitatory postsynaptic potentials in layer 4 fast-spiking (i.e. putative parvalbumin containing) cells (Agmon and Connors, 1992; Beierlein et al., 2003; Zhu and Connors, 1999). These authors recorded monosynaptic thalamic input in regular spiking (i.e., putative non-parvalbumin) cells located in the lower portion of supragranular layers in juvenile animals. Our present results do not provide a strong case for the existence of non-parvalbumin targets in adult brains, although our data cannot entirely exclude this possibility. Moreover, although immunocytochemistry was not a suitable approach for the visualization of somatostatin-labeled dendrites with existing antibodies, we have observed an instance of a thalamocortical synapse with a somatostatin-positive soma. In any case, if somatostatin cells are indeed a target of thalamic input in adult animals, they are likely exceptionally rare. In examining a large pool of thalamocortical synaptic terminals (Table 1), we failed to encounter any GABA-positive target dendrite that was not also parvalbumin-positive in adult cortex. Furthermore, species differences should also be considered; while the predominant projection of thalamocortical axons in the ferret remains largely within layer 4 (Nahmani and Erisir, 2005), in mouse and rat they often extend into supragranular layers (unpublished observations). 
Accordingly, while our results provide the first anatomical evidence for monosynaptic input to parvalbumin cells from visual thalamus, they also suggest that parvalbumin cells constitute the first level of hierarchy in cortical inhibitory circuits. This strict selectivity of thalamocortical axons for parvalbumin containing cells indicates that regardless of the possible subtypes or parallel pathways involved, parvalbumin containing cells are the initial source of feedforward inhibition following sensory activation.

\section{Flow of sensory activity through cortical inhibitory circuits}

How might the flow of sensory activity impinge on the subsequent cortical circuit? PV-ir basket cells in both barrel (Galarreta and Hestrin, 1999; Gibson et al., 1999; Simon et al., 2005; Tamas et al., 2000) and visual cortex (Fukuda and Kosaka, 2003; Fukuda et al., 2006a; Tamas et al., 1998) are frequently electrical coupled via their proximal dendritic arbors, as evidenced by paired intracellular recordings and electron microscopy. Given their abundant electrical and chemical synapses with one another, parvalbumin cells are poised to direct the initial "wave" of inhibition across cortical layers. Interestingly, large PV-ir basket cells whose dendrites extend throughout layer 4, send axonal projections over $1 \mathrm{~mm}$ from their parent soma, and display a bi-modal bouton distribution with respect to ocular dominance columns (Buzas et al., 2001; Kisvarday and Eysel, 1993; Martin et al., 1983). That is, individual basket cells are able to innervate both ipsilateral and contralateral eye columns with equally strong axonal 
projections. Thus, parvalbumin-containing basket cells in adult visual cortex form an interconnected network of inhibitory interneurons able to affect neuronal populations across cortical columns. In addition, as the sole recipients of potent thalamocortical activity, parvalbumin cells are attractive candidates to participate in the generation of cortical responses at the first level of sensory integration.

Cortical response properties in visual cortex necessarily arise from the precise arrangement of feedforward thalamocortical relay axons and the resultant cascade of cortical activation. In most mammals, the majority of cortical receptive fields within the thalamocortical projection (layer 4 and upper layer 6) have a "simple" arrangement, possessing adjacent regions that respond to stimuli of opposing luminance (Ferster and Miller, 2000; Hubel and Wiesel, 1962). This stereotypical organization is thought to arise largely via excitatory thalamic 'push' (Chapman et al., 1991; Reid and Alonso, 1995; Tanaka, 1983) and cortical inhibitory 'pull' (Borg-Graham et al., 1998; Heggelund, 1986). Under this model, layer 4 inhibitory interneurons with structured receptive fields similar to those of excitatory spiny cells (Hirsch et al., 2003), provide the antagonistic hyperpolarization (given their opposing stimulus preference) following the withdrawal of a depolarizing stimulus to an excitatory neuron.

As the sole GABAergic target of thalamocortical input to adult layer 4 , our findings suggest that PV-ir fast-spiking interneurons likely mediate the opponent 'pull' response at the first level of cortical processing. Moreover, this selective drive onto layer 4 parvalbumin cells suggests that they may comprise the simple and/or complex cortical inhibitory cells integral to the contrast-invariant 
generation of orientation selectivity (Hirsch and Martinez, 2005; Lauritzen and Miller, 2003; Shapley et al., 2003; White et al., 2001).

\section{Implications of selective thalamocortical drive to PV interneurons during a period of developmental plasticity}

Thalamic axons increase their synapses with PV-ir interneurons in a steady, incremental manner over postnatal development. Hence, while at p47 less than $4 \%$ of thalamocortical contacts are onto PV cells, at P60 this percentage has increased to $\sim 6 \%$. Previously, we had demonstrated a proportionally larger thalamocortical input onto inhibitory interneurons in early development versus adulthood (Erisir and Dreusicke, 2005). We replicate those results here, finding that at p47 approximately $20 \%$ of thalamocortical targets are GABAergic, while this percentage drops to $10 \%$ in adulthood. Furthermore, PV-ir interneurons comprise $<4 \%$ of these GABAergic targets in p47 visual cortex, yet can account for nearly every GABAergic target in adult. Hence, thalamic axons may initially target a majority of GABAergic interneurons that do not contain parvalbumin, switching this preference in favor of PV-ir cells over critical period ages. Evidence in support of this hypothesis comes from thalamocortical slice preparations of barrel cortex in postnatal day 9-21 aged rodents, wherein monosynaptic activation of somatostatin-containing (Beierlein et al., 2003) and calbindin-containing interneurons were also encountered (Porter et al., 2001). These findings position thalamocortical input in a primary role for differentially 
regulating the excitation/inhibition balance during and after the decline of ocular dominance plasticity in cortex.

In the past decade, several studies have begun to elucidate how the balance between excitation/inhibition may constrain cortical plasticity. For example, the enhancement of cortical GABA release in visual cortex is sufficient to shorten the period that the cells are susceptible to deprivations of visual activity in wild-type animals, as well as to restore this 'critical period' plasticity in $\mathrm{GAD}_{65}$ knock-out animals (Hensch et al., 1998; Iwai et al., 2003). Furthermore, the maturation of cortical inhibitory circuitry may suppress the activity-dependent relay of sensory activity to supragranular layers, effectively prohibiting competitive synaptic strengthening (Rozas et al., 2001).

Parvalbumin-expressing interneurons have been proposed to be key players in critical period inhibition based on several lines of evidence. PV-ir fastspiking cortical interneurons are preferentially surrounded by perineuronal nets in adult animals (Celio and Chiquet-Ehrismann, 1993), which are postulated to isolate their somato-dendritic compartments from cations in the extracellular space (Hartig et al., 1999). Moreover, in adult animals, critical period plasticity can be reactivated following the enzymatic degradation of chondroitin sulphate proteoglycans, a component of perineuronal nets (Pizzorusso et al., 2002). Due to their abundant electrical connections, parvalbumin cells are also ideally situated to relay synchronous activity across columnar distances (Fukuda et al., 2006a). These findings have contributed to the hypothesis that PV-ir 'large basket cells' provide the necessary inhibitory input to engage critical period 
machinery, and presumably loose this capacity via perineuronal net encapsulation in adulthood (Hensch, 2005a).

Our data supports a role for parvalbumin-expressing interneurons as key modulators of thalamocortical activity in the mature visual cortex. Whether parvalbumin cells are also the recipients of thalamocortical input during the critical period awaits further investigation. Parvalbumin immunoreactivity increases slowly after eye opening in the ferret (Gao et al., 2000) and cat (Alcantara and Ferrer, 1994), and here we show that the development of thalamocortical input onto PV-ir cells in layer 4 seems to mirror this pattern. This feature of parvalbumin staining may necessitate the use of other markers or genetic tools in juvenile animals, to identify those cells destined to become PV-ir interneurons. In any case, parvalbumin cell modulation of the critical period predicts one (or more) conditions: (1) An anatomical and/or functional change in thalamic drive to parvalbumin cells across development, (2) A difference in the parvalbumin terminal postsynaptic targets and/or GABAergic release at critical period initiation vs. closure, (3) An alteration in GABAergic postsynaptic receptor activation during this period. Studies aimed at addressing these issues will aid in understanding what role parvalbumin-expressing interneurons play during the critical period. 
References

Agmon A, Connors BW. 1992. Correlation between intrinsic firing patterns and thalamocortical synaptic responses of neurons in mouse barrel cortex. $J$ Neurosci 12(1):319-329.

Ahmed B, Anderson JC, Douglas RJ, Martin KA, Nelson JC. 1994. Polyneuronal innervation of spiny stellate neurons in cat visual cortex. J Comp Neurol 341(1):39-49.

Ahmed B, Anderson JC, Martin KA, Nelson JC. 1997. Map of the synapses onto layer 4 basket cells of the primary visual cortex of the cat. J Comp Neurol 380(2):230-242.

Akil M, Lewis DA. 1992. Differential distribution of parvalbumin-immunoreactive pericellular clusters of terminal boutons in developing and adult monkey neocortex. Exp Neurol 115(2):239-249.

Alcantara S, Ferrer I. 1994. Postnatal development of parvalbumin immunoreactivity in the cerebral cortex of the cat. J Comp Neurol 348(1):133-149.

Alonso JM, Swadlow HA. 2005. Thalamocortical specificity and the synthesis of sensory cortical receptive fields. J Neurophysiol 94(1):26-32.

Antonini A, Fagiolini M, Stryker MP. 1999. Anatomical correlates of functional plasticity in mouse visual cortex. J Neurosci 19(11):4388-4406.

Antonini A, Stryker MP. 1996. Plasticity of geniculocortical afferents following brief or prolonged monocular occlusion in the cat. J Comp Neurol 369(1):64-82.

Azouz R, Gray CM, Nowak LG, McCormick DA. 1997. Physiological properties of inhibitory interneurons in cat striate cortex. Cereb Cortex 7(6):534-545.

Bacci A, Rudolph U, Huguenard JR, Prince DA. 2003. Major differences in inhibitory synaptic transmission onto two neocortical interneuron subclasses. J Neurosci 23(29):9664-9674.

Beierlein M, Gibson JR, Connors BW. 2003. Two dynamically distinct inhibitory networks in layer 4 of the neocortex. J Neurophysiol 90(5):2987-3000.

Benshalom G, White EL. 1986. Quantification of thalamocortical synapses with spiny stellate neurons in layer IV of mouse somatosensory cortex. J Comp Neurol 253(3):303-314.

Berardi N, Domenici L, Parisi V, Pizzorusso T, Cellerino A, Maffei L. 1993. Monocular deprivation effects in the rat visual cortex and lateral geniculate nucleus are prevented by nerve growth factor (NGF). I. Visual cortex. Proc Biol Sci 251(1330):17-23.

Binzegger T, Douglas RJ, Martin KA. 2004. A quantitative map of the circuit of cat primary visual cortex. J Neurosci 24(39):8441-8453.

Blumcke I, Hof PR, Morrison JH, Celio MR. 1990. Distribution of parvalbumin immunoreactivity in the visual cortex of Old World monkeys and humans. J Comp Neurol 301(3):417-432. 
Blumcke I, Hof PR, Morrison JH, Celio MR. 1991. Parvalbumin in the monkey striate cortex: a quantitative immunoelectron-microscopy study. Brain Res 554(1-2):237-243.

Borg-Graham LJ, Monier C, Fregnac Y. 1998. Visual input evokes transient and strong shunting inhibition in visual cortical neurons. Nature 393(6683):369373.

Budd JM. 2000. Inhibitory basket cell synaptic input to layer IV simple cells in cat striate visual cortex (area 17): a quantitative analysis of connectivity. Vis Neurosci 17(3):331-343.

Buzas P, Eysel UT, Adorjan P, Kisvarday ZF. 2001. Axonal topography of cortical basket cells in relation to orientation, direction, and ocular dominance maps. J Comp Neurol 437(3):259-285.

Catalano SM, Chang CK, Shatz CJ. 1997. Activity-dependent regulation of NMDAR1 immunoreactivity in the developing visual cortex. J Neurosci 17(21):8376-8390.

Celio MR. 1986. Parvalbumin in most gamma-aminobutyric acid-containing neurons of the rat cerebral cortex. Science 231(4741):995-997.

Celio MR, Baier W, Scharer L, de Viragh PA, Gerday C. 1988. Monoclonal antibodies directed against the calcium binding protein parvalbumin. Cell Calcium 9(2):81-86.

Celio MR, Chiquet-Ehrismann R. 1993. 'Perineuronal nets' around cortical interneurons expressing parvalbumin are rich in tenascin. Neurosci Lett 162(1-2):137-140.

Celio MR, Keller GA, Bloom FE. 1986. Immunoelectronmicroscopy of neural antigens on ultrathin frozen sections. J Histochem Cytochem 34(4):491500.

Chapman B, Zahs KR, Stryker MP. 1991. Relation of cortical cell orientation selectivity to alignment of receptive fields of the geniculocortical afferents that arborize within a single orientation column in ferret visual cortex. J Neurosci 11(5):1347-1358.

Chattopadhyaya B, Di Cristo G, Higashiyama H, Knott GW, Kuhlman SJ, Welker E, Huang ZJ. 2004. Experience and activity-dependent maturation of perisomatic GABAergic innervation in primary visual cortex during a postnatal critical period. J Neurosci 24(43):9598-9611.

Chattopadhyaya B, Di Cristo G, Wu CZ, Knott G, Kuhlman S, Fu Y, Palmiter RD, Huang ZJ. 2007. GAD67-mediated GABA synthesis and signaling regulate inhibitory synaptic innervation in the visual cortex. Neuron 54(6):889-903.

Chiu C, Weliky M. 2002. Relationship of correlated spontaneous activity to functional ocular dominance columns in the developing visual cortex. Neuron 35(6):1123-1134.

Chow A, Erisir A, Farb C, Nadal MS, Ozaita A, Lau D, Welker E, Rudy B. 1999. $\mathrm{K}(+)$ channel expression distinguishes subpopulations of parvalbumin- and somatostatin-containing neocortical interneurons. J Neurosci 19(21):93329345. 
Coleman JE, Nahmani M, Erisir A, Bear MF. 2007. Rapid, experience-dependent structural remodeling of thalamocortical synapses in mouse primary visual cortex. Society for Neuroscience. San Diego, CA.

Crair MC, Ruthazer ES, Gillespie DC, Stryker MP. 1997. Relationship between the ocular dominance and orientation maps in visual cortex of monocularly deprived cats. Neuron 19(2):307-318.

Cynader M. 1983. Prolonged sensitivity to monocular deprivation in dark-reared cats: effects of age and visual exposure. Brain Res 284(2-3):155-164.

Dantzker JL, Callaway EM. 2000. Laminar sources of synaptic input to cortical inhibitory interneurons and pyramidal neurons. Nat Neurosci 3(7):701-707.

Davis TL, Sterling P. 1979. Microcircuitry of cat visual cortex: classification of neurons in layer IV of area 17, and identification of the patterns of lateral geniculate input. J Comp Neurol 188(4):599-627.

DeFelipe J, Fairen A. 1982. A type of basket cell in superficial layers of the cat visual cortex. A Golgi-electron microscope study. Brain Res 244(1):9-16.

DeFelipe J, Hendry SH, Jones EG. 1989. Visualization of chandelier cell axons by parvalbumin immunoreactivity in monkey cerebral cortex. Proc Natl Acad Sci U S A 86(6):2093-2097.

del Rio JA, de Lecea L, Ferrer I, Soriano E. 1994. The development of parvalbumin-immunoreactivity in the neocortex of the mouse. Brain Res Dev Brain Res 81(2):247-259.

Demeulemeester H, Vandesande F, Orban GA, Brandon C, Vanderhaeghen JJ. 1988. Heterogeneity of GABAergic cells in cat visual cortex. J Neurosci 8(3):988-1000.

Demeulemeester H, Vandesande F, Orban GA, Heizmann CW, Pochet R. 1989. Calbindin D-28K and parvalbumin immunoreactivity is confined to two separate neuronal subpopulations in the cat visual cortex, whereas partial coexistence is shown in the dorsal lateral geniculate nucleus. Neurosci Lett 99(1-2):6-11.

Desai NS, Cudmore RH, Nelson SB, Turrigiano GG. 2002. Critical periods for experience-dependent synaptic scaling in visual cortex. Nat Neurosci 5(8):783-789.

Dumitriu D, Cossart R, Huang J, Yuste R. 2007. Correlation between axonal morphologies and synaptic input kinetics of interneurons from mouse visual cortex. Cereb Cortex 17(1):81-91.

Erisir A, Dreusicke M. 2005. Quantitative morphology and postsynaptic targets of thalamocortical axons in critical period and adult ferret visual cortex. $J$ Comp Neurol 485(1):11-31.

Erisir A, Lau D, Rudy B, Leonard CS. 1999. Function of specific $K(+)$ channels in sustained high-frequency firing of fast-spiking neocortical interneurons. $\mathrm{J}$ Neurophysiol 82(5):2476-2489.

Erisir A, Levey Al, Aoki C. 2001. Muscarinic receptor M(2) in cat visual cortex: laminar distribution, relationship to gamma-aminobutyric acidergic neurons, and effect of cingulate lesions. J Comp Neurol 441(2):168-185. 
Erisir A, Van Horn SC, Sherman SM. 1997. Relative numbers of cortical and brainstem inputs to the lateral geniculate nucleus. Proc Natl Acad Sci U S A 94(4):1517-1520.

Fagiolini M, Fritschy JM, Low K, Mohler H, Rudolph U, Hensch TK. 2004. Specific GABAA circuits for visual cortical plasticity. Science 303(5664):1681-1683.

Fagiolini M, Hensch TK. 2000. Inhibitory threshold for critical-period activation in primary visual cortex. Nature 404(6774):183-186.

Ferster D, Chung S, Wheat $\mathrm{H}$. 1996. Orientation selectivity of thalamic input to simple cells of cat visual cortex. Nature 380(6571):249-252.

Ferster D, Miller KD. 2000. Neural mechanisms of orientation selectivity in the visual cortex. Annu Rev Neurosci 23:441-471.

Freund TF, Martin KA, Soltesz I, Somogyi P, Whitteridge D. 1989. Arborisation pattern and postsynaptic targets of physiologically identified thalamocortical afferents in striate cortex of the macaque monkey. J Comp Neurol 289(2):315-336.

Froemke RC, Poo MM, Dan Y. 2005. Spike-timing-dependent synaptic plasticity depends on dendritic location. Nature 434(7030):221-225.

Fukuda T, Kosaka T. 2003. Ultrastructural study of gap junctions between dendrites of parvalbumin-containing GABAergic neurons in various neocortical areas of the adult rat. Neuroscience 120(1):5-20.

Fukuda T, Kosaka T, Singer W, Galuske R. 2006a. Gap Junctions among Dendrites of Cortical GABAergic Neurons Establish a

Dense and Widespread Intercolumnar Network. J Neurosci 26:3434-3443.

Fukuda T, Kosaka T, Singer W, Galuske RA. 2006b. Gap junctions among dendrites of cortical GABAergic neurons establish a dense and widespread intercolumnar network. J Neurosci 26(13):3434-3443.

Galarreta M, Hestrin S. 1999. A network of fast-spiking cells in the neocortex connected by electrical synapses. Nature 402(6757):72-75.

Gao WJ, Wormington AB, Newman DE, Pallas SL. 2000. Development of inhibitory circuitry in visual and auditory cortex of postnatal ferrets: immunocytochemical localization of calbindin- and parvalbumin-containing neurons. J Comp Neurol 422(1):140-157.

Gibson JR, Beierlein M, Connors BW. 1999. Two networks of electrically coupled inhibitory neurons in neocortex. Nature 402(6757):75-79.

Gonchar Y, Burkhalter A. 1997. Three distinct families of GABAergic neurons in rat visual cortex. Cereb Cortex 7(4):347-358.

Gordon JA, Stryker MP. 1996. Experience-dependent plasticity of binocular responses in the primary visual cortex of the mouse. J Neurosci 16(10):3274-3286.

Guillery RW, Sherman SM. 2002. Thalamic relay functions and their role in corticocortical communication: generalizations from the visual system. Neuron 33(2):163-175.

Haas JS, Nowotny T, Abarbanel HD. 2006. Spike-timing-dependent plasticity of inhibitory synapses in the entorhinal cortex. J Neurophysiol 96(6):33053313. 
Hanover JL, Huang ZJ, Tonegawa S, Stryker MP. 1999. Brain-derived neurotrophic factor overexpression induces precocious critical period in mouse visual cortex. J Neurosci 19(22):RC40.

Hartig W, Derouiche A, Welt K, Brauer K, Grosche J, Mader M, Reichenbach A, Bruckner G. 1999. Cortical neurons immunoreactive for the potassium channel Kv3.1b subunit are predominantly surrounded by perineuronal nets presumed as a buffering system for cations. Brain Res 842(1):15-29.

Hasenstaub A, Shu Y, Haider B, Kraushaar U, Duque A, McCormick DA. 2005. Inhibitory postsynaptic potentials carry synchronized frequency information in active cortical networks. Neuron 47(3):423-435.

Heggelund P. 1986. Quantitative studies of enhancement and suppression zones in the receptive field of simple cells in cat striate cortex. J Physiol 373:293310.

Hendry SH, Jones EG, Emson PC, Lawson DE, Heizmann CW, Streit P. 1989. Two classes of cortical GABA neurons defined by differential calcium binding protein immunoreactivities. Exp Brain Res 76(2):467-472.

Hensch TK. 2005a. Critical period mechanisms in developing visual cortex. Curr Top Dev Biol 69:215-237.

Hensch TK. 2005b. Critical period plasticity in local cortical circuits. Nat Rev Neurosci 6(11):877-888.

Hensch TK, Fagiolini M, Mataga N, Stryker MP, Baekkeskov S, Kash SF. 1998. Local GABA circuit control of experience-dependent plasticity in developing visual cortex. Science 282(5393):1504-1508.

Hirsch JA. 1995. Synaptic integration in layer IV of the ferret striate cortex. J Physiol 483 ( Pt 1):183-199.

Hirsch JA, Martinez LM. 2005. Circuits that build visual cortical receptive fields. Trends Neurosci.

Hirsch JA, Martinez LM, Pillai C, Alonso JM, Wang Q, Sommer FT. 2003. Functionally distinct inhibitory neurons at the first stage of visual cortical processing. Nat Neurosci 6(12):1300-1308.

Hofer SB, Mrsic-Flogel TD, Bonhoeffer T, Hubener M. 2006. Lifelong learning: ocular dominance plasticity in mouse visual cortex. Curr Opin Neurobiol 16(4):451-459.

Huang ZJ, Di Cristo G, Ango F. 2007. Development of GABA innervation in the cerebral and cerebellar cortices. Nat Rev Neurosci 8(9):673-686.

Huang ZJ, Kirkwood A, Pizzorusso T, Porciatti V, Morales B, Bear MF, Maffei L, Tonegawa S. 1999. BDNF regulates the maturation of inhibition and the critical period of plasticity in mouse visual cortex. Cell 98(6):739-755.

Hubel DH, Wiesel TN. 1962. Receptive fields, binocular interaction and functional architecture in the cat's visual cortex. J Physiol 160:106-154.

Hubel DH, Wiesel TN. 1970. The period of susceptibility to the physiological effects of unilateral eye closure in kittens. J Physiol 206(2):419-436.

Issa NP, Trachtenberg JT, Chapman B, Zahs KR, Stryker MP. 1999. The critical period for ocular dominance plasticity in the Ferret's visual cortex. $\mathrm{J}$ Neurosci 19(16):6965-6978. 
Itami C, Kimura F, Nakamura S. 2007. Brain-derived neurotrophic factor regulates the maturation of layer 4 fast-spiking cells after the second postnatal week in the developing barrel cortex. J Neurosci 27(9):22412252.

Iwai Y, Fagiolini M, Obata K, Hensch TK. 2003. Rapid critical period induction by tonic inhibition in visual cortex. J Neurosci 23(17):6695-6702.

Jackson CA, Hickey TL. 1985. Use of ferrets in studies of the visual system. Lab Anim Sci 35(3):211-215.

Jiang B, Trevino M, Kirkwood A. 2007. Sequential development of long-term potentiation and depression in different layers of the mouse visual cortex. J Neurosci 27(36):9648-9652.

Jones EG, Powell TP. 1970. An electron microscopic study of the laminar pattern and mode of termination of afferent fibre pathways in the somatic sensory cortex of the cat. Philos Trans R Soc Lond B Biol Sci 257(812):45-62.

Karube F, Kubota Y, Kawaguchi Y. 2004. Axon branching and synaptic bouton phenotypes in GABAergic nonpyramidal cell subtypes. J Neurosci 24(12):2853-2865.

Katagiri H, Fagiolini M, Hensch TK. 2007. Optimization of somatic inhibition at critical period onset in mouse visual cortex. Neuron 53(6):805-812.

Katz LC, Gilbert CD, Wiesel TN. 1989. Local circuits and ocular dominance columns in monkey striate cortex. J Neurosci 9(4):1389-1399.

Kaufman DL, Houser CR, Tobin AJ. 1991. Two forms of the gamma-aminobutyric acid synthetic enzyme glutamate decarboxylase have distinct intraneuronal distributions and cofactor interactions. J Neurochem 56(2):720-723.

Kawaguchi Y. 1993. Groupings of nonpyramidal and pyramidal cells with specific physiological and morphological characteristics in rat frontal cortex. $\mathrm{J}$ Neurophysiol 69(2):416-431.

Kawaguchi Y. 1995. Physiological subgroups of nonpyramidal cells with specific morphological characteristics in layer II/III of rat frontal cortex. J Neurosci 15(4):2638-2655.

Kawaguchi Y, Kondo S. 2002. Parvalbumin, somatostatin and cholecystokinin as chemical markers for specific GABAergic interneuron types in the rat frontal cortex. J Neurocytol 31(3-5):277-287.

Kawaguchi Y, Kubota Y. 1997. GABAergic cell subtypes and their synaptic connections in rat frontal cortex. Cereb Cortex 7(6):476-486.

Kawaguchi Y, Kubota Y. 1998. Neurochemical features and synaptic connections of large physiologically-identified GABAergic cells in the rat frontal cortex. Neuroscience 85(3):677-701.

Kisvarday ZF, Cowey A, Somogyi P. 1986. Synaptic relationships of a type of GABA-immunoreactive neuron (clutch cell), spiny stellate cells and lateral geniculate nucleus afferents in layer IVC of the monkey striate cortex. Neuroscience 19(3):741-761.

Kisvarday ZF, Eysel UT. 1993. Functional and structural topography of horizontal inhibitory connections in cat visual cortex. Eur J Neurosci 5(12):15581572. 
Kisvarday ZF, Martin KA, Whitteridge D, Somogyi P. 1985. Synaptic connections of intracellularly filled clutch cells: a type of small basket cell in the visual cortex of the cat. J Comp Neurol 241(2):111-137.

Latawiec D, Martin KA, Meskenaite V. 2000. Termination of the geniculocortical projection in the striate cortex of macaque monkey: a quantitative immunoelectron microscopic study. J Comp Neurol 419(3):306-319.

Lauritzen TZ, Miller KD. 2003. Different roles for simple-cell and complex-cell inhibition in V1. J Neurosci 23(32):10201-10213.

Law MI, Zahs KR, Stryker MP. 1988. Organization of primary visual cortex (area 17 ) in the ferret. J Comp Neurol 278(2):157-180.

LeVay S, Stryker MP, Shatz CJ. 1978. Ocular dominance columns and their development in layer IV of the cat's visual cortex: a quantitative study. $J$ Comp Neurol 179(1):223-244.

Luth HJ, Blumcke I, Winkelmann E, Celio MR. 1993. The calcium-binding protein calretinin is localized in a subset of interneurons in the rat cerebral cortex: a light and electron immunohistochemical study. J Hirnforsch 34(1):93103.

Majewska A, Sur M. 2003. Motility of dendritic spines in visual cortex in vivo: changes during the critical period and effects of visual deprivation. Proc Natl Acad Sci U S A 100(26):16024-16029.

Majewska AK, Newton JR, Sur M. 2006. Remodeling of synaptic structure in sensory cortical areas in vivo. J Neurosci 26(11):3021-3029.

Martin KA, Somogyi P, Whitteridge D. 1983. Physiological and morphological properties of identified basket cells in the cat's visual cortex. Exp Brain Res 50(2-3):193-200.

Mitchell SJ, Silver RA. 2003. Shunting inhibition modulates neuronal gain during synaptic excitation. Neuron 38(3):433-445.

Mower GD, Christen WG. 1989. Evidence for an enhanced role of GABA inhibition in visual cortical ocular dominance of cats reared with abnormal monocular experience. Brain Res Dev Brain Res 45(2):211-218.

Mower GD, Christen WG, Burchfiel JL, Duffy FH. 1984. Microiontophoretic bicuculline restores binocular responses to visual cortical neurons in strabismic cats. Brain Res 309(1):168-172.

Nahmani M, Erisir A. 2005. VGluT2 immunochemistry identifies thalamocortical terminals in layer 4 of adult and developing visual cortex. J Comp Neurol 484(4):458-473.

Nahmani M, Rudy B, Erisir A. (submitted). Specificity of thalamocortical input for parvalbumin-containing interneurons in ferret visual cortex. Cereb Cortex.

Nahmani M, Rudy B, Erisir A. submitted. Specificity of thalamocortical input for parvalbumin-containing interneurons in ferret visual cortex. Cereb Cortex.

Park HJ, Kong JH, Kang YS, Park WM, Jeong SA, Park SM, Lim JK, Jeon CJ. 2002. The distribution and morphology of calbindin D28K- and calretininimmunoreactive neurons in the visual cortex of mouse. Mol Cells 14(1):143-149. 
Peters A, Feldman ML. 1977. The projection of the lateral geniculate nucleus to area 17 of the rat cerebral cortex. IV. Terminations upon spiny dendrites. J Neurocytol 6(6):669-689.

Peters A, Proskauer CC, Ribak CE. 1982. Chandelier cells in rat visual cortex. J Comp Neurol 206(4):397-416.

Pizzorusso T, Medini P, Berardi N, Chierzi S, Fawcett JW, Maffei L. 2002. Reactivation of ocular dominance plasticity in the adult visual cortex. Science 298(5596):1248-1251.

Polleux F, Dehay C, Kennedy H. 1997. The timetable of laminar neurogenesis contributes to the specification of cortical areas in mouse isocortex. $\mathrm{J}$ Comp Neurol 385(1):95-116.

Porter JT, Johnson CK, Agmon A. 2001. Diverse types of interneurons generate thalamus-evoked feedforward inhibition in the mouse barrel cortex. J Neurosci 21(8):2699-2710.

Reid RC, Alonso JM. 1995. Specificity of monosynaptic connections from thalamus to visual cortex. Nature 378(6554):281-284.

Rozas C, Frank H, Heynen AJ, Morales B, Bear MF, Kirkwood A. 2001. Developmental inhibitory gate controls the relay of activity to the superficial layers of the visual cortex. J Neurosci 21(17):6791-6801.

Rudy B, McBain CJ. 2001. Kv3 channels: voltage-gated K+ channels designed for high-frequency repetitive firing. Trends Neurosci 24(9):517-526.

Schummers J, Sharma J, Sur M. 2005. Bottom-up and top-down dynamics in visual cortex. Prog Brain Res 149:65-81.

Shapley R, Hawken M, Ringach DL. 2003. Dynamics of orientation selectivity in the primary visual cortex and the importance of cortical inhibition. Neuron 38(5):689-699.

Shatz CJ, Stryker MP. 1978. Ocular dominance in layer IV of the cat's visual cortex and the effects of monocular deprivation. J Physiol 281:267-283.

Simon A, Olah S, Molnar G, Szabadics J, Tamas G. 2005. Gap-junctional coupling between neurogliaform cells and various interneuron types in the neocortex. J Neurosci 25(27):6278-6285.

Somogyi P, Kisvarday ZF, Martin KA, Whitteridge D. 1983. Synaptic connections of morphologically identified and physiologically characterized large basket cells in the striate cortex of cat. Neuroscience 10(2):261-294.

Somogyi P, Tamas G, Lujan R, Buhl EH. 1998. Salient features of synaptic organisation in the cerebral cortex. Brain Res Brain Res Rev 26(2-3):113135.

Staiger JF, Zilles K, Freund TF. 1996. Distribution of GABAergic elements postsynaptic to ventroposteromedial thalamic projections in layer IV of rat barrel cortex. Eur J Neurosci 8(11):2273-2285.

Stichel CC, Kagi U, Heizmann CW. 1986. Parvalbumin in cat brain: isolation, characterization, and localization. J Neurochem 47(1):46-53.

Swadlow HA. 2003. Fast-spike interneurons and feedforward inhibition in awake sensory neocortex. Cereb Cortex 13(1):25-32. 
Tamas G, Buhl EH, Lorincz A, Somogyi P. 2000. Proximally targeted GABAergic synapses and gap junctions synchronize cortical interneurons. Nat Neurosci 3(4):366-371.

Tamas G, Buhl EH, Somogyi P. 1997. Massive autaptic self-innervation of GABAergic neurons in cat visual cortex. J Neurosci 17(16):6352-6364.

Tamas G, Somogyi P, Buhl EH. 1998. Differentially interconnected networks of GABAergic interneurons in the visual cortex of the cat. J Neurosci 18(11):4255-4270.

Tanaka K. 1983. Cross-correlation analysis of geniculostriate neuronal relationships in cats. J Neurophysiol 49(6):1303-1318.

Thomson AM, West DC, Hahn J, Deuchars J. 1996. Single axon IPSPs elicited in pyramidal cells by three classes of interneurones in slices of rat neocortex. J Physiol 496 ( Pt 1):81-102.

Troyer TW, Krukowski AE, Priebe NJ, Miller KD. 1998. Contrast-invariant orientation tuning in cat visual cortex: thalamocortical input tuning and correlation-based intracortical connectivity. J Neurosci 18(15):5908-5927.

Tsiola A, Hamzei-Sichani F, Peterlin Z, Yuste R. 2003. Quantitative morphologic classification of layer 5 neurons from mouse primary visual cortex. J Comp Neurol 461(4):415-428.

Valverde F. 1971. Rate and extent of recovery from dark rearing in the visual cortex of the mouse. Brain Res 33(1):1-11.

Wang Y, Gupta A, Toledo-Rodriguez M, Wu CZ, Markram H. 2002. Anatomical, physiological, molecular and circuit properties of nest basket cells in the developing somatosensory cortex. Cereb Cortex 12(4):395-410.

Weiser M, Bueno E, Sekirnjak C, Martone ME, Baker H, Hillman D, Chen S, Thornhill W, Ellisman M, Rudy B. 1995. The potassium channel subunit $\mathrm{KV} 3.1 \mathrm{~b}$ is localized to somatic and axonal membranes of specific populations of CNS neurons. J Neurosci 15(6):4298-4314.

White LE, Bosking WH, Williams SM, Fitzpatrick D. 1999. Maps of central visual space in ferret $\mathrm{V} 1$ and $\mathrm{V} 2$ lack matching inputs from the two eyes. $\mathrm{J}$ Neurosci 19(16):7089-7099.

White LE, Coppola DM, Fitzpatrick D. 2001. The contribution of sensory experience to the maturation of orientation selectivity in ferret visual cortex. Nature 411(6841):1049-1052.

Williams SM, Goldman-Rakic PS, Leranth C. 1992. The synaptology of parvalbumin-immunoreactive neurons in the primate prefrontal cortex. $\mathrm{J}$ Comp Neurol 320(3):353-369.

Wonders CP, Anderson SA. 2006. The origin and specification of cortical interneurons. Nat Rev Neurosci 7(9):687-696.

Young JM, Waleszczyk WJ, Wang C, Calford MB, Dreher B, Obermayer K. 2007. Cortical reorganization consistent with spike timing-but not correlationdependent plasticity. Nat Neurosci 10(7):887-895.

Zhu JJ, Connors BW. 1999. Intrinsic firing patterns and whisker-evoked synaptic responses of neurons in the rat barrel cortex. J Neurophysiol 81(3):11711183. 


\section{FIGURE LEGENDS}

Figure 1. Calretinin and somatostatin labeled cells in adult primary visual cortex. Calretinin (CR) immunoreactivity appeared in somata and dendrites within layers 1-6, though appeared most dense in layer $2 / 3$. Somatostatin (SOM) antibody labeled cell bodies of non-pyrmidal cells which also clustered within layer $2 / 3$. These immunoreactive cells were more numerous than calretinin labeled cells and appeared to distribute evenly across layers 4-6. Scale bar $=100 \mu \mathrm{m}$.

Figure 2. Parvalbumin-immunoreactivity in ferret primary visual cortex. A. Parvalbumin-immunoreactive (PV-ir) cells (green) are distributed throughout cortical layers 2-6 and appear most dense in upper layers 2/3 and 5. Dotted white line indicates pial surface. B. Parvalbumin cells display multiple sizes and morphologies. Higher magnification of field in (A), asterisk references position of blood vessel. Note the large layer 4 PV-ir basket-type cells (arrow), small ovoid cells (skinny arrow), bipolar cells (arrowhead), horizontally oriented cells (fat arrows) and basket forming puncta (triangles) in layers $2 / 3$ and $5 \mathrm{~A}$. C. Representative doublelabeled section stained for parvalbumin and VGluT2 (thalamic terminals; red puncta), centered on layer 4 . Note the presence of PV-ir cells within the primary thalamocortical projection in layer 4 . Scale bars: $100 \mu \mathrm{m}(\mathrm{A})$, $100 \mu \mathrm{m}(\mathrm{C}$, same for $B)$. 
Figure 3. Developing and adult PV-ir cells colocalize with $\mathrm{GAD}_{65 / 67}$ and $\mathrm{Kv3.1b}$.

A. A dual-labeled coronal section of adult ferret visual cortex. PV-ir cells (green) are nearly all double-labeled for $\mathrm{GAD}_{65 / 67}$ (red). B. Collapsed zstacks and one z-step (optical section) of a dual-labeled visual cortex section for parvalbumin and $\mathrm{Kv} 3.1 \mathrm{~b}$, a $\mathrm{K}^{+}$- channel localizing to fastspiking interneurons. PV. High magnification image of a parvalbumin confocal stack. Arrow shows PV-ir puncta surrounding an unlabeled cell body. Kv3.1b. Kv3.1b staining of the same area. Note the pericellular localization of the Kv3.1b antibody. Merge. Colocalization of PV-ir and Kv3.1b at pericellular locations (arrow) and in somata (arrowhead). Zslice. A single optical section through the same area suggesting that Kv3.1b label is localized intracellularly at PV-ir somata membranes. C. Representative coronal section from p47 visual cortex illustrating PV-ir cells dually labeled for parvalbumin and Kv3.1 within layer 4. Scale bars: $100 \mu \mathrm{m}(\mathrm{A}) ; 50 \mu \mathrm{m}(\mathrm{B}-\mathrm{C})$.

Figure 4. Thalamocortical terminals contact parvalbumin targets in adult visual cortex. A. A VGluT2-labeled thalamic terminal (TC) with a synapse onto a PV-ir dendrite (indicated by silver/gold label) and an unlabeled spine (s). An unlabeled terminal nearby has an asymmetric synapse with this same PV-ir dendrite. B. Thalamocortical terminal with a synapse onto a PV-ir soma. C. A thalamocortical terminal synapses with a PV-ir dendite (D) and an unlabeled spine (s). Note the 'spinule'-like protrusion emanating 
from the unlabeled spine. D. A thalamic terminal with a synapse onto an unlabeled spine (s), adjacent to a PV-ir dendrite (D). Arrows point to postsynaptic density; AS=asymmetric terminal; Scale bar: 500nm.

Figure 5. GABAergic targets of thalamic axons contain parvalbumin. Triple label electron micrograph for VGluT2 (DAB), parvalbumin (silver intensified gold, white arrow), and GABA (small gold particles, arrowhead). A representative instance of a VGluT2 labeled thalamocortical terminal (TC) forming a synapse (black arrow) onto a PV-ir/GABA-positive dendrite $(\mathrm{D}+/+)$. Note the spinule-like inclusion within the labeled terminal (asterisk), a common feature of adult thalamic terminals. Every GABAergic target of thalamic terminals was double-labeled for parvalbumin. Scale bar: 500nm.

Figure 6. Thalamic axons synapse with PV interneurons in developing visual cortex. A. At representative electron micrograph from a p47 animal showing a thalamocortical terminal synapse (large arrow) with a PVpositive dendrite and PV-negative spines (small arrows). Arrowheads indicate two symmetric (putative GABAergic) synapses made with this same large PV dendrite. B. By p60, most thalamocortical boutons had synapses (arrows) with spines. Note the adjacent unlabeled terminal forming an asymmetric synapse (arrowhead) with a nearby PV-positive dendrite. C. Though less numerous, at p60 thalamic contacts (large 
arrow) were also observed with PV-positive dendrites. In addition, two thalamic terminals contact unlabeled spines in the periphery. Abbreviations: $\mathrm{TC}=$ thalamocortical terminal; $\mathrm{D}=\mathrm{PV}$ dendrite; $\mathrm{S}=$ spine. Scale bar $=500 \mathrm{~nm}$.

Table 1. Thalamocortical input to PV-positive and PV-negative targets. Percent parvalbumin column shows the proportion of thalamic targets that contained parvalbumin for each individual animal, with total numbers of thalamocortical synapses (n) shown in parentheses. Synapse length columns give the mean synapse cross-section lengths for PV-positive and PV-negative targets postsynaptic to thalamic terminals. Percent dendrite columns indicate the proportion of dendrites (versus spines and somas) for PV-positive and negative targets. $\quad p 47$ triple $=$ Tissue stained for VGluT2, parvalbumin and GABA at p47 (details in text). 
Figure 1.

1

$2 / 3$

4

5

6

CR

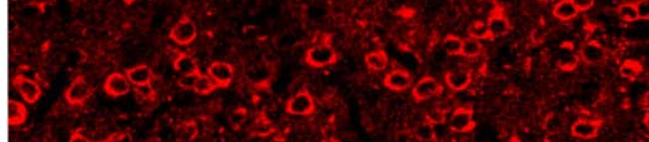

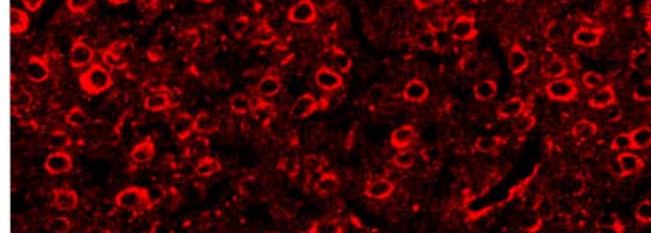

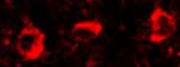

2013

사연
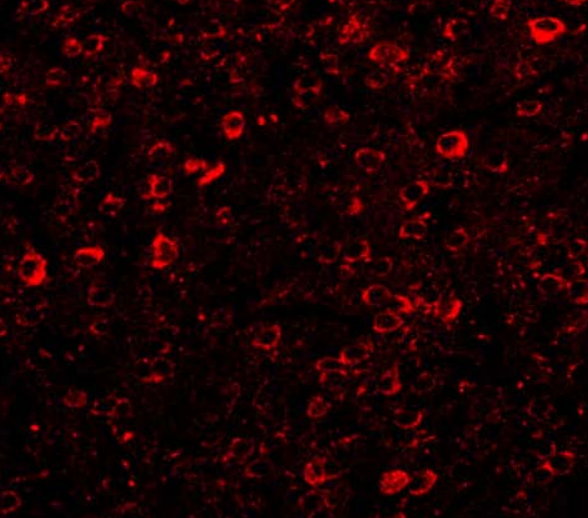
Figure 2.

$\mathbf{A}$

1

$2 / 3$

4

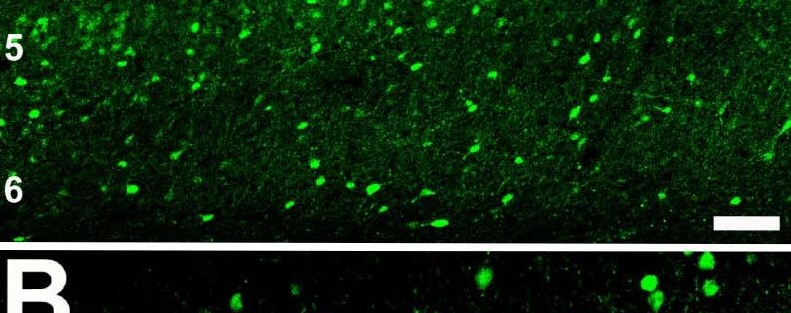

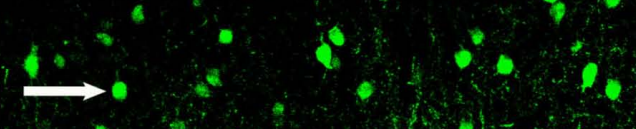
$40, \quad D(,+1)$ s. 00 6.

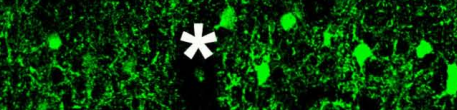

,

(i)

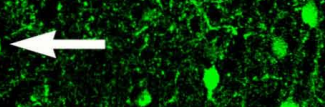

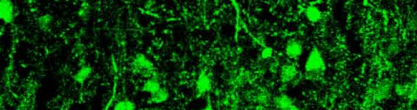
1.5.

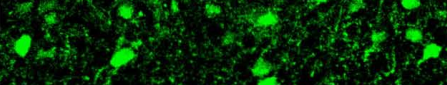

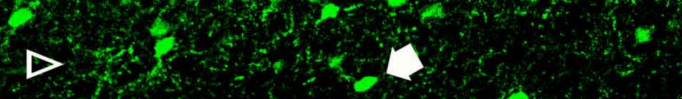
(2)

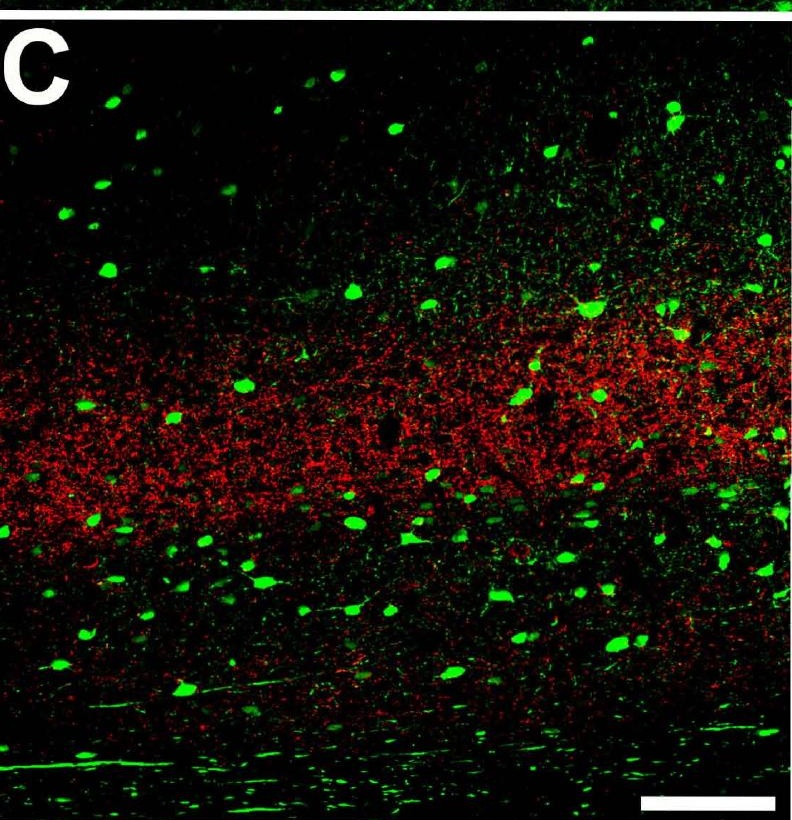




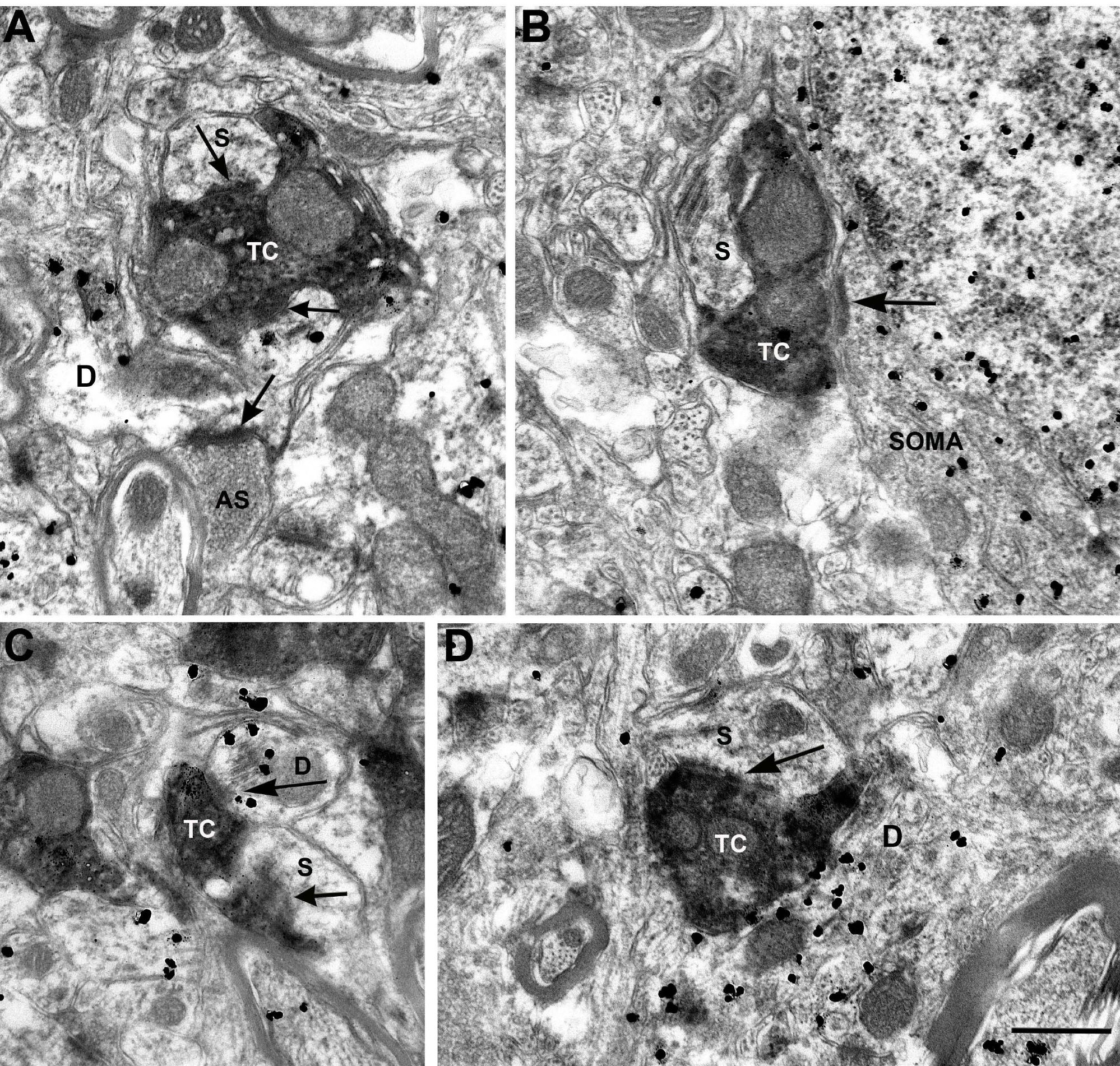




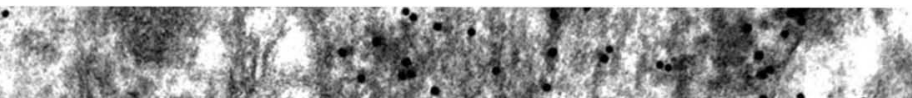

19.

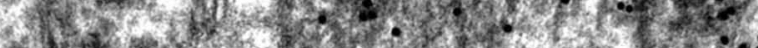

(1)

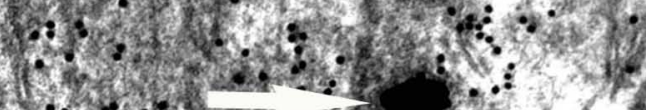

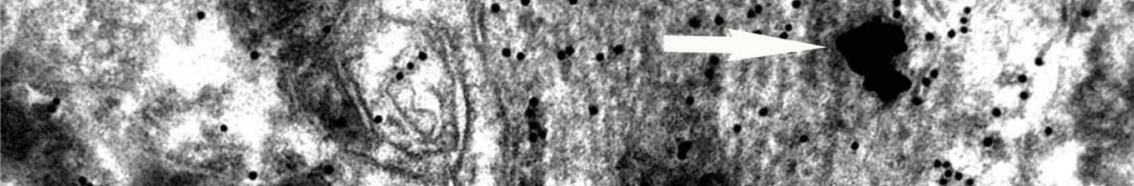

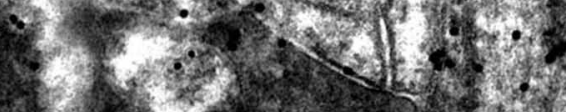
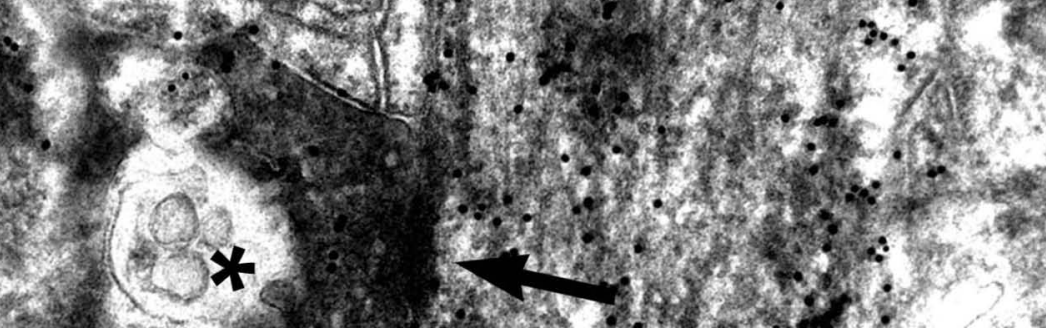

1.

$-5$

Q.

40

(6)

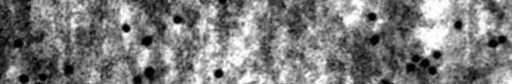

Q

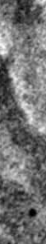

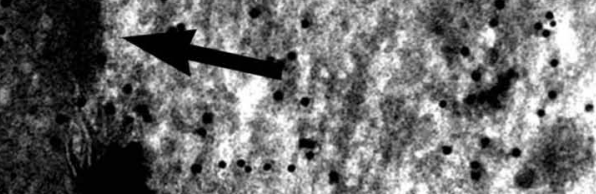

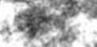

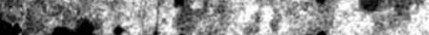

tor.

ons

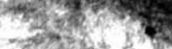

(3)

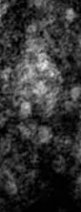

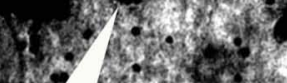

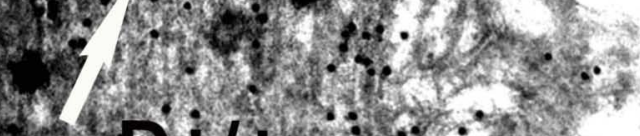

$D+1+$

$x \cdot 3,1=2 \div$ Whate

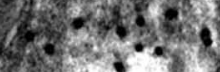

,

2907- 71 as

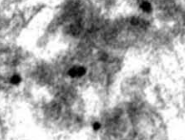

4.

7

it:

- $0,21,2$ 4.

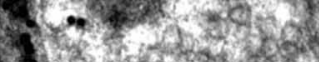

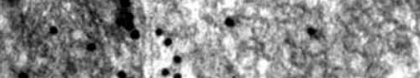
.

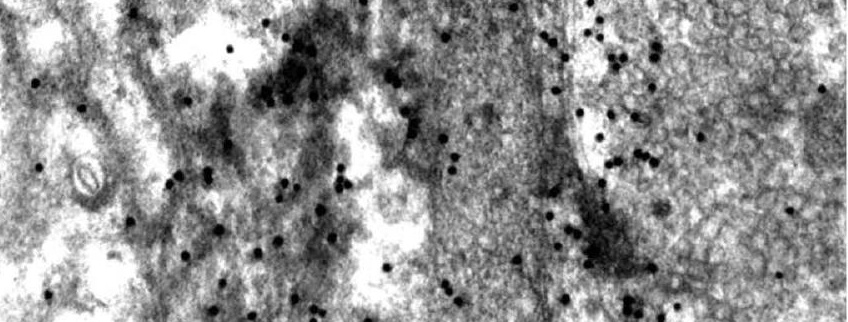




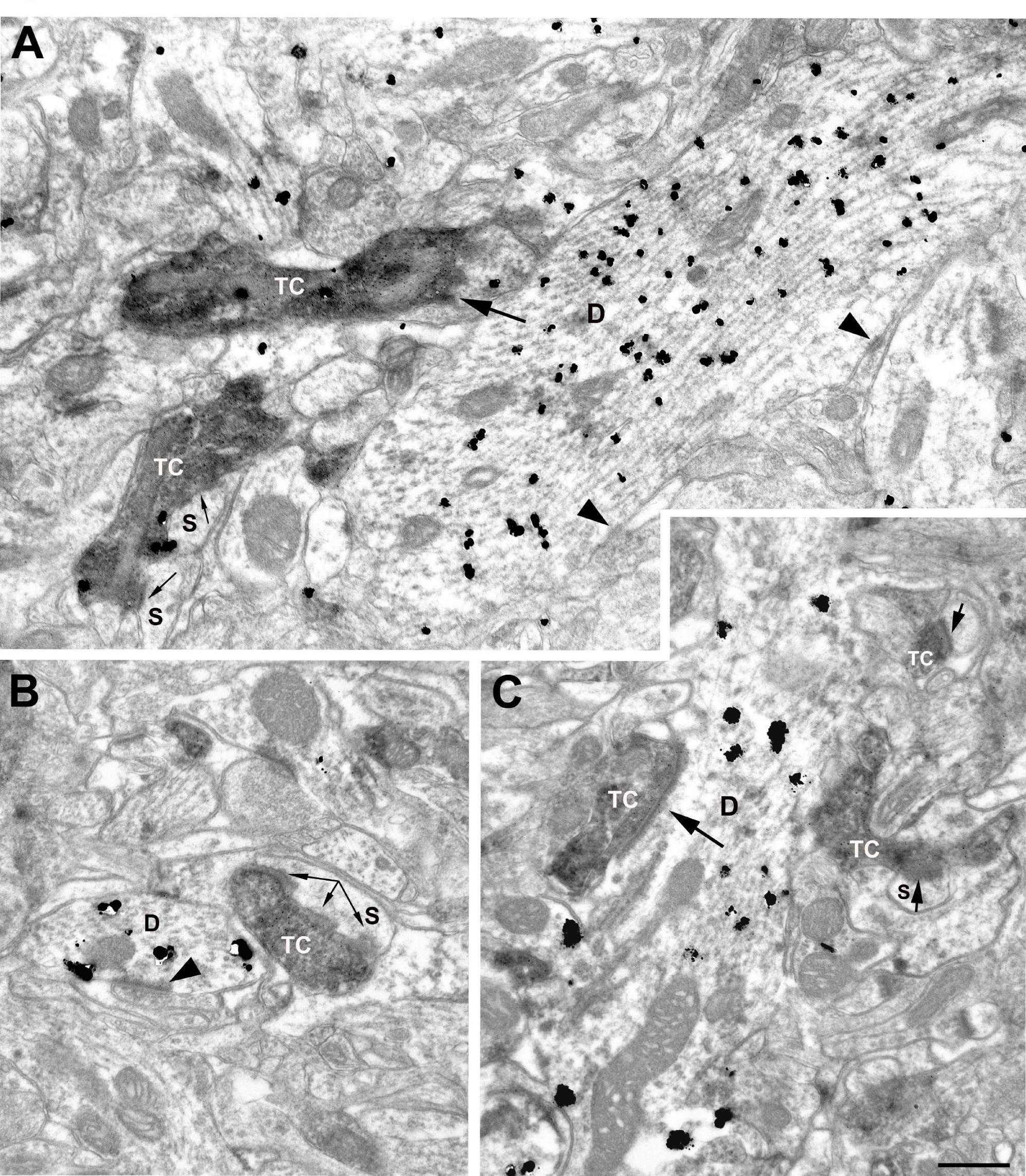


Table 1. Thalamocortical Input to PV-positive and PV-negative Targets.

\begin{tabular}{|c|c|c|c|c|c|}
\hline Animal & $\begin{array}{c}\% \mathrm{PV} \\
\text { targets } \\
(\mathrm{n})\end{array}$ & $\begin{array}{l}\text { Synapse } \\
\text { Length } \\
(\mathrm{PV}+)\end{array}$ & $\begin{array}{l}\text { Synapse } \\
\text { Length } \\
\text { (total) }\end{array}$ & $\begin{array}{c}\% \\
\text { Dendrite } \\
(\mathrm{PV}+)\end{array}$ & $\begin{array}{c}\% \\
\text { Dendrite } \\
\text { (PV-) }\end{array}$ \\
\hline Adult 1 & $\begin{array}{c}10.3 \\
(213)\end{array}$ & $0.43 \mu \mathrm{m}^{2}$ & $0.38 \mu \mathrm{m}^{2}$ & 60.9 & 12.0 \\
\hline Adult 2 & $\begin{array}{c}10.6 \\
(161) \\
\end{array}$ & $0.40 \mu \mathrm{m}^{2}$ & $0.41 \mu \mathrm{m}^{2}$ & 52.9 & 11.1 \\
\hline Adult 3 & $\begin{array}{c}10.3 \\
(165)\end{array}$ & $0.54 \mu \mathrm{m}^{2}$ & $0.48 \mu \mathrm{m}^{2}$ & 64.7 & 23.0 \\
\hline Means: & 10.4 & $\overline{0.45 \mu \mathrm{m}^{2}}$ & $0.42 \mu \mathrm{m}^{2}$ & 59.5 & 15.4 \\
\hline 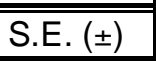 & 0.08 & 0.04 & 0.03 & 3.5 & 3.8 \\
\hline p43 & $3.5(85)$ & $\overline{0.45 \mu \mathrm{m}^{2}}$ & $\overline{0.33 \mu \mathrm{m}^{2}}$ & 33.3 & $\overline{|c|}$ \\
\hline$\overline{p 47}$ & $\begin{array}{ll}3.6(83) \\
\end{array}$ & $\overline{0.57 \mu \mathrm{m}^{2}}$ & $\overline{0.39 \mu \mathrm{m}^{2}}$ & 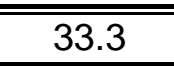 & $\overline{\overline{9.6}}$ \\
\hline$\overline{p 600}$ & $\overline{5.7(88)}$ & $\overline{0.43 \mu \mathrm{m}^{2}}$ & $\overline{0.37 \mu \mathrm{m}^{2}}$ & 100 & 19.3 \\
\hline p47 triple & $3.3(90)$ & 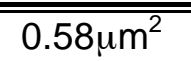 & 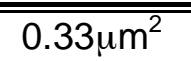 & $\overline{\overline{100}}$ & 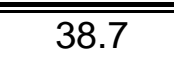 \\
\hline
\end{tabular}


CHAPTER III:

LAMINAR AND TARGET-SPECIFIC ALTERATIONS OF PARVALBUMIN-CONTAINING INTERNEURON CONNECTIVITY OVER CRITICAL PERIOD AGES 
Paradigms investigating critical periods for cortical plasticity attempt to determine aspects of a particular microcircuit that differ between a phase of relative malleability and one of relative stability. However, currently we lack a fundamental understanding as to how synaptic connections between cortical neurons develop, and a determination of which specific connections might engage the necessary cascades to modulate this plasticity.

Accumulating evidence suggests that functional $\gamma$-aminobutryic acid (GABA)ergic circuitry, particularly fast-spiking parvalbumin containing interneurons, may exert permissive control over critical period initiation as well as provide essential modulation over substrates that eventually prohibit anatomical changes (Hensch, 2005b). Indeed, the anatomical properties of parvalbumin containing interneurons support a model in which they play an essential role in critical period duration. Fast-spiking parvalbumin containing interneurons are the largest subset of GABAergic cells in cortex (Gonchar and Burkhalter, 1997), with far reaching axons and electrically coupled dendrites that make them prime candidates to exert inhibitory control over excitatory transmission during the critical period (Fukuda et al., 2006b). Furthermore, parvalbumin containing interneurons increase their basket-like synapses around pyramidal cell somas during the critical period, and the development of these connections is delayed by sensory deprivation (Chattopadhyaya et al., 2004; Chattopadhyaya et al., 2007).

Interestingly, while sensory perturbations effectively delay parvalbumin containing interneuron maturation, the targeted acceleration of this circuitry's 
development induces a shortened critical period for ocular dominance plasticity (Hanover et al., 1999; Huang et al., 1999). These findings suggest an integral link between alterations of parvalbumin interneuron input and the waning of critical period plasticity. However, the crucial components of parvalbumin containing interneuron connectivity that may underlie aspects of cortical plasticity remain elusive, due to our lack of information on their synaptic development at different levels of the cortical circuit.

Hence, we sought to determine the developmental schema of parvalbumin containing interneuron input to excitatory and inhibitory cell populations in distinct lamina of primary visual cortex. Moreover, we aimed to quantify the ontogenetic course of inhibitory and excitatory synapses with parvalbumin containing cells. In adult animals, parvalbumin containing interneurons have defined input characteristics based on their anatomical subgroup and target cortical lamina. Large parvalbumin containing basket cells primarily target the somata, proximal dendrites, and spines of layer 5/6 pyramidal cells (Somogyi et al., 1983), while smaller parvalbumin-immunoreactive clutch cells prefer spiny stellate and pyramidal dendrites (Kisvarday et al., 1986). Furthermore, parvalbumin containing chandelier cells predominantly synapse with the initial axon segments of layer 2/3 pyramidal cells (DeFelipe et al., 1989; Peters et al., 1982). Therefore, a laminar analysis of the development of PV interneuron connectivity will not only contribute to our understanding of the role of inhibition in visual cortex, it will highlight how parvalbumin containing interneuron inhibition impinges on specific circuits in relation to the critical period. 
Our results indicated that parvalbumin containing interneuron input to other GABAergic cells is nearly lost in layers $2 / 3$ and 4 , at an age commensurate with the peak for anatomical plasticity in visual cortex. By the end of this critical period, parvalbumin containing interneurons have established a strong reciprocal inhibitory circuit with other GABAergic cells. These results are discussed in relation to the role of parvalbumin containing interneurons play within the primary visual microcircuit, and their possible modulation of primary sensory drive at ages of reduced anatomical and physiological malleability. 


\section{METHODS}

\section{Source of Tissue}

We used a total of 9 mice from the previously characterized B13 line of BAC transgenic mice in which the parvalbumin promoter drove enhanced green fluorescent protein (EGFP) expression in approximately $50 \%$ of parvalbuminimmunoreactive cells (supplied by Dr. Bernardo Rudy, NYU; characterized in (Dumitriu et al., 2007)). Ages and numbers of mice were as follows: 3 at postnatal day $(\mathrm{P}) 21,3$ at $\mathrm{P} 26$, and 3 at P41. All animal procedures and protocols were in accordance with $\mathrm{NIH}$ guidelines for humane handling of animals and approved by the institutional Animal Care and Use Committee at the University of Virginia.

\section{Tissue Preparation and Immunovisualization}

Perfusions. Animals were given an overdose of pentobarbital sodium (Nembutal $^{\circledast}$, in excess of $50 \mathrm{mg} / \mathrm{kg}$ ) and perfused transcardially with $100 \mathrm{~mL}$ of room temperature Tyrode's solution $(0.8 \% \mathrm{NaCl}, 0.1 \% \alpha$-D-Glucose, $0.0006 \%$ $\mathrm{MgCl}_{2}, 0.015 \% \mathrm{KCl}, 0.006 \% \mathrm{NaH}_{2} \mathrm{PO}_{4}, 0.01 \% \mathrm{CaCl}_{2}, 0.1 \% \mathrm{NaHCO}_{3}$ in $\mathrm{dH}_{2} \mathrm{O}$ ) for 3 minutes, and $500 \mathrm{~mL}$ of $4 \%$ paraformaldehyde and $0.5 \%$ gluteraldehyde in $0.1 \mathrm{M}$ phosphate buffer (PB; pH 7.4) as fixatives, delivered in 15 minutes. Next, brains were removed and stored in $4 \%$ paraformaldehyde overnight at $4^{\circ} \mathrm{C}$. On the following day, each brain was blocked to isolate the occipital cortex and 
sectioned on a vibratome at $50 \mu \mathrm{m}$. Free-floating sections were immediately treated with $1 \% \mathrm{NaBH}_{4}$, rinsed in PB until bubbles were no longer present, and stored in $0.01 \mathrm{M}$ phosphate buffered saline (PBS; pH 7.4) containing $0.1 \% \mathrm{NaN}_{3}$ at $4^{\circ} \mathrm{C}$. This procedure was used for sections processed for both confocal and electron microscopy.

Confocal and light microscopy preparation. Sections were rinsed three times for 3 minutes in PBS. Next, sections were preincubated in PBS containing $1 \%$ bovine serum albumin for 30 minutes, and then put into primary antibody: chicken anti-GFP (1:500; Abcam, Cambridge, MA) and rabbit anti-Kv3.1b (1:1000; gift of Dr. Bernardo Rudy, NYU; produced and previously characterized in (Weiser et al., 1995)) in 1\% bovine serum albumin, 0.3\% Triton-X for $24-48$ hours. Following primary incubation, sections were rinsed three times for 3 minutes in PBS, and then incubated in the appropriate secondary antibodies: biotinylated anti-rabbit (1:100; Vector labs, Burlingame, CA), anti-chicken Alexa 488, and/or anti-rabbit Rhodamine Red-X (both at $5 \mu \mathrm{g} / \mathrm{mL}$; Molecular Probes, Eugene, OR) for 2 hours. After rinsing in PBS, sections were mounted onto glass coverslips in a 2:1 glycerol:PBS solution (confocal) for imaging.

Electron microscopy preparation. Preembedding immunocytochemistry. After a preincubation in PBS containing $0.05 \%$ Triton- $\mathrm{X}$ and $1 \%$ bovine serum albumin for 30 minutes, the sections were incubated in primary antibody: rabbit polyclonal 
anti-GFP (1:100; Millipore, Billerica, MA) containing 1\% bovine serum albumin and $0.05 \% \mathrm{NaN}_{3}$ in PBS for 2 days. Next, sections were immersed in biotinylated anti-rabbit secondary (1:200; Vector Labs, Burlingame, CA) containing $1 \%$ bovine serum albumin/PBS for 2 hours. Sections were then put into avidin-biotin complex in PBS (Vectastain kit, Vector Labs) for 2 hours, and processed in a $1 \%$ diaminobenzidene (DAB) solution in the presence of $0.01 \%$ $\mathrm{H}_{2} \mathrm{O}_{2}$ with gentle agitation for 4-8 minutes. Sections were then rinsed in PB and embedded in resin as follows.

Embedding. Sections were embedded for electron microscopy following previously published protocols (Erisir et al., 2001; Nahmani and Erisir, 2005). To summarize, sections were postfixed in $1 \% \mathrm{OsO}_{4}$, rinsed in $50 \%$ ethanol, and then incubated in $4 \%$ filtered uranyl acetate. Next, sections were dehydrated in a series of ethanols and acetone, and placed into a 1:1 acetone-Epon mixture for 2 hours or overnight. Sections were then placed in 100\% Epon for 2 hours or overnight. Following this, sections were placed flat between two sheets of aclar (SPI supplies, West Chester, PA) and placed in a $60^{\circ} \mathrm{C}$ oven overnight for polymerization. Desired areas in sections were excised from the flat embeds, placed in BEEM capsules, filled with Epon, and left in a $60^{\circ} \mathrm{C}$ oven overnight or until polymerized. Next, outlines and landmarks were traced using a camera lucida, and a trapezoidal area containing all cortical layers (pia - white mater) was carefully trimmed within the mouse binocular region (Oc1B). Ultrathin 
sections of trimmed areas were cut at $\sim 70 \mathrm{~nm}$ on an ultramicrotome and collected on nickel mesh grids.

\section{Postembedding and Triple-labeling immunocytochemistry. Sections to be} postembedded for GABA were processed as previously described (Erisir and Dreusicke, 2005; Erisir et al., 1997). Ultrathin sections of were collected on nickel grids and rinsed in TRIS-buffered saline (TBS) containing $0.1 \%$ Triton-X $(\mathrm{pH} 7.4)$ for 15 minutes. Sections were then incubated in primary antibody: rabbit anti-GABA (1:500; Sigma) and left overnight at room temperature. Next, sections were rinsed in TBS ( $\mathrm{pH} 7.4$ ), then in TBS ( $\mathrm{pH} 8.2)$, followed by incubation in secondary antibody: goat anti-rabbit 15nm gold (1:25 in TBS pH 8.2; Ted Pella, Redding, $\mathrm{CA}$ ) for 2 hours. Sections were rinsed in TBS ( $\mathrm{pH} 7.4$ ), fixed in $2 \%$ gluteraldehyde solution for 10 minutes, and rinsed in $\mathrm{dH}_{2} \mathrm{O}$ two times for 5 minutes. They were then counterstained in $5 \%$ uranyl acetate in methanol for 10 minutes, followed by Reynolds solution containing $2 \%$ lead citrate for 2 minutes, and allowed to air dry.

\section{Sampling and Measurements}

Sampling and Measurements with confocal microscope. Sections prepared for confocal microscopy were imaged on an Olympus IX70 laser scanning confocal microscope, with 543nm and 633nm krypton/argon lasers. Labeled areas were examined with $\mathrm{X} 20$ and $\mathrm{X} 40$ objectives, possessing numerical apertures of 0.50 and 0.85 , respectively. Images were captured with Olympus Fluoview FV300 
v.5.0 software (Olympus Optical Co., Ltd.), and obtained by z-series (step size: $1 \mu \mathrm{m}(\mathrm{X} 20)$ and $0.5 \mu \mathrm{m}(\mathrm{X} 40)$ at $1024 \mathrm{X} 1024$ pixel resolution. For double labeling experiments, optical sections of approximately $1422 \mu \mathrm{m}^{2} /$ each were examined separately for instances of colocalization and/or double labeling.

Sampling and Measurements with electron microscope. Ultrathin sections were examined on a JEOL 1010 electron microscope and digital pictures were captured using a 16 megapixel SIA-12C (sia-cam.com) digital camera coupled with MaxIm DL ${ }^{\circledR}$ CCD software (Diffraction Limited, Ottawa, Canada). Because the antibody penetration can be limited to several microns from the surface of the thick slices, ultrathin sections close to the tissue-epon interface were systematically examined to detect labeled profiles. Every labeled profile encountered was photographed at 12,000X magnification. Each electron micrograph was examined using Image Pro Plus ${ }^{\circledR}$ v.5.0 software, at a final magnification of 60,000-80,000X. Profiles that were positive for EGFP and/or GABA were located in each digital picture and given sample numbers for identification. Profiles were identified as synaptic terminals if they possessed the following criteria: 1) presence of at least 3 vesicles, 2) parallel alignment of presynaptic terminal membrane in apposition with that of the postsynaptic membrane, 3) presence of a symmetric postsynaptic density. If synaptic, the postsynaptic target was classified as a dendritic spine, shaft, axon or soma. Dendritic shafts were defined principally by the presence of an organized arrangement of microtubules or at least one mitochondrion. Axon shafts were 
identified by the presence of conspicuous vesicles. Dendritic spines were identified by their filamentous actin, absence of mitochondria and microtubules, or presence of smooth endoplasmic reticulum (spine apparatus). Given the likelihood of sectioning through dendritic shafts coursing through cortex at irregular angles, it is possible that some dendritic shafts were absent of conspicuous mitochondria and recognizable microtubules, and hence were misidentified as spines. Therefore, numbers of spines may have been overestimated.

Gold label criterion. Parvalbumin containing somata, dendrites and spines were identified by the presence of EGFP-DAB and GABA-gold coincident labeling. The 'GABA-positive' postembedding criterion was determined individually for each animal by calculating the $99^{\text {th }}$ percentile for gold label density within terminals that formed asymmetric junctions. This population represents putative GABA-negative (excitatory) axonal terminals. Pre- and postsynaptic profiles were considered GABA-positive if their calculated gold density rose above the $99^{\text {th }}$ percentile for gold labeling as described above; also see (Erisir and Dreusicke, 2005).

Synapse length. Synapses were traced by following the entire length of the postsynaptic density along the parallel membranes of the synapse, and were given a synapse sample number indicating the target identity. In the event that a postsynaptic density was perforated by a spine protrusion, the synapse was assumed to continue along the length of the protrusion. 
Layer 2/3 Soma Analysis. To determine the percentage of somas within layer $2 / 3$ that had at least one PV terminal synapse, we searched ultra thin sections at low magnification for somata. Once a soma was identified, we took pictures around the somatic membrane at 20,000X magnification. Individual somata were tallied for the appearance of EGFP labeled terminals making symmetric synapses. The number of somata with at least one PV synapse, as well as the number with greater than one, were divided by the total somata observed in three animals/age, at P26 vs. P41 in layer 2/3.

Statistical Analyses. One-way analysis of variance (ANOVA) analyses were used for all comparisons of connectivity percentages within lamina and across age groups. Bonferroni post-hoc tests were then performed between individual age groups. To detect differences in the terminal cross section area distributions across age groups, Mann-Whitney $U$ tests were performed. Whereas to detect statistical differences between the percentages of somas postsynaptic to PV terminals within layer $2 / 3$ across ages, Student's t-Tests (two-tailed) were used. $p$-value significance was set at $p<0.05$ for all comparisons. 


\section{RESULTS}

\section{EGFP-PV cells are fast-spiking interneurons}

To visualize parvalbumin containing (PV) interneurons across cortical lamina, we processed sections of a previously characterized line of BAC transgenic mice in which the parvalbumin promoter drives enhanced green fluorescent protein (EGFP) expression (Dumitriu et al., 2007) for light and confocal microscopy. EGFP-labeled neurons of varying morphologies were present throughout the cortical depth (Fig. 1). Labeled apical, basal, and horizontally arranged processes could be seen extending from individual somata in each lamina.

Under confocal microscopy, sections of binocular visual cortex contained fluorescent cells throughout layers $2 / 3,4,5$ and 6 . Dense projections of dendritic and axonal arbors were present across the cortical depth, and were seen emanating from single neurons (Fig. 2).

To verify that these EGFP-PV neurons were molecularly similar to previously reported fast-spiking interneurons in mice (Chow et al., 1999), we incubated sections of visual cortex in antibodies against EGFP and Kv3.1b, a voltage-gated potassium channel engendering high frequency action potentials (Erisir et al., 1999). We examined approximately 540 single optical sections from the binocular regions of three postnatal day $(P) 26$ age mice. Every EGFPpositive cell observed colocalized with Kv3.1b label (Fig. 2B, Merge), confirming that this subset of EGFP-PV cells in the binocular visual cortex are the 
physiologically and molecularly described fast-spiking, parvalbumin containing interneurons in rodent neocortex (Chow et al., 1999; Dumitriu et al., 2007; Erisir et al., 1999; Galarreta and Hestrin, 1999; Gibson et al., 1999; Weiser et al., 1995).

\section{PV interneurons synapse with inhibitory and excitatory neurites}

To explore the relationship of PV interneuron synaptic input to inhibitory and excitatory neuronal populations in cortex, we incubated adjacent sections to those used for confocal imaging experiments in antibody against EGFP (DAB chromagen) and GABA (15nm gold conjugate; details in Methods). At P21, the earliest age examined and approximately 7 days after eye opening, synaptic contracts were observed between GABAergic terminals and PV dendrites (Fig. $3 A_{1}$ ), as well as between PV terminals and GABAergic dendrites throughout the cortical depth (Fig. $\left.3 \mathrm{~A}_{2}\right)$. Note the representative symmetric postsynaptic density formed parallel to the PV terminal membrane indicating an inhibitory contact (Fig. $\left.3 \mathrm{~A}_{2}\right)$. Dendrites containing EGFP-PV label could be dissociated from EGFP-PV terminals due to their larger cross section areas, prevalent postsynaptic densities, lack of neurotransmitter vesicles and relative patchiness of bound EGFP label (compare Fig. $3 A_{1}$ and $A_{3}$ ). At P26, a majority of the PV terminal boutons encountered seem to contact non-GABAergic excitatory structures (Fig. $3 \mathrm{~B}_{1}$ and $\mathrm{B}_{2}$ ). In addition, $\mathrm{PV}$ dendrites at this age were often studded with multiple asymmetric postsynaptic densities indicating excitatory 
synaptic contacts (Fig. 3B $\mathrm{B}_{3}$ ). By P41, when anatomical plasticity in mouse visual cortex is significantly reduced (Antonini et al., 1999), we observed both excitatory and inhibitory synapses with PV interneuron dendrites (Fig. $3 \mathrm{C}_{1}$ and $\mathrm{C}_{3}$ ).

Furthermore, PV axonal boutons in layer 4 seemed to contact more GABAergic dendrites at this age, some possessing synapses from putative excitatory terminals as well (Fig. $3 \mathrm{C}_{2}$ ). However, to determine how the development of PV interneuron synaptic connections impinges on the visual cortex microcircuit, we needed to perform a laminar analysis of PV interneuron synapses with inhibitory and excitatory neurons across critical period ages.

\section{Distinct laminar alterations of cortical inhibitory circuitry}

To characterize the maturation of PV interneuron inhibition to excitatory and inhibitory targets in binocular visual cortex, we quantified the number of synapses made by PV boutons with cortical somas and neurites in layer 2/3, 4 and 5/6 at P21, P26 and P41 ( $n=3$ animals/age). These ages were chosen to represent periods of incremental exposure to primary sensory input, as well as developmental time points of decreasing anatomical malleability in mouse visual cortex (Antonini et al., 1999; Majewska and Sur, 2003; Majewska et al., 2006; Valverde, 1971). We examined a total of 108 ultrathin sections, containing 160 (P21), 168 (P26) and 169 (P41) synaptic PV interneuron terminals. In addition, in these same sections we identified a total of 300 (P21), 229 (P26) and 263 (P41) GABAergic (non-PV) synaptic terminals. We quantified the number of 
EGFP-PV terminal contacts made with GABA-positive and GABA-negative profiles (see Methods for details), and calculated the number of these synapses as a percentage of total PV contacts within each cortical layer. Moreover, we determined the proportion of GABAergic input to EGFP-PV structures in the same manner. As PV interneuron axonal morphology and target preference differ widely with respect to the lamina of study (see (Huang et al., 2007) for review), we performed a laminar analysis of PV and GABAergic cell input to clarify distinct changes within separate cortical layers.

Layer 4. In binocular visual cortex, layer 4 is the predominant site of sensory input relayed from the lateral geniculate nucleus via thalamocortical axons. Thalamic axons terminating within layer 4 target $P V$ interneurons with increasing affinity over early postnatal ages, ultimately eschewing all other subsets of GABAergic interneurons to preferentially target these fast-spiking cells in adult (Nahmani et al., (submitted)). Accordingly, PV interneuron synaptic output progressively provides faster and more powerful feedforward inhibition over postnatal development.

Fast-spiking PV cells of layer 4 are mostly large, nest, or clutch/small basket cells with axons and dendrites that ramify within their lamina of origin (Kisvarday et al., 1985; Wang et al., 2002). A noted exception are large basket cells whose axonal arbors can spread to lower layer 2/3 and layer 5/6 (Somogyi et al., 1983). Other inhibitory interneurons within layer 4 include non-PV nest and small basket cells and double bouquet cells, possessing dendritic trees that 
terminate within layer 4 (Tamas et al., 1998; Wang et al., 2002). A majority of reciprocal inhibitory interactions in layer 4 are thought to occur between basket cells, while pyramidal and stellate cells are the major excitatory targets of layer 4 inhibition (Ahmed et al., 1997; Binzegger et al., 2004; Tamas et al., 1998). . PV interneuron inhibition to excitatory and inhibitory cells within layer 4 was determined by counting the number of EGFP-PV labeled terminals making symmetric synapses onto postsynaptic targets with and without GABA-gold label in the identical sections. This procedure was adopted in analyzing layers $2 / 3$ and $5 / 6$ as well.

Distribution of input to PV. Excitatory and inhibitory input to PV interneurons in layer 4 was not significantly altered from P21 to P26 $(11 \pm 1.9 \%$ and $13 \pm 2.5 \%$, respectively; ANOVA one-way, $F(2,6)=7.7$, Bonferroni Test, $p>0.05)$. However from P26 to P41, the percentage of GABAergic inhibition to PV cells more than doubled $(13 \pm 2.5 \%$ vs. $29 \pm 5.0 \%, p<0.05$, Fig. 4$)$.

Distribution of PV output. From P21 to P26, PV connections lose a significant proportion of their synaptic input to other GABAergic cells in layer 4 $(20 \pm 3.6 \%$ vs. $2.2 \pm 2.2 \%$, respectively; ANOVA one-way, $F(2,6)=13.7$, $p<0.006$; Bonferroni Test, $p<0.05)$. Interestingly, by P41, the percentage of PV connectivity to other inhibitory interneurons was reestablished to levels commensurate with that one week after eye opening $(20 \pm 2.4 \%, p<0.05$ vs. P26; $p>0.05$ vs. P21). Therefore, both GABAergic input to PV cells and PV output to inhibitory interneurons increase in a reciprocal manner by P41 (Figs. 4 and 5). 
Layer 2/3. Axonal and dendritic projections of GABAergic cells located in cortical layer $2 / 3$ belong to fast-spiking PV cells and adapting (non-PV) interneurons. These non-PV GABAergic interneurons include Marinotti cells, small and nest adapting basket cells, double bouquet and neurogliaform cells (Dantzker and Callaway, 2000; Kawaguchi and Kubota, 1997; Kawaguchi and Kubota, 1998). A vast majority of $\mathrm{PV}$ interneurons in layer $2 / 3$ have basket- or chandelier-like morphology, preferentially contacting proximal dendrites, spines, somata and axon initial segments of stellate and pyramidal cells (Akil and Lewis, 1992; DeFelipe and Fairen, 1982; Wang et al., 2002; Williams et al., 1992). To quantify developmental changes in the proportion of GABAergic versus excitatory input to EGFP-PV cells we assessed the number of asymmetric and symmetric synapses made with EGFP-PV neurites and somas within layer 2/3.

Distribution of input to PV. GABAergic input to layer 2/3 PV interneurons was not significantly altered from P21 to P41 $(19 \pm 5.0 \%, 11 \pm 3.4 \%, 21 \pm 2.6 \%$ for P21, P26 and P41, respectively; ANOVA one-way, $F(2,6)=1.9, p>0.2$, Fig 4).

Distribution of PV output. Although the proportion of GABAergic synapses onto PV dendrites did not change from P21 to P41, PV synapses to layer 2/3 excitatory and inhibitory cells changed dramatically over these ages of anatomical plasticity. At P21, a relatively low percentage of PV interneuron terminals contact layer 2/3 GABAergic targets, remaining at a similarly low level until at least P26 (Mean \pm S.E.; $9.1 \pm 0.8 \%$ and $1.9 \pm 1.9 \%$, respectively; ANOVA one-way, $F(2,6)=12.8, p<0.007 ;$ Bonferroni Test, $p>0.05)$. Yet by P41, the percentage of $\mathrm{PV}$ cell inhibition to other GABAergic interneurons is nearly nine 
times that at P26 (18 $\pm 5.6 \%$ vs. $2 \pm 1.9 \%$, respectively; Bonferroni Test; $p<0.05)$. Hence, while the input to PV interneurons remains relatively constant over early postnatal development, layer 2/3 PV interneurons actively modify their connectivity to excitatory and inhibitory cells during this period (Fig. 5).

Layer 5/6. PV interneuron inhibitory contacts in layer 5 and 6 primarily target the dendrites and somata of pyramidal cells and an undetermined portion of GABAergic cells (Somogyi et al., 1983; Somogyi et al., 1998; Thomson et al., 1996). Here, we find that PV connectivity to GABAergic cells in layer $5 / 6$ followed a developmental course that appeared to precede that of layer $2 / 3$ and 4 .

Distribution of input to PV. Inhibitory input to layer 5/6 PV interneurons followed a similar pattern. From P21 to P26, inhibitory contacts with PV cells increased by a factor of two ( $10 \pm 2.7 \%$ vs. $24 \pm 3.3 \%$, respectively; ANOVA oneway, $F(2,6)=8.1, p<0.02$; Bonferroni Test, $p<0.05)$. However at P41, numbers of GABAergic contacts with PV interneurons were not significantly different than P26 $(24 \pm 3.3 \%$ and $14 \pm 1.3 \%, p>0.05 ;$ Fig. 4$)$.

Distribution of PV output. At P21, almost all of PV inhibition is onto excitatory cells in layer 5/6, however by P26, the level of PV synapses with other interneurons increased nearly eight-fold $(2 \pm 1.5 \%$ vs. $17 \pm 2.4 \%$, respectively; ANOVA one-way, $F(2,6)=20.8, p<0.002$; Bonferroni Test, $p<0.05)$. Following this early surge, from P26 to P41, PV connectivity to GABAergic cells in layer 5/6 did not measurably change $(17 \pm 2.4 \%$ and $15 \pm 1.5 \%, p>0.05$; Fig. 5$)$. 


\section{Alterations of PV connectivity do not reflect changes in total GABA input}

Modifications of PV inhibition over postnatal ages might reflect overall changes in the undifferentiated total (or 'global') GABAergic circuitry, or alterations specific to PV interneurons. To differentiate between these two alternatives, we analyzed the developmental preference of all synaptic GABAergic terminals (excluding EGFP-PV) for excitatory and inhibitory (excluding EGFP-PV) cells in binocular visual cortex. We chose to examine these changes within layer 4 , as this was the site of the most dramatic alterations in PV connections from P21 to P26, and P26 to P41 (Fig. 6).

Contrary to the observed loss of PV interneuron synapses to other inhibitory cells from P21 to P26; global GABAergic input in layer 4 remained at a high level over the identical time points $(20 \pm 1.8 \%$ (P21) and $20 \pm 2 \%$ (P26), $p>0.05)$. Furthermore, while PV input to GABA containing cells increases dramatically by $\mathrm{P} 41$, global GABAergic input is halved by this age $(10 \pm 0.3 \%$, ANOVA one-way, $F(2,6)=14.2, p<0.006$, Bonferroni Test, $p<0.05)$. These results indicate that the developmental alterations in PV interneuron connectivity do not coincide with changes to the total GABAergic input in layer 4, suggesting that PV interneurons undergo specific modifications of their synaptic connectivity over ages of waning anatomical plasticity. 


\section{PV interneuron terminal maturation and target preference}

To investigate how PV terminal ultrastructure changes from P21 to P41, we measured the terminal area and synapse length of synaptic PV boutons in layers $2 / 3,4$ and $5 / 6$. We found no changes in PV bouton cross-section area or synapse length distributions across layers 2/3, 4 and 5/6 from P21 to P26 (MannWhitney $U, p>0.3$, Table 1). However, layer $2 / 3$ and 4 PV terminal distributions were significantly different from P26 to P41 (Mann-Whitney $U, p<0.02$ and $p<0.03$, respectively, Table 1). In addition, postsynaptic synapse lengths at layer 2/3 PV terminal junctions had a distribution skewed toward larger synapses at P41 vs. P26 (Mann-Whitney U, p<0.04, Table 1). Thus, PV terminal maturation ensues in an age and laminar specific manner in primary visual cortex.

To determine whether the observed changes in PV terminal contacts with GABAergic and excitatory cells were accompanied by alterations in the location of these synapses, we analyzed the percentage of PV contacts with postsynaptic targets across ages within individual lamina. PV terminal synapse proportions with postsynaptic dendrites, spines, somata, axons and PV-to-PV connections across lamina and postnatal ages are detailed in Table 1. No significant changes in PV terminal preference for dendrites, spines, axons or PV-to-PV connections were observed within layer $2 / 3,4$ or $5 / 6$ at P21, P26 and P41. However, PV terminals within layer 2/3 did exhibit an increased synaptic preference for somata from P26 to P41 ( $2 \pm 1.5 \%$ vs. $14 \pm 1.4 \%$; ANOVA oneway; $F(2,6)=7.7, p<0.03$; Bonferroni Test, $p<0.05)$. 
As layer 2/3 PV terminals and synapse lengths also increase in size from P26 to P41, we sought to confirm our finding of increased PV axosomatic target prevalence in layer 2/3. Accordingly, we calculated the percentage of somata within layer 2/3 that received at least one PV synapse at P26 and P41. At P41, cortical cell bodies within layer $2 / 3$ were more than twice as likely to be postsynaptic to a PV terminal than at P26 $(34 \pm 3.3 \%(n=68)$ vs. $12 \pm 1.4 \%$ ( $n=88)$, P41 vs. P26 respectively, Student's t-Test, two-tailed, p<0.004). Moreover, approximately $8 \%$ of cortical somata at P41 had synapses with two or more PV terminals, while we did not observe any somata at P26 with multiple PV contacts (Student's t-Test, two-tailed, $p<0.007$ ). In sum, we find that PV interneuron axosomatic contacts and the proportion of cells contacted within layer 2/3, increase in a laminar specific manner from P26 to P41. 


\section{DISCUSSION}

Fast-spiking PV interneuron connectivity has been implicated in initiating and modulating the closure for a critical period for plasticity in binocular visual cortex (Berardi et al., 1993; Chattopadhyaya et al., 2004; Katagiri et al., 2007). In the present study, we explored the synaptic relationship of inhibitory PV terminal contacts with excitatory and GABAergic neuronal populations across ages of anatomical malleability in mouse visual cortex. Moreover, we determined the contribution of inhibitory and excitatory connections to PV interneurons at these same ages. We found that GABAergic circuitry undergoes dramatic changes in laminar connectivity and target preference over early postnatal development (Fig. 7).

At P26, an age commensurate with a significant degree of morphological plasticity in rodent cortex (Antonini et al., 1999; Chattopadhyaya et al., 2004; Majewska et al., 2006; Valverde, 1971), PV interneurons lost nearly all their inhibitory contacts with other interneurons in favor of excitatory cells in layers $2 / 3$ and 4. By P41, PV interneurons had reestablished relatively high levels of synaptic inhibition to other interneurons in layers $2 / 3$ and 4 , coincident with a twofold increase in reciprocal GABAergic input to PV cells in these layers. In addition, in layer 2/3 the proportion of cells receiving PV somatic inhibition doubled from P26 to P41. Hence, a reciprocal GABAergic circuit is established within layers $2 / 3$ and 4 by P41, commensurate with a two-fold increase in PV axosomatic inhibition to excitatory cortical cells within layer $2 / 3$. 
Interestingly, alterations of PV interneuron connections in layer $5 / 6$ seem to precede those in layer 4 and $2 / 3$. Hence at P21, PV interneurons had very few contacts with other GABAergic cells. Yet, by P26 the proportion of PV terminal synapses to layer 5/6 interneurons had already increased eight-fold, remaining steady at least until P41. Furthermore, while PV terminal areas within layer 5/6 remained at a similar size across the ages examined, PV bouton areas in layer 4 and $2 / 3$ increased significantly from P26 to P41. These findings suggest that the maturation of $P V$ interneuron circuitry in layers $5 / 6,4$ and $2 / 3$, parallels the early inside-out development of cortical lamination.

\section{Impact of PV interneuron inhibition on cells in visual cortex}

In this study, EGFP-PV was expressed in approximately $50 \%$ of neurons immunoreactive for parvalbumin in mouse cortex. While this small subset of cells possess class-defining features (i.e. fast-spiking, axonal bifurcations), they include cells of varying somato-dendritic morphologies, and have axons that terminate within distinct cortical lamina (Dumitriu et al., 2007; Tamas et al., 1998). Despite these disparate arborization patterns, physiological and morphological analyses have determined that the great majority of cortical inhibition to other GABAergic interneurons originates from inhibitory cells residing within the same lamina (Binzegger et al., 2004; Dantzker and Callaway, 2000; Karube et al., 2004; Tamas et al., 1997). Under this framework, we are able to integrate our developmental results within the existing literature, to highlight the 
flow of PV interneuron inhibition to excitatory and GABAergic cells within separable laminar circuits.

\section{Layer 4}

Primary thalamocortical input to subsets of GABAergic cells in layer 4 of visual cortex progressively shifts over postnatal development, wherein PV interneurons are the sole target of this monosynaptic input in adult (Nahmani et al., (submitted)). This powerful feedforward inhibition is then relayed from PV interneurons to excitatory and GABAergic cells. At one week post-eye opening, nearly $80 \%$ of all PV contacts are excitatory neurites; presumably spines of stellate cells and apical dendrites of layer 4 and 5/6 pyramidal cells (Budd, 2000; Hirsch, 1995; Martin et al., 1983). Other GABAergic interneurons (non-PV) within layer 4 receive the remainder of PV inhibition at P21.

Curiously, we found little evidence for a substantial amount of PV-to-PV interneuron connectivity $(<4 \%)$ across the developmental ages studied. A previous study in layer 4 of adult cat visual cortex found that up to $79 \%$ of basket cell inhibitory connections could be attributed to other basket cells (Ahmed et al., 1997). This finding was estimated based on the bouton size of anatomically identified interneuron synapses, likely including at least a large population of nonPV adapting nest and small basket cells within layer 4 (Dantzker and Callaway, 2000; Wang et al., 2002). Hence, differences in the interneuron populations, criteria for PV interneuron identification and the age and species of animals examined explain the discrepancies with our results. Importantly however, 
synchronization of fast-spiking output is mostly incumbent on the electrical connections among PV cells, rather than the abundant chemical connections between various interneuron subtypes (Galarreta and Hestrin, 1999; Gibson et al., 1999).

By P26, PV cells in layer 4 receive stronger thalamic drive, and now target excitatory cells almost exclusively (Fig. 7A). Thus, feedforward excitation from layer 4 to $2 / 3$ is tightly regulated by PV interneuron inhibition at the pinnacle of periods for both anatomical and physiological plasticity in mouse visual cortex (Antonini et al., 1999; Gordon and Stryker, 1996). Moreover, the lack of PV interneuron synapses with other GABAergic cells at this age suggests one of two possibilities: (1) a switch in preference from GABAergic to excitatory neurites OR (2) a wholesale loss of PV synapses from 4 inhibitory dendrites and spines.

Since no changes in PV interneuron preference for cortical targets were detected in layer 4 at this age, we suggest that a shift in PV inhibition to excitatory cells is the more parsimonious explanation. In addition, parvalbumin immunoreactivity within neurites of mouse visual cortex increases steadily from P7 onward (del Rio et al., 1994). However, we cannot completely rule out a loss in PV input at P26 without a measure of PV bouton density across developmental time points.

Remarkably, by P41 the percentage of PV interneuron synapses with GABAergic cells has doubled, returning to a level similar to that of P21 animals ( $20 \%$ of total PV input to layer 4). This rebound in PV inhibitory contacts with GABAergic cells coincides with a more than two-fold increase in the proportion of GABAergic feedback to PV interneurons. Although this GABAergic feedback to 
PV interneurons remained steady from $\mathrm{P} 21$ to $\mathrm{P} 26$, by $\mathrm{P} 41$ a strong reciprocal inhibitory loop is set up wherein nearly one-third of all GABA contacts in layer 4 are with $\mathrm{PV}$ interneurons at this age. Thus, following strong monosynaptic sensory stimulation, PV interneurons provide the initial feedforward inhibition to a majority of pyramidal and stellate dendrites. This PV interneuron inhibition is then reciprocated by other GABAergic cells in layer 4, likely initiating a progressive spike timing dependent potentiation of these inhibitory synapses and rapid control over pyramidal cell action potential generation (Haas et al., 2006; Hasenstaub et al., 2005).

\section{Layer $2 / 3$}

Unlike connectivity within layer 4, neither PV interneuron synapses with cortical cells, nor reciprocal GABAergic output to PV interneurons, are altered within layer 2/3 from P21 to P26. Yet by P41, the proportion of inhibitory input to $\mathrm{PV}$ interneurons is dramatically increased, as are PV terminal contacts with other GABAergic interneurons. Accordingly, prior to P26 the balance of network activity within layer $2 / 3$ is tilted toward inhibition. Although similar to layer 4 , after P26 a reciprocal inhibitory circuit between GABAergic interneurons matures within layer $2 / 3$, suggesting excitatory cells are relatively disinhibited by P41. However, the proportion of PV terminals contacting somata, and the percentage of excitatory layer 2/3 cell bodies with PV synapses increases from P26 to P41. Hence, the maturation of $\mathrm{PV}$ interneuron connectivity progressively engages a shunting-like inhibition of layer $2 / 3$ excitatory somata, while paradoxically 
disengaging from a significant proportion of excitatory neurites. In sum, the functional outcome of these GABAergic circuit alterations may be to ensure greater temporal precision, effectively reducing the gain of intralaminar activity at later postnatal ages (Mitchell and Silver, 2003).

Notably, we found no evidence for an increase in layer $2 / 3$ chandelier-like axoaxonal contacts across the ages examined. It is likely that these contacts reached peak levels at an earlier developmental stage than those of PV pericellular basket terminals (Akil and Lewis, 1992). In fact, we found that PV terminal areas increase over development in this layer, indicating that aspects of PV bouton development persist until at least P41. In any case, axonal targets represented a relatively minor portion $(<4 \%$ at any age) of the total PV connectivity in layer $2 / 3$.

\section{Layer 5/6}

At P21, nearly $90 \%$ of inhibitory synapses within layers $5 / 6$ are with excitatory cells (Figs. 3 and 4). Hence, layer 5/6 excitatory cells, comprising local interneurons and pyramidal cells with tufted apical dendrites (Tsiola et al., 2003), likely must overcome powerful inhibition if they are to relay information to superficial layers at this age. Yet by P26, PV interneurons and other GABAergic cells target one another in dramatically higher proportions, disinhibiting the large pyramidal cells carrying sensory feedback information. Consequently, at times of peak inhibitory connectivity to layer $2 / 3$ and 4 excitatory neurites, excitatory cells within layer $5 / 6$ are likely able to maintain efficacious firing to superficial layers; and vice versa. 
This shift in the balance of inhibition, from excitatory cells to other GABAergic interneurons within layer $5 / 6$, seems to precede a similar switch in layers 4 and $2 / 3$. Indeed, additional measures of ongoing circuit alterations such as terminal area, synapse length and target preference, remain stable from P21 to P41 in layer 5/6. These findings indicate that infragranular GABAergic circuitry may develop prior to that of layer 4 and $2 / 3$, perhaps in parallel with the insideout development of cortical lamination (Polleux et al., 1997). In fact, the maturation of circuit properties such as long-term potentiation, long term depression, NMDA receptor expression and synaptic scaling, all occur in an identical laminar sequence (Catalano et al., 1997; Desai et al., 2002; Jiang et al., 2007).

\section{PV interneuron connectivity and critical period plasticity}

It remains unclear as to the role of $\mathrm{PV}$ circuitry with respect to periods associated with the initiation of physiological and anatomical plasticity. Evidence suggesting the involvement of PV basket interneurons in the onset of cortical plasticity stem primarily from studies investigating the role of brain-derived neurotrophic factor (BDNF) in modulating both PV cell maturation and ocular dominance plasticity. Specifically, they report that upregulation of BDNF within the neocortex results in a precocious increase in parvalbumin immunoreactivity and an early end of the critical period for ocular dominance (Huang et al., 1999). In fact, BDNF is likely required for the normal expression of parvalbumin protein 
and the development of PV interneuron fast-spiking behavior in visual cortex (both mature by P14) (Itami et al., 2007).

Yet, these findings seem to support a role for PV interneurons in the reduction of cortical plasticity, rather than its initiation. Along these lines, previous studies from our lab have found that $\mathrm{PV}$ interneurons receive a minority of monosynaptic sensory drive to GABAergic interneurons in primary visual cortex, at ages commensurate with the beginning of the critical period. However by the end of the critical period and into adulthood, PV interneurons are the major recipient and eventually the exclusive GABAergic target of thalamocortical synapses, respectively (Erisir and Dreusicke, 2005; Nahmani et al., submitted).

Hence, the timing of fast-spiking interneuron circuit modifications to populations of excitatory and inhibitory cells at different levels of the cortical circuit, might contribute to the eventual solidification of synaptic wiring in the visual cortex. This process is amenable to a spike-timing model of plasticity, wherein the entrainment of a "student" neuron(s) is wholly dependent on the firing frequency and connections of a "teacher" neuron(s) (Froemke et al., 2005; Young et al., 2007). At different stages of postnatal development, specific classes of cells compete to control the timing of a particular regions' activity. Those neurons with higher firing probabilities are able to entrain those neurons with lower firing probabilities. For instance, from P21 to P26, when the overall amplitude or gain in the system is high (Desai et al., 2002), the spatial range of spike-timing dependent plasticity peaks. Thus, the predominance of layer $5 / 6$ pyramidal projections at P26 might out compete local GABAergic interneurons 
due to their relative lack of presynaptic inhibition. By P41, PV interneurons have set up a reciprocal inhibitory network that may act to decrease net gain and facilitate local interactions; in effect reducing the ability of long-range connections to compete in a spike-timing dependent fashion (Young et al., 2007). Accordingly, PV interneuron connections might modulate the visual microcircuit by constraining network gain and limiting the spatial spread of competitive interactions at ages of reduced cortical plasticity. 


\section{References}

Ahmed B, Anderson JC, Martin KA, Nelson JC. 1997. Map of the synapses onto layer 4 basket cells of the primary visual cortex of the cat. J Comp Neurol 380(2):230-242.

Akil M, Lewis DA. 1992. Differential distribution of parvalbumin-immunoreactive pericellular clusters of terminal boutons in developing and adult monkey neocortex. Exp Neurol 115(2):239-249.

Antonini A, Fagiolini M, Stryker MP. 1999. Anatomical correlates of functional plasticity in mouse visual cortex. J Neurosci 19(11):4388-4406.

Berardi N, Domenici L, Parisi V, Pizzorusso T, Cellerino A, Maffei L. 1993. Monocular deprivation effects in the rat visual cortex and lateral geniculate nucleus are prevented by nerve growth factor (NGF). I. Visual cortex. Proc Biol Sci 251(1330):17-23.

Binzegger T, Douglas RJ, Martin KA. 2004. A quantitative map of the circuit of cat primary visual cortex. J Neurosci 24(39):8441-8453.

Budd JM. 2000. Inhibitory basket cell synaptic input to layer IV simple cells in cat striate visual cortex (area 17): a quantitative analysis of connectivity. Vis Neurosci 17(3):331-343.

Catalano SM, Chang CK, Shatz CJ. 1997. Activity-dependent regulation of NMDAR1 immunoreactivity in the developing visual cortex. J Neurosci 17(21):8376-8390.

Chattopadhyaya B, Di Cristo G, Higashiyama H, Knott GW, Kuhlman SJ, Welker E, Huang ZJ. 2004. Experience and activity-dependent maturation of perisomatic GABAergic innervation in primary visual cortex during a postnatal critical period. J Neurosci 24(43):9598-9611.

Chattopadhyaya B, Di Cristo G, Wu CZ, Knott G, Kuhlman S, Fu Y, Palmiter RD, Huang ZJ. 2007. GAD67-mediated GABA synthesis and signaling regulate inhibitory synaptic innervation in the visual cortex. Neuron 54(6):889-903.

Chow A, Erisir A, Farb C, Nadal MS, Ozaita A, Lau D, Welker E, Rudy B. 1999. $\mathrm{K}(+)$ channel expression distinguishes subpopulations of parvalbumin- and somatostatin-containing neocortical interneurons. J Neurosci 19(21):93329345.

Dantzker JL, Callaway EM. 2000. Laminar sources of synaptic input to cortical inhibitory interneurons and pyramidal neurons. Nat Neurosci 3(7):701-707.

DeFelipe J, Fairen A. 1982. A type of basket cell in superficial layers of the cat visual cortex. A Golgi-electron microscope study. Brain Res 244(1):9-16.

DeFelipe J, Hendry SH, Jones EG. 1989. Visualization of chandelier cell axons by parvalbumin immunoreactivity in monkey cerebral cortex. Proc Natl Acad Sci U S A 86(6):2093-2097.

del Rio JA, de Lecea L, Ferrer I, Soriano E. 1994. The development of parvalbumin-immunoreactivity in the neocortex of the mouse. Brain Res Dev Brain Res 81(2):247-259.

Desai NS, Cudmore RH, Nelson SB, Turrigiano GG. 2002. Critical periods for experience-dependent synaptic scaling in visual cortex. Nat Neurosci 5(8):783-789. 
Dumitriu D, Cossart R, Huang J, Yuste R. 2007. Correlation between axonal morphologies and synaptic input kinetics of interneurons from mouse visual cortex. Cereb Cortex 17(1):81-91.

Erisir A, Dreusicke M. 2005. Quantitative morphology and postsynaptic targets of thalamocortical axons in critical period and adult ferret visual cortex. J Comp Neurol 485(1):11-31.

Erisir A, Lau D, Rudy B, Leonard CS. 1999. Function of specific $\mathrm{K}(+)$ channels in sustained high-frequency firing of fast-spiking neocortical interneurons. J Neurophysiol 82(5):2476-2489.

Erisir A, Levey Al, Aoki C. 2001. Muscarinic receptor M(2) in cat visual cortex: laminar distribution, relationship to gamma-aminobutyric acidergic neurons, and effect of cingulate lesions. J Comp Neurol 441(2):168-185.

Erisir A, Van Horn SC, Sherman SM. 1997. Relative numbers of cortical and brainstem inputs to the lateral geniculate nucleus. Proc Natl Acad Sci U S A 94(4):1517-1520.

Froemke RC, Poo MM, Dan Y. 2005. Spike-timing-dependent synaptic plasticity depends on dendritic location. Nature 434(7030):221-225.

Fukuda T, Kosaka T, Singer W, Galuske RA. 2006. Gap junctions among dendrites of cortical GABAergic neurons establish a dense and widespread intercolumnar network. J Neurosci 26(13):3434-3443.

Galarreta M, Hestrin S. 1999. A network of fast-spiking cells in the neocortex connected by electrical synapses. Nature 402(6757):72-75.

Gibson JR, Beierlein M, Connors BW. 1999. Two networks of electrically coupled inhibitory neurons in neocortex. Nature 402(6757):75-79.

Gonchar Y, Burkhalter A. 1997. Three distinct families of GABAergic neurons in rat visual cortex. Cereb Cortex 7(4):347-358.

Gordon JA, Stryker MP. 1996. Experience-dependent plasticity of binocular responses in the primary visual cortex of the mouse. J Neurosci 16(10):3274-3286.

Haas JS, Nowotny T, Abarbanel HD. 2006. Spike-timing-dependent plasticity of inhibitory synapses in the entorhinal cortex. J Neurophysiol 96(6):33053313.

Hanover JL, Huang ZJ, Tonegawa S, Stryker MP. 1999. Brain-derived neurotrophic factor overexpression induces precocious critical period in mouse visual cortex. J Neurosci 19(22):RC40.

Hasenstaub A, Shu Y, Haider B, Kraushaar U, Duque A, McCormick DA. 2005. Inhibitory postsynaptic potentials carry synchronized frequency information in active cortical networks. Neuron 47(3):423-435.

Hensch TK. 2005. Critical period plasticity in local cortical circuits. Nat Rev Neurosci 6(11):877-888.

Hirsch JA. 1995. Synaptic integration in layer IV of the ferret striate cortex. J Physiol 483 ( Pt 1):183-199.

Huang ZJ, Di Cristo G, Ango F. 2007. Development of GABA innervation in the cerebral and cerebellar cortices. Nat Rev Neurosci 8(9):673-686. 
Huang ZJ, Kirkwood A, Pizzorusso T, Porciatti V, Morales B, Bear MF, Maffei L, Tonegawa S. 1999. BDNF regulates the maturation of inhibition and the critical period of plasticity in mouse visual cortex. Cell 98(6):739-755.

Itami C, Kimura F, Nakamura S. 2007. Brain-derived neurotrophic factor regulates the maturation of layer 4 fast-spiking cells after the second postnatal week in the developing barrel cortex. J Neurosci 27(9):22412252.

Jiang B, Trevino M, Kirkwood A. 2007. Sequential development of long-term potentiation and depression in different layers of the mouse visual cortex. J Neurosci 27(36):9648-9652.

Karube F, Kubota Y, Kawaguchi Y. 2004. Axon branching and synaptic bouton phenotypes in GABAergic nonpyramidal cell subtypes. J Neurosci 24(12):2853-2865.

Katagiri H, Fagiolini M, Hensch TK. 2007. Optimization of somatic inhibition at critical period onset in mouse visual cortex. Neuron 53(6):805-812.

Kawaguchi Y, Kubota Y. 1997. GABAergic cell subtypes and their synaptic connections in rat frontal cortex. Cereb Cortex 7(6):476-486.

Kawaguchi Y, Kubota Y. 1998. Neurochemical features and synaptic connections of large physiologically-identified GABAergic cells in the rat frontal cortex. Neuroscience 85(3):677-701.

Kisvarday ZF, Cowey A, Somogyi P. 1986. Synaptic relationships of a type of GABA-immunoreactive neuron (clutch cell), spiny stellate cells and lateral geniculate nucleus afferents in layer IVC of the monkey striate cortex. Neuroscience 19(3):741-761.

Kisvarday ZF, Martin KA, Whitteridge D, Somogyi P. 1985. Synaptic connections of intracellularly filled clutch cells: a type of small basket cell in the visual cortex of the cat. J Comp Neurol 241(2):111-137.

Majewska A, Sur M. 2003. Motility of dendritic spines in visual cortex in vivo: changes during the critical period and effects of visual deprivation. Proc Natl Acad Sci U S A 100(26):16024-16029.

Majewska AK, Newton JR, Sur M. 2006. Remodeling of synaptic structure in sensory cortical areas in vivo. J Neurosci 26(11):3021-3029.

Martin KA, Somogyi P, Whitteridge D. 1983. Physiological and morphological properties of identified basket cells in the cat's visual cortex. Exp Brain Res 50(2-3):193-200.

Mitchell SJ, Silver RA. 2003. Shunting inhibition modulates neuronal gain during synaptic excitation. Neuron 38(3):433-445.

Nahmani M, Erisir A. 2005. VGluT2 immunochemistry identifies thalamocortical terminals in layer 4 of adult and developing visual cortex. J Comp Neurol 484(4):458-473.

Nahmani M, Rudy B, Erisir A. (submitted). Specificity of thalamocortical input for parvalbumin-containing interneurons in ferret visual cortex. Cereb Cortex.

Nahmani M, Rudy B, Erisir A. submitted. Specificity of thalamocortical input for parvalbumin-containing interneurons in ferret visual cortex. Cereb Cortex.

Peters A, Proskauer CC, Ribak CE. 1982. Chandelier cells in rat visual cortex. J Comp Neurol 206(4):397-416. 
Polleux F, Dehay C, Kennedy H. 1997. The timetable of laminar neurogenesis contributes to the specification of cortical areas in mouse isocortex. J Comp Neurol 385(1):95-116.

Somogyi P, Kisvarday ZF, Martin KA, Whitteridge D. 1983. Synaptic connections of morphologically identified and physiologically characterized large basket cells in the striate cortex of cat. Neuroscience 10(2):261-294.

Somogyi P, Tamas G, Lujan R, Buhl EH. 1998. Salient features of synaptic organisation in the cerebral cortex. Brain Res Brain Res Rev 26(2-3):113135.

Tamas G, Buhl EH, Somogyi P. 1997. Massive autaptic self-innervation of GABAergic neurons in cat visual cortex. J Neurosci 17(16):6352-6364.

Tamas G, Somogyi P, Buhl EH. 1998. Differentially interconnected networks of GABAergic interneurons in the visual cortex of the cat. J Neurosci 18(11):4255-4270.

Thomson AM, West DC, Hahn J, Deuchars J. 1996. Single axon IPSPs elicited in pyramidal cells by three classes of interneurones in slices of rat neocortex. J Physiol 496 ( Pt 1):81-102.

Tsiola A, Hamzei-Sichani F, Peterlin Z, Yuste R. 2003. Quantitative morphologic classification of layer 5 neurons from mouse primary visual cortex. J Comp Neurol 461(4):415-428.

Valverde F. 1971. Rate and extent of recovery from dark rearing in the visual cortex of the mouse. Brain Res 33(1):1-11.

Wang Y, Gupta A, Toledo-Rodriguez M, Wu CZ, Markram H. 2002. Anatomical, physiological, molecular and circuit properties of nest basket cells in the developing somatosensory cortex. Cereb Cortex 12(4):395-410.

Weiser M, Bueno E, Sekirnjak C, Martone ME, Baker H, Hillman D, Chen S, Thornhill W, Ellisman M, Rudy B. 1995. The potassium channel subunit $\mathrm{KV} 3.1 \mathrm{~b}$ is localized to somatic and axonal membranes of specific populations of CNS neurons. J Neurosci 15(6):4298-4314.

Williams SM, Goldman-Rakic PS, Leranth C. 1992. The synaptology of parvalbumin-immunoreactive neurons in the primate prefrontal cortex. $\mathrm{J}$ Comp Neurol 320(3):353-369.

Young JM, Waleszczyk WJ, Wang C, Calford MB, Dreher B, Obermayer K. 2007. Cortical reorganization consistent with spike timing-but not correlationdependent plasticity. Nat Neurosci 10(7):887-895. 


\section{FIGURE LEGENDS}

Figure 1. Light micrograph composites of parvalbumin-containing interneurons in mouse primary visual cortex. Two adjacent sections of mouse binocular visual cortex were stained for Nissl (left) and against EGFP (right). Dotted black lines indicate approximate laminar boundaries. Section labeled for EGFP-PV cells show dark accumulations of the DAB chromagen in neurites originating from PV somata (arrowheads). Notice that EGFP-PV interneurons have varying dendritic and axonal characteristics both across and within cortical lamina. Scale bar = $100 \mu \mathrm{m}$.

Figure 2. EGFP-PV cells are fast-spiking interneurons. A. EGFP-PV expressing cells are present in layers $2 / 3,4$ and $5 / 6$ in mouse binocular visual cortex, possessing varying somato-dendritic morphologies. Regardless of laminar position, every EGFP-PV cell colocalized with Kv3.1b label (Merge). B. Higher magnification centered on layer 4, showing EGFP-PV dendritic and axonal (arrows) labeling. Although every EGFP-cell contained Kv3.1b label, not every Kv3.1b-positive cell expressed EGFP. Scale bars: $200 \mu \mathrm{m}(\mathrm{A})$ and $50 \mu \mathrm{m}(\mathrm{B})$.

Figure 3. Immuno-electron microscopy demonstrates PV interneuron synaptic connectivity across postnatal ages. Representative electron micrographs, double-labeled for GABA (15nm gold particles) and EGFP (PV cells). $\mathbf{A}_{1}-\mathbf{A}_{3}$ : At P21, GABAergic terminals form synapses with PV dendrites (arrowhead, $A_{1}$, layer 4), and PV boutons contact excitatory $\left(A_{3}\right.$, layer $\left.5 / 6\right)$ and inhibitory $\left(A_{2}\right.$, 
layer 4) dendrites. Note the symmetric postsynaptic densities indicating inhibitory synapses (arrows). $\mathbf{B}_{1}-\mathbf{B}_{3}$ : At P26, a majority of PV boutons had synapses (arrows) with excitatory dendrites; examples shown from layer $2 / 3\left(B_{1}\right)$ and layer 5/6 $\left(B_{2}\right)$. In addition, most contacts with PV dendrites (arrowheads) throughout cortical lamina were from excitatory terminals (see large layer 4 PV dendrite; $B_{3}$ ). C1-C3: By P41, PV terminal input to other GABAergic neurons increased dramatically in layer $4\left(\mathrm{C}_{2}\right)$. PV interneuron dendrites receive relatively high amounts of reciprocal inhibitory input at this age (arrowheads, C1 and C3; layer 5/6). Note that the PV dendrite in $\mathrm{C}_{1}$ is contacted by an excitatory terminal as well (arrowhead). Abbreviations: $P V_{t}$ and $P V_{d}=P V$ terminal and dendrite; $\mathrm{T}^{+}$and $\mathrm{D}^{+}=\mathrm{GABAergic}$ terminal and dendrite; $\mathrm{T}^{-}$and $\mathrm{D}^{-}=$excitatory terminal and dendrite; Scale bars: 500nm $\left(A_{1}-A_{3}\right) ; 500 n m\left(B_{1}-B_{2}\right) ; 1 \mu m\left(B_{3}\right)$; $500 \mathrm{~nm}\left(\mathrm{C}_{1}-\mathrm{C}_{3}\right)$.

Figure 4. Laminar and developmental analysis of GABAergic synapses with PV interneurons. Graphs indicate the percentage of total GABAergic targets that contained EGFP-PV at P21, P26 and P41 in layers $2 / 3,4$ and 5/6 of binocular visual cortex. ${ }^{*}=$ significant at $\mathrm{p}<0.05$ (Bonferonni Test).

Figure 5. Laminar and developmental analysis of PV interneuron connectivity. A. Graphs on the left display the percentage of total PV terminal targets that contained GABA postnatal at P21, P26 and P41 in layers 2/3, 4 and 5/6 of binocular visual cortex. ${ }^{*}=$ significant at $p<0.05$ (Bonferonni Test). B. 
Percentage of GABAergic (inhibitory; blue) and non-GABAergic (excitatory; red) targets of PV terminals at P21, P26 and P41.

Figure 6. Modifications of PV interneuron developmental connectivity are not the result of changes to non-specific global inhibition. A. The percentage of total GABAergic targets containing GABA in layer 4. Alterations in global GABAergic (non-PV) synapses do not parallel those of PV interneurons in layer 4 (see Fig. 3). ${ }^{*}=$ significant at $p<0.05$ (Bonferonni Test) B. Examples of PV terminals making symmetric synapses (arrows) onto somata at P26 and P41 in layer 2/3. At P41, note the non-PV inhibitory axosomatic synapse adjacent to the PV bouton. From P26 to P41, the percentage of cells within layer 2/3 receiving at least one PV synapse increases nearly 3-fold. Scale bar: $1 \mu \mathrm{m}$.

Figure 7. Schematic depiction of PV interneuron developmental connectivity in layers $4,2 / 3$ and $5 / 6$. Left side of figure illustrates percentages of inhibitory (blue) and excitatory (red) afferent input to PV interneurons, while right side displays the proportion of PV output to cortical inhibitory (I) and excitatory cells (Ex) within individual lamina. A. From P21 to P26, PV interneuron output to other inhibitory cells decreases dramatically in layer 4 , with little change in the afferent input to PV interneurons. However at P41, PV interneurons and GABAergic cells inhibit each other in greater proportions, commensurate with increased thalamic input (TC) to PV interneurons. B. Neither PV nor GABAergic circuitry is significantly altered from $\mathrm{P} 21$ to $\mathrm{P} 26$ in layer $2 / 3$. Yet by P41, PV 
interneurons and GABAergic cells target one another in greater numbers. C. Changes in PV interneuron inhibition and in inhibitory input to PV cells within layer $5 / 6$ precede that in layers 4 and $2 / 3$, such that no changes in this microcircuitry occur from P26 to P41 in this layer.

Table 1. Developmental and Laminar Analysis of PV Interneuron Terminal Morphology and Target Preference. Table 1 displays the mean cross section area and synapse length for PV boutons across the postnatal ages examined. In addition, the proportion of PV synapses with various postsynaptic targets is given as a percentage of total PV input to a given lamina/age. ${ }^{*}=$ significant at $p<0.05$ for Mann-Whitney U, Bonferroni, or Student's t-Test; $\pm=$ S.E. 
Figure 2.

A
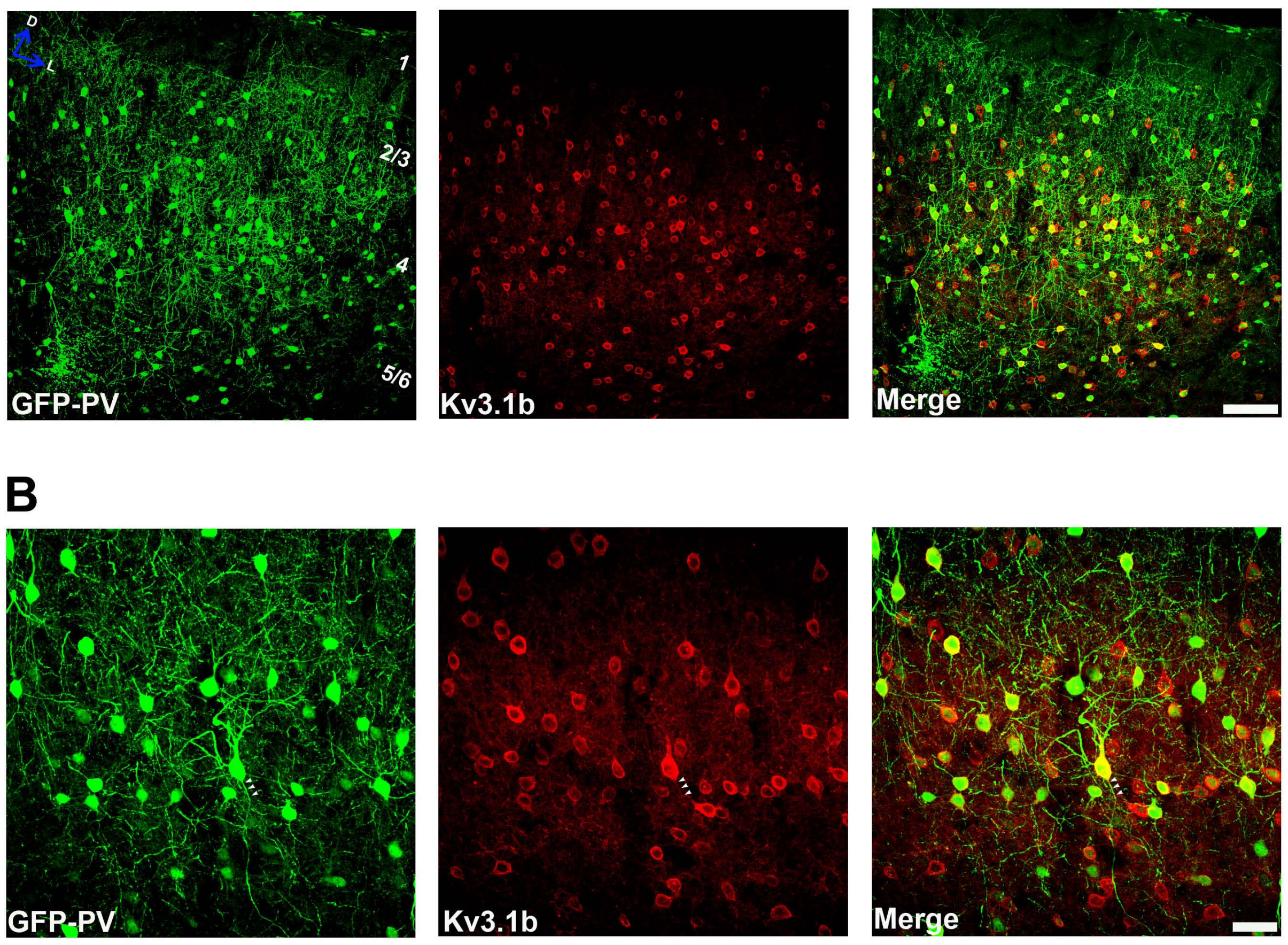

Merge

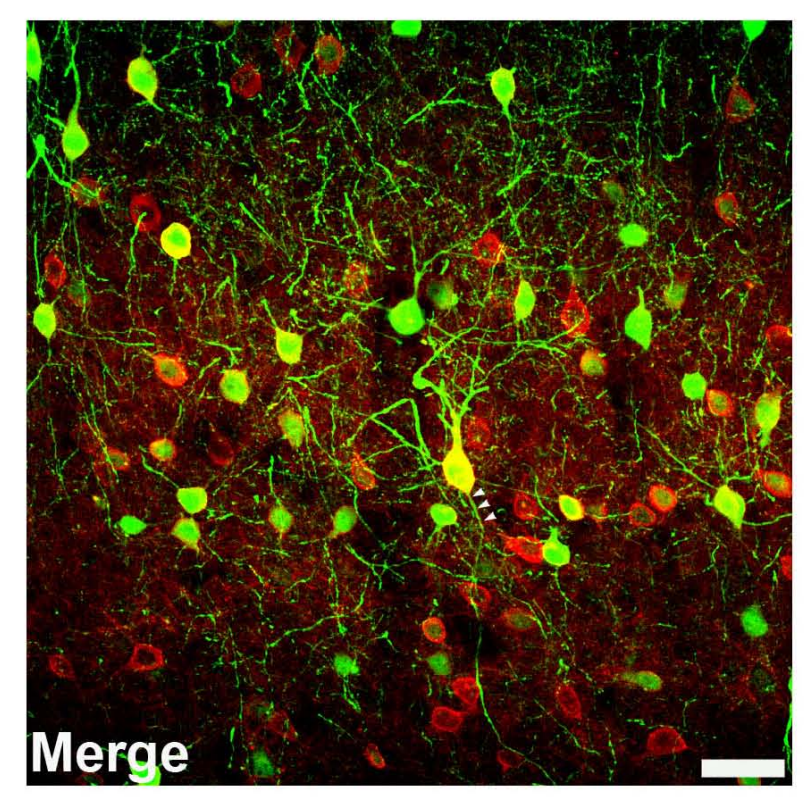


Figure 4.

GABAergic Input to PV interneurons
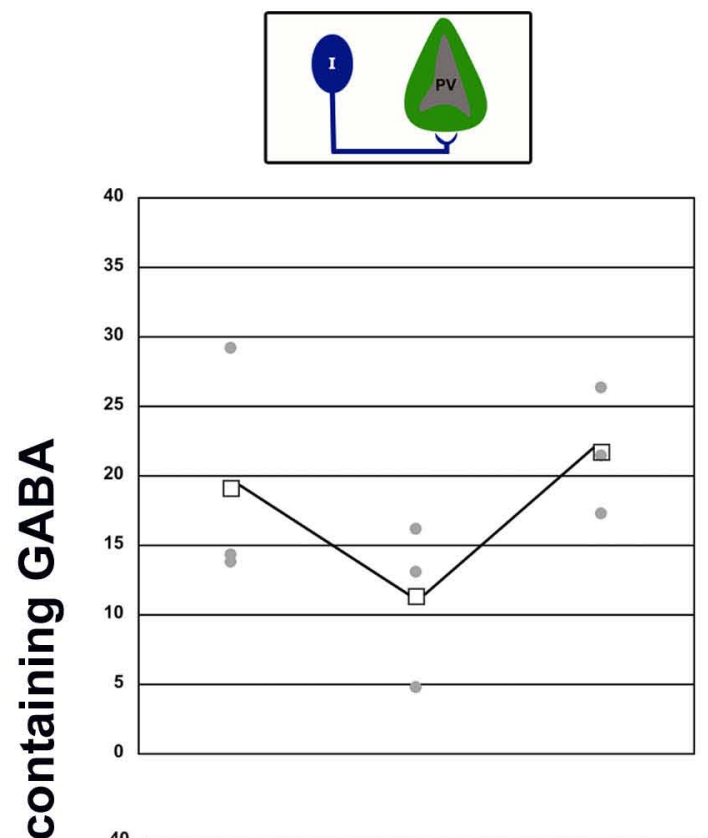

Layer 2/3

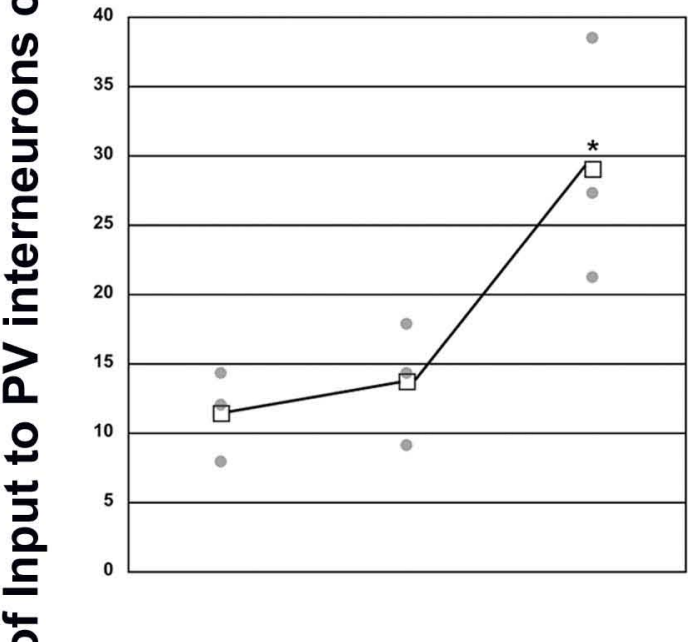

Layer 4

은

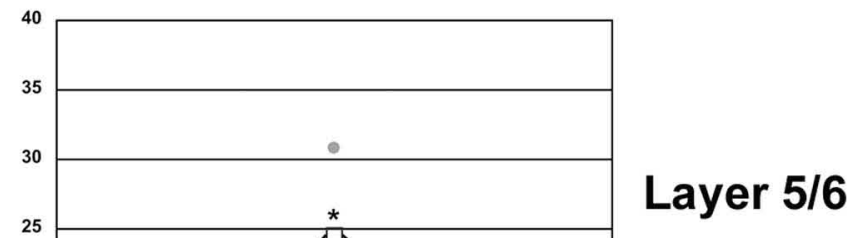

= Individual animals

( 20 terminals/animal)

$=$ Means 


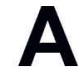

B

PV Output to GABAergic Targets
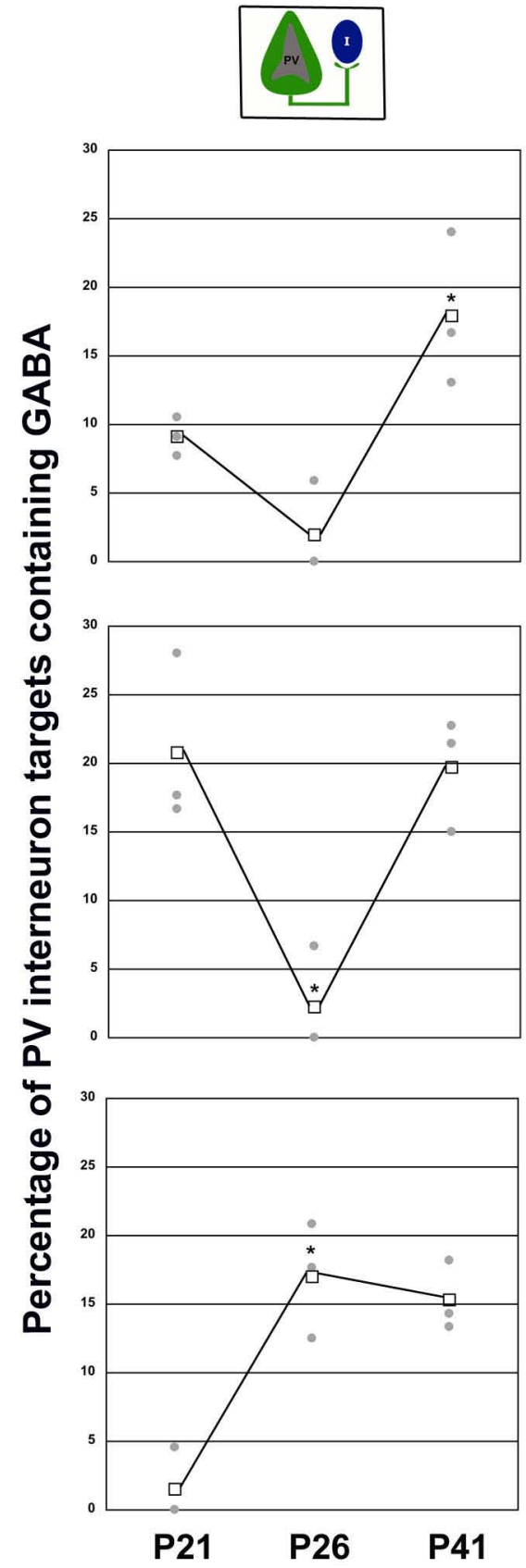

Layer 2/3

Layer 4

Layer 5/6

PV Output to All Targets
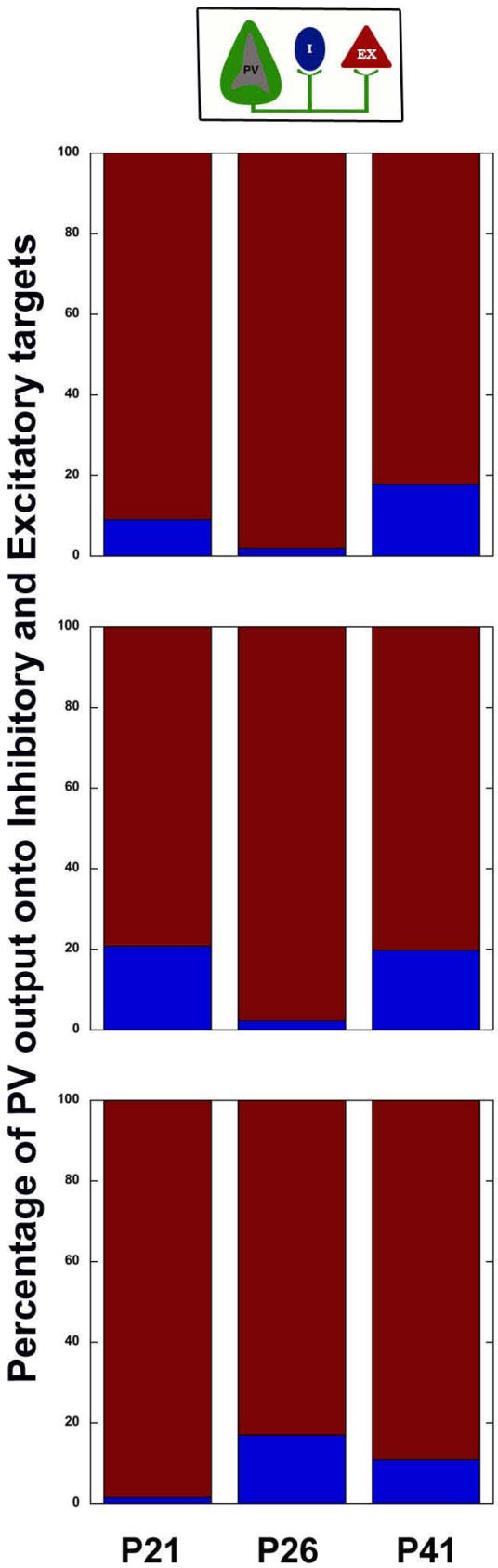

= Individual animals ( 20 terminals/animal)

= Excitatory targets

$=$ Inhibitory targets 


\section{A Layer 4 Global GABA Connecitivity B}
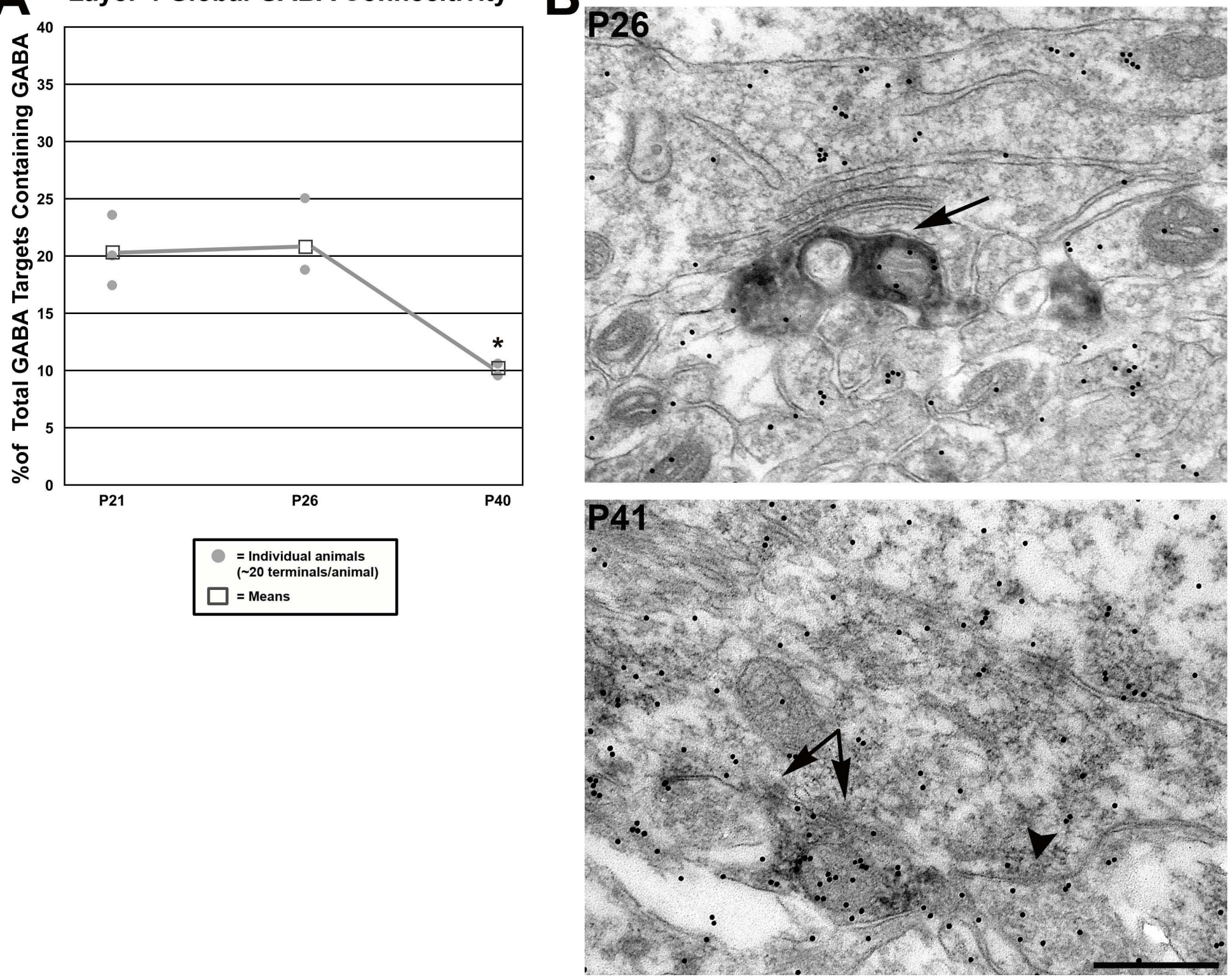
Table 1. Developmental and Laminar Analysis of PV Interneuron Terminal Morphology and Target Preference

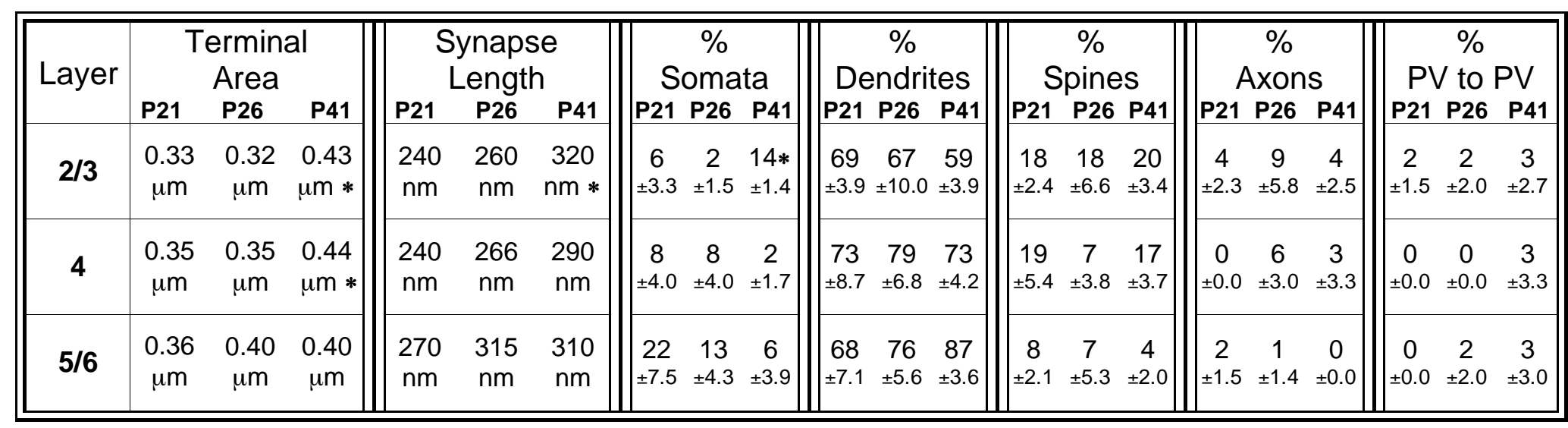




\section{CHAPTER IV:}

\section{GENERAL DISCUSSION}


In these chapters I hypothesized that if parvalbumin-containing (PV) interneurons were central to opponent inhibition during cortical response generation, they would receive a significant proportion of thalamocortical sensory drive in adulthood. In addition, I posited that if these PV cells were crucial to regulating the closure for critical period plasticity in visual cortex, PV interneurons should receive increased thalamic input and differentially alter their connectivity at the onset for this window for cortical malleability versus its end.

I determined that PV immunoreactive cells are fast-spiking interneurons in developing and adult ferret visual cortex, intimating that these interneurons are a highly conserved feature of the GABAergic microcircuit in visual cortex (Dumitriu et al., 2007; Gibson et al., 1999). Furthermore, by analyzing sections stained for VGluT2, parvalbumin, and GABA I concluded that PV interneurons receive the majority, if not all thalamocortical input in adult visual cortex. In laminar and developmental analyses of PV circuitry, I found that PV interneurons receive progressively stronger thalamic input over postnatal development, and dynamically modify their connections during the critical period. Moreover, at an age of limited cortical plasticity, PV interneurons had set up a strong reciprocal inhibitory circuit with other GABAergic cells within layers 4 and $2 / 3$. These findings are discussed below with respect to the significance and ramifications they hold for both cortical physiology and models of plasticity.

\section{Specificity of sensory input for parvalbumin-containing interneurons}


Results from the experiments detailed in Chapters II and III elucidate the relationship of thalamic input to inhibitory interneurons within layer 4 , and examine how the consequent feedforward inhibition impinges on excitatory and GABAergic circuitry throughout postnatal development in visual cortex. Earlier examinations of thalamocortical synapses in cortex utilized degeneration or tract tracing to visualize a relatively small number of thalamic terminals (Anderson et al., 1992; Jones and Powell, 1970) and broad morphological criteria or GABA labeling to identify a heterogeneous group of interneurons (Ahmed et al., 1997; Freund et al., 1989; Peters and Feldman, 1977). However, here we were able to quantify the synaptic preference of a large pool of the thalamic terminals in primary visual cortex, by using a marker we characterized as exclusive for thalamocortical axons (Nahmani and Erisir, 2005). Moreover, we determined the specificity of these contacts for fast-spiking PV interneurons by using triple labeling immuno-electron microscopy. Hence, the application of these tools will enhance our ability to tease out the complex synaptic connectivity of visual cortex with a greater degree of precision and fecundity.

Inhibitory interneurons within layer 4 of primary visual cortex have diverse physiological phenotypes, as well as varied dendritic and axonal laminar arborization patterns (Huang et al., 2007). Indeed, in Chapter II I found that a corollary of this heterogeneity in interneuron subtypes is the distinct maturation in the proportions of their primary visual input. To the best of our knowledge, this is the first report for a high selectivity of thalamocortical input for a specific subset 
of GABAergic cells, namely PV interneurons. At p60 and into adulthood, PV interneurons receive the large majority of monosynaptic thalamocortical synapses. Due to this prominence at the first stage of cortical processing, PV interneurons are prime candidates to direct a feedforward inhibitory response following thalamic stimulation.

\section{Involvement of PV interneuron connectivity in the development and maintenance of cortical receptive field properties}

Studies of simple receptive field generation in visual cortex have found that thalamic axons are the source of the "push" response that drive the initial response to light/dark in cortical cells (Hubel and Wiesel, 1962; Reid and Alonso, 1995; Tanaka, 1985), while cortical inhibition is thought to modulate the "pull" or antagonistic response that immediately follows stimulus withdrawal (for review see (Hirsch and Martinez, 2005)). As the sole GABAergic recipient of thalamocortical primary input in adult, we suggest that PV interneurons are necessarily the source of this inhibitory pull response. Hence, less than $2 m s$ after the thalamic relay of sensory input (Simons et al., 2007; Swadlow, 2003), fast-spiking PV interneurons in adult cortex respond en masse with a powerful and rapid inhibitory response in layer 4 . Moreover, changes in PV connectivity during postnatal development may allow for the maturation of simple receptive field organization. For instance, appropriate developmental inhibitory receptor 
activation is necessary for the normal reduction in spatial extent and temporal duration of receptive fields in primary sensory cortex (Chang et al., 2005). Specifically, these changes are dependent on $\mathrm{GABA}_{A} \propto 1$ receptor activation (Tao and Poo, 2005), known to be present at a majority of fast-spiking PV interneuron synapses in hippocampus (Bacci et al., 2003). In visual cortex, inhibitory cells within layer 4 display both simple ("push-pull”) and complex ("push-push") receptive fields (Hirsch et al., 2003). Accordingly, a determination of which changes to PV interneuron synaptic development in layer 4 might modulate receptive field development will likely require a combined receptive field mapping and ultrastructural approach. However, our findings demonstrate that PV interneuron synapses do alter their postsynaptic target preference at defined postnatal ages, intimating that a dynamic process of synaptic refinement regulates the maintenance of receptive field antagonism in visual cortex layer 4 .

\section{PV interneuron connectivity and critical period modulation}

PV interneurons have been implicated in both the induction and closure of the critical period for ocular dominance and anatomical plasticity in primary visual cortex. While the findings in Chapters II and III cannot speak to causal links between PV connectivity and the critical period, these results do carry predictive value based on how well they correlate with prevalent theories. These 
relationships are discussed in detail below under headings related to their prominent theoretical bases.

\section{Long-term potentiation and depression}

Theories giving a central role to long-term potentiation and depression (LTP and LTD) in modulating the end of the critical period, posit that the maturation of intracortical inhibition acts a "gate" to reduce the high-frequency feedforward excitation from layer 4 to layers 2/3 (Kirkwood et al., 1995; Ramoa and Sur, 1996). In these studies, white matter stimulation (corresponding to the thalamocortical projection) from P28 to P42 is gradually unable to produce LTP at layer 2/3 synapses, instead inducing a significant increase in paired pulse depression of these connections (Rozas et al., 2001). This phenomenon parallels the height and end for the critical period respectively, and is thought to stem from the increased inhibition of back propagating pyramidal cell action potentials within layer 4.

If $\mathrm{PV}$ inteneurons play a role in this gating phenomenon, we would expect

their synapses to increase with excitatory neurites from P28 to P41 within layer 4 . Yet, PV contacts to excitatory cells decrease from $\sim 98$ to 80 percent of their total input to layer 4 over this time period. Furthermore, a precipitous increase of similar magnitude in PV synapses to excitatory cells occurs between P21 and P26, yet under this protocol no change in LTP or LTD occurs therein (Rozas et al., 2001). Hence, alterations of PV connectivity within layer 4 are not integrally 
linked to the expression of LTP or LTD in layer 4 or $2 / 3$ under this model, yet they may play a role in the inhibition of pyramidal cell excitation at P26.

\section{Excitatory-Inhibitory balance}

Evidence in favor of the theory that a shift in the balance of excitatory versus inhibitory network forces regulates the critical period, stems from work demonstrating the necessity of GABA release for critical period initiation. Mice whose inhibitory cells release very low amounts of GABA do not show ocular dominance plasticity after monocular deprivation during the critical period (Hensch et al., 1998), yet this plasticity can be rescued following the infusion of a $\mathrm{GABA}_{A} \propto 1$ agonist into visual cortex (Fagiolini et al., 2004). Importantly, infusion of this agonist into the visual cortex of wild-type mice significantly shortens the period for ocular dominance plasticity (Iwai et al., 2003). Therefore, appropriate GABA release is necessary to reveal the effects of monocular deprivation and to modulate the natural end of this critical period. Proponents of this theory suggest that large PV basket cells forming axosomatic synapses engage the appropriate downstream molecular cascades (presumably in excitatory pyramidal cells) to facilitate both physiological and anatomical plasticity. In addition, this theory postulates that the ability of these PV basket-like synapses to form, and hence for plasticity to be present, is directly related to increasing age (Hensch, 2005). That is, PV axosomatic synapses are predicted to increase with the maturation of the critical period, yet at some point a crucial GABAergic "balance" is reached, wherein these contacts begin to induce the natural end for this plasticity. 
Although laminar differences in PV interneuron circuitry do not figure prominently in the excitatory-inhibitory balance hypothesis, predictions can be made from the analyses of PV target preference within Chapter III. From the onset to the height of the critical period ( P21-P26), PV axosomatic synapses do not increase their proportions in layers $2 / 3,4$ or $5 / 6$ in mouse visual cortex. This finding indicates that PV basket synapses may not be required to initiate this period for plasticity. Yet, from the height of the critical period to its closure ( P26-P41), these basket-like synapses do show an increase in layer 2/3. Under this model, this data seems to place PV axosomatic synapses as modulators of critical period closure. However, since the presence of the critical period is assayed via recordings of cortical ocular dominance shifts in layer $2 / 3$, PV basket-like synapses would be expected to show some change in this layer if levels of plasticity are a direct function of these synapses. Whether additional changes occur at these PV interneuron contacts, such as increased synaptic strength due to changes in GABA subunit composition, awaits further analysis. Nonetheless, the findings from Chapter III support a role of PV connections in modulating the end of this critical period for plasticity, rather than its initiation.

\section{Spike-timing dependent plasticity}

Models of spike-timing dependent plasticity theorize that anatomical modifications to cortical circuitry occur via the entrainment of a "student" neuron(s) which is wholly dependent on the firing frequency and connections of a 
"teacher" neuron(s) (Dan and Poo, 2004; Froemke et al., 2005). In this manner, measurements of physiology can inform upon alterations in morphology, and vice-versa. At different stages of postnatal development, specific classes of cells compete to control the timing of a particular regions' activity. Those neurons with higher firing probabilities are able to entrain those neurons with lower firing probabilities. Hence, neurons of higher firing probability are able to converge their inputs in zones of lower firing probability. However, experimentally the spatial and temporal spread of this spike-timing dependent plasticity peaks when gain or amplitude in a given area is high, whereas low gain effectively limits the ability of a given neuron to "entrain" another (Young et al., 2007). Interestingly in rodent primary visual cortex gain is high at critical period onset, yet this amplitude progressively wanes with age (Desai et al., 2002). In layer $2 / 3$ and 4 of visual cortex, fast-spiking inhibitory cells displaying complex receptive fields have been shown to provide a mechanism for this global amplitude modulation, in (Hirsch et al., 2003; Shapley et al., 2003; Wielaard et al., 2001). Accordingly, if layer 2/3 and 4 fast-spiking $\mathrm{PV}$ inteneurons act as gain filters to progressively reduce cortical competition, their connections would be expected to dampen cortical gain in an age and laminar-dependent manner.

In layer $2 / 3$, cortical input to $P V$ interneurons is not significantly altered from P21 to P41, however PV inhibition of other GABAergic cells increases as plasticity declines (P41). In layer 4, PV interneurons alternate between providing a relatively large component of their inhibition to excitatory cells at P26, and then set up a powerful reciprocal inhibitory circuit by P41. Thus, it may be that the 
gradual maturation of this reciprocal inhibitory circuit acts to reduce the ability of excitatory cells to fire high amplitude, steady action potentials. That is, following monosynaptic thalamic stimulation, PV interneurons engage a widespread reciprocal inhibitory network, progressively limiting the temporal summation and of excitatory output and reducing the spatial spread of spike-timing dependent competition (see Fig. 1). Moreover at the beginning of the critical period (P21), when thalamic drive likely targets mostly non-PV interneurons, the identical outcome would be achieved. Specifically, non-PV cells receiving both strong thalamic and PV input would again form a strong reciprocal inhibitory circuit with PV interneurons in this layer, limiting the ability of excitatory cells to summate. It is not clear how a large PV output onto excitatory cells at P26 might affect synaptic gain. However, the lack of a strong reciprocal inhibitory circuit at this age, coupled with a small thalamic drive to PV interneurons, suggests that PV inhibition of excitatory output is slow and desynchronized with excitatory cell firing. Hence at the peak age for cortical plasticity, PV inhibition of excitatory cells is delayed following thalamic stimulation, allowing for a relatively large degree of excitatory cell temporal summation.

This model predicts that PV interneurons within layer 4, receiving larger amounts of thalamic drive, would begin to limit cortical malleability within their lamina of origin. As excitatory output within layer 4 decreased, limiting the spread of excitation, cortical plasticity should begin to decrease within layer $2 / 3$ in a spike-timing dependent manner. Indeed, such a model is well supported by studies reporting that synaptic gain, as well as both anatomical and physiological 
plasticity within layer 4 end prior to that of supragranular layers in visual cortex (Daw et al., 2004; Desai et al., 2002; Maffei et al., 2004; Trachtenberg et al., 2000).

\section{Conclusion}

In sum, the findings from Chapters II and III have increased our understanding of the hierarchical organization of visual cortex and detailed innovative methods for investigating the relationship between identified classes of neurons and their postsynaptic targets. I have shown that PV cells are fastspiking interneurons in mouse and ferret, and that they are the predominant targets of primary sensory input in adult primary visual cortex. In addition, I found that cortical GABAergic circuitry, and PV interneurons specifically, rearrange their synaptic connections in a dynamic fashion over ages of anatomical and physiological plasticity. The pattern and temporal sequence of these PV circuit alterations fit well with models of spike-timing dependent plasticity in regulating this critical period for anatomical malleability. However, a resolution of the functional outcome of these changes awaits studies investigating causal links between these synaptic modifications and standardized measures of cortical plasticity. 


\section{References}

Ahmed B, Anderson JC, Martin KA, Nelson JC. 1997. Map of the synapses onto layer 4 basket cells of the primary visual cortex of the cat. J Comp Neurol 380(2):230-242.

Anderson JC, Dehay C, Friedlander MJ, Martin KA, Nelson JC. 1992. Synaptic connections of physiologically identified geniculocortical axons in kitten cortical area 17. Proc R Soc Lond B Biol Sci 250(1329):187-194.

Bacci A, Rudolph U, Huguenard JR, Prince DA. 2003. Major differences in inhibitory synaptic transmission onto two neocortical interneuron subclasses. J Neurosci 23(29):9664-9674.

Chang EF, Bao S, Imaizumi K, Schreiner CE, Merzenich MM. 2005. Development of spectral and temporal response selectivity in the auditory cortex. Proc Natl Acad Sci U S A 102(45):16460-16465.

Dan Y, Poo MM. 2004. Spike timing-dependent plasticity of neural circuits. Neuron 44(1):23-30.

Daw N, Rao Y, Wang XF, Fischer Q, Yang Y. 2004. LTP and LTD vary with layer in rodent visual cortex. Vision Res 44(28):3377-3380.

Desai NS, Cudmore RH, Nelson SB, Turrigiano GG. 2002. Critical periods for experience-dependent synaptic scaling in visual cortex. Nat Neurosci 5(8):783-789.

Dumitriu D, Cossart R, Huang J, Yuste R. 2007. Correlation between axonal morphologies and synaptic input kinetics of interneurons from mouse visual cortex. Cereb Cortex 17(1):81-91.

Erisir A, Dreusicke M. 2005. Quantitative morphology and postsynaptic targets of thalamocortical axons in critical period and adult ferret visual cortex. J Comp Neurol 485(1):11-31.

Fagiolini M, Fritschy JM, Low K, Mohler H, Rudolph U, Hensch TK. 2004. Specific GABAA circuits for visual cortical plasticity. Science 303(5664):1681-1683.

Freund TF, Martin KA, Soltesz I, Somogyi P, Whitteridge D. 1989. Arborisation pattern and postsynaptic targets of physiologically identified thalamocortical afferents in striate cortex of the macaque monkey. J Comp Neurol 289(2):315-336.

Froemke RC, Poo MM, Dan Y. 2005. Spike-timing-dependent synaptic plasticity depends on dendritic location. Nature 434(7030):221-225.

Gibson JR, Beierlein M, Connors BW. 1999. Two networks of electrically coupled inhibitory neurons in neocortex. Nature 402(6757):75-79.

Hensch TK. 2005. Critical period plasticity in local cortical circuits. Nat Rev Neurosci 6(11):877-888.

Hensch TK, Fagiolini M, Mataga N, Stryker MP, Baekkeskov S, Kash SF. 1998. Local GABA circuit control of experience-dependent plasticity in developing visual cortex. Science 282(5393):1504-1508.

Hirsch JA, Martinez LM. 2005. Circuits that build visual cortical receptive fields. Trends Neurosci. 
Hirsch JA, Martinez LM, Pillai C, Alonso JM, Wang Q, Sommer FT. 2003.

Functionally distinct inhibitory neurons at the first stage of visual cortical processing. Nat Neurosci 6(12):1300-1308.

Huang ZJ, Di Cristo G, Ango F. 2007. Development of GABA innervation in the cerebral and cerebellar cortices. Nat Rev Neurosci 8(9):673-686.

Hubel DH, Wiesel TN. 1962. Receptive fields, binocular interaction and functional architecture in the cat's visual cortex. J Physiol 160:106-154.

Iwai Y, Fagiolini M, Obata K, Hensch TK. 2003. Rapid critical period induction by tonic inhibition in visual cortex. J Neurosci 23(17):6695-6702.

Jones EG, Powell TP. 1970. An electron microscopic study of terminal degeneration in the neocortex of the cat. Philos Trans R Soc Lond B Biol Sci 257(812):29-43.

Kirkwood A, Lee HK, Bear MF. 1995. Co-regulation of long-term potentiation and experience-dependent synaptic plasticity in visual cortex by age and experience. Nature 375(6529):328-331.

Maffei A, Nelson SB, Turrigiano GG. 2004. Selective reconfiguration of layer 4 visual cortical circuitry by visual deprivation. Nat Neurosci 7(12):13531359.

Nahmani M, Erisir A. 2005. VGluT2 immunochemistry identifies thalamocortical terminals in layer 4 of adult and developing visual cortex. J Comp Neurol 484(4):458-473.

Peters A, Feldman ML. 1977. The projection of the lateral geniculate nucleus to area 17 of the rat cerebral cortex. IV. Terminations upon spiny dendrites. J Neurocytol 6(6):669-689.

Peters A, Payne BR. 1993. Numerical relationships between geniculocortical afferents and pyramidal cell modules in cat primary visual cortex. Cereb Cortex 3(1):69-78.

Ramoa AS, Sur M. 1996. Short-term synaptic plasticity in the visual cortex during development. Cereb Cortex 6(4):640-646.

Reid RC, Alonso JM. 1995. Specificity of monosynaptic connections from thalamus to visual cortex. Nature 378(6554):281-284.

Rozas C, Frank H, Heynen AJ, Morales B, Bear MF, Kirkwood A. 2001. Developmental inhibitory gate controls the relay of activity to the superficial layers of the visual cortex. J Neurosci 21(17):6791-6801.

Shapley R, Hawken M, Ringach DL. 2003. Dynamics of orientation selectivity in the primary visual cortex and the importance of cortical inhibition. Neuron 38(5):689-699.

Simons DJ, Carvell GE, Kyriazi HT, Bruno RM. 2007. Thalamocortical conduction times and stimulus-evoked responses in the rat whisker-to-barrel system. J Neurophysiol 98(5):2842-2847.

Swadlow HA. 2003. Fast-spike interneurons and feedforward inhibition in awake sensory neocortex. Cereb Cortex 13(1):25-32.

Tanaka K. 1985. Organization of geniculate inputs to visual cortical cells in the cat. Vision Res 25(3):357-364.

Tao HW, Poo MM. 2005. Activity-dependent matching of excitatory and inhibitory inputs during refinement of visual receptive fields. Neuron 45(6):829-836. 
Trachtenberg JT, Trepel C, Stryker MP. 2000. Rapid extragranular plasticity in the absence of thalamocortical plasticity in the developing primary visual cortex. Science 287(5460):2029-2032.

Wielaard DJ, Shelley M, McLaughlin D, Shapley R. 2001. How simple cells are made in a nonlinear network model of the visual cortex. J Neurosci 21(14):5203-5211.

Young JM, Waleszczyk WJ, Wang C, Calford MB, Dreher B, Obermayer K. 2007. Cortical reorganization consistent with spike timing-but not correlationdependent plasticity. Nat Neurosci 10(7):887-895. 


\section{Figure Legends}

Figure 1. Hypothesized model of spike-timing dependent parvalbumin interneuron (PV) modulation of visual cortex plasticity within layer 4. During periods of relatively stability (P21 and P41), PV interneuron inhibition is tightly regulated by means of a reciprocal inhibitory loop with neighboring GABAergic cells. At P21, this is accomplished via strong thalamic drive to non-PV inhibitory cells (I) and a strong reciprocal PV feedback, whereas at P41 thalamic axons mainly target PV interneurons with strong recurrent non-PV to PV cell inhibition in place. At these ages, the synchronous temporal inhibition of nearby excitatory cell (Ex) limits their ability to summate inputs over time, and hence constrains the range of spike-timing competition. However, when reciprocal PV to non-PV inhibtion is weak (P26), excitatory cell inhibition is desynchronized, leading to increased temporal summation and spatial spread of spike-timing competition. 


\section{Figure 1.}

Onset of Plasticity (P21)

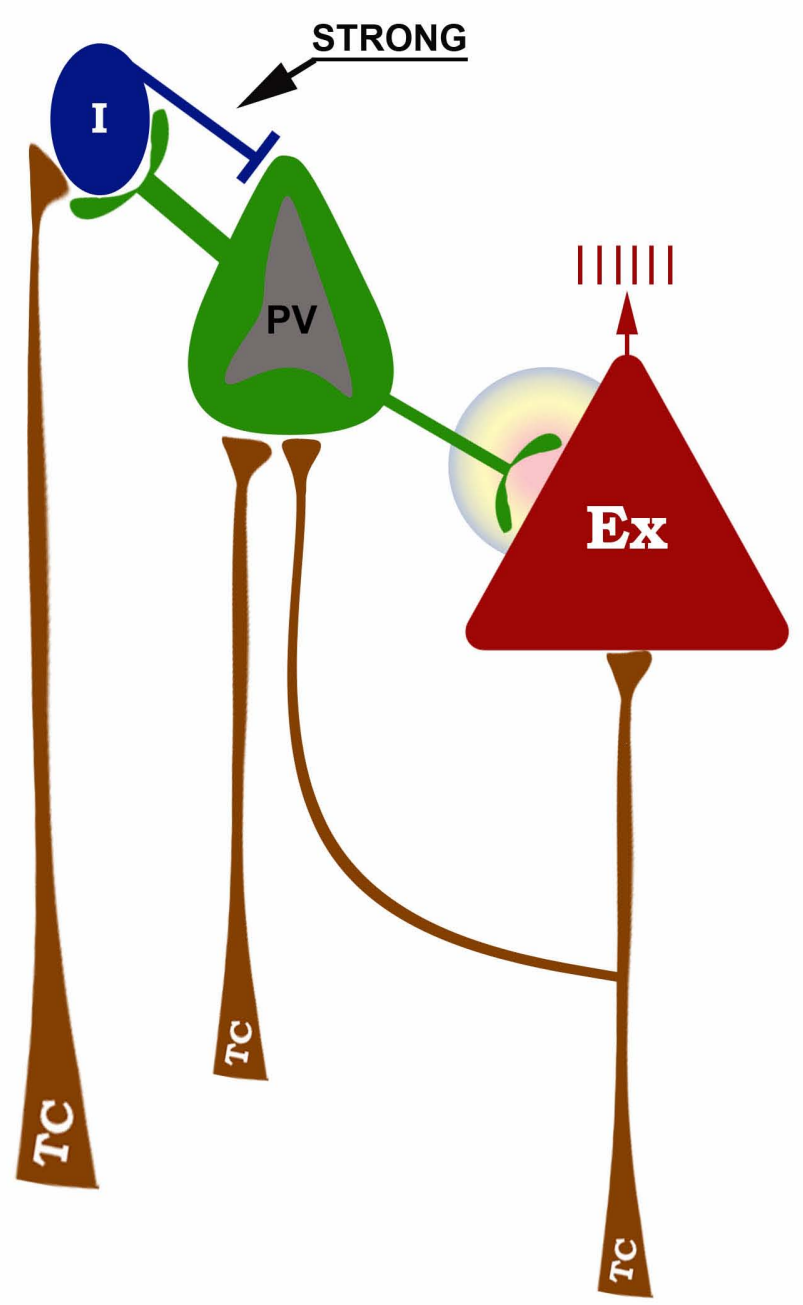

Peak Plasticity (P26)

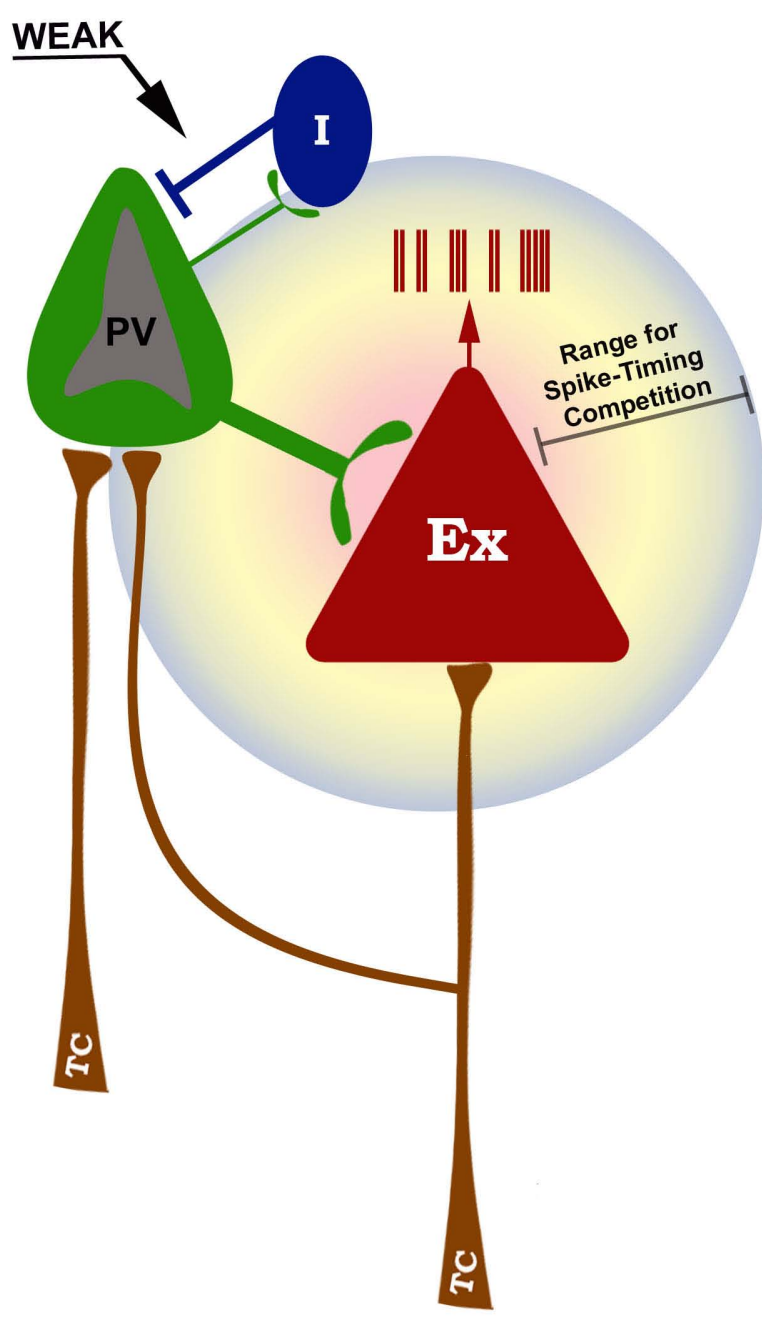

Reduced Plasticity (P41)

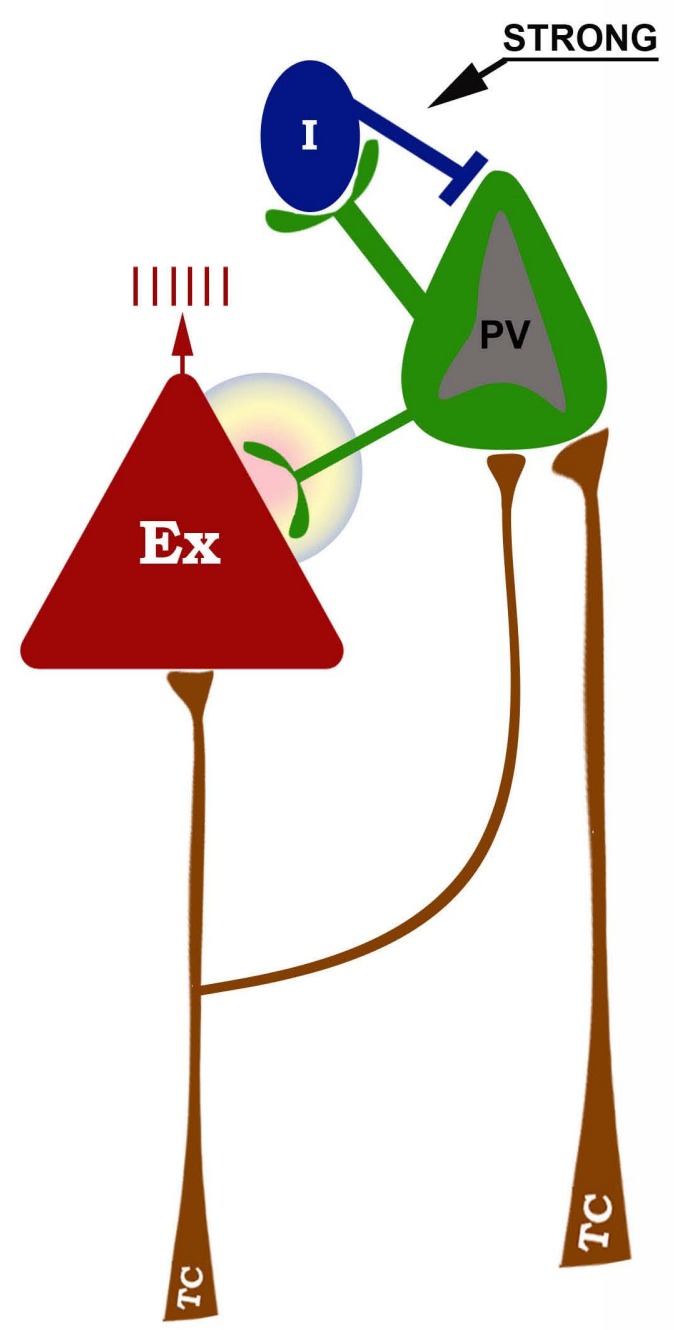

